\title{
WestVirginiaUniversity
}

THE RESEARCH REPOSITORY @ WVU

Graduate Theses, Dissertations, and Problem Reports

2009

\section{Implementing energy release rate calculations into the LaModel program}

\author{
Morgan M. Sears \\ West Virginia University
}

Follow this and additional works at: https://researchrepository.wvu.edu/etd

\section{Recommended Citation}

Sears, Morgan M., "Implementing energy release rate calculations into the LaModel program" (2009). Graduate Theses, Dissertations, and Problem Reports. 2082.

https://researchrepository.wvu.edu/etd/2082

This Thesis is protected by copyright and/or related rights. It has been brought to you by the The Research Repository @ WVU with permission from the rights-holder(s). You are free to use this Thesis in any way that is permitted by the copyright and related rights legislation that applies to your use. For other uses you must obtain permission from the rights-holder(s) directly, unless additional rights are indicated by a Creative Commons license in the record and/ or on the work itself. This Thesis has been accepted for inclusion in WVU Graduate Theses, Dissertations, and Problem Reports collection by an authorized administrator of The Research Repository @ WVU. For more information, please contact researchrepository@mail.wvu.edu. 


\title{
Implementing Energy Release Rate Calculations Into the LaModel Program
}

\author{
Morgan M. Sears \\ Thesis submitted to the \\ College of Engineering and Mineral Resources \\ at West Virginia University \\ In partial fulfillment of the requirements \\ for the degree of
}

Master of Science

in

Mining Engineering

\section{Keith A. Heasley, Ph.D., Chair Syd S. Peng, Ph.D \\ Yi Luo, Ph.D.}

Department of Mining Engineering

Morgantown, West Virginia

2009

Keywords: ERR, Energy Release Rate, Coal Mine Bumps, Rock Burst, LaModel 


\section{ABSTRACT \\ Implementing Energy Release Rate Calculations Into the LaModel Program}

\section{Morgan M. Sears}

Mining activity at increasingly greater depths and the tragedy at Crandall Canyon that claimed the lives of nine miners have forced coal bump research to the forefront of mining engineering research. Near the end of the last century, the National Institute for Occupational Safety and Health (NIOSH) and the former U.S. Bureau of Mines investigated the mechanics, conditions, and mitigation of coal bumps. Unfortunately, the exact mechanics of coal bumps is still not fully understood. Following this period, research into coal bumps in the United States has been limited.

The Energy Release Rate (ERR) calculation quantifies the dissipation ("release") of the gravitational potential energy of the rock mass as mining progresses. This release of energy can occur passively in the form of heat and sound, or dynamically in the form of coal or rock outbursts. From the initial application of a calculated ERR in the deep hard-rock mines of South Africa, the ERR was found to have a significant correlation with the risk or potential of damaging coal bumps or rock bursts. In the mid 1990s, the ERR was incorporated into the MULSIM/NL displacement-discontinuity computer program and used with limited success.

In this research, an ERR calculation is incorporated into the modern LaModel computer program to facilitate an analysis for potential coal bumps. Initially, the ERR calculations in LaModel are verified using a case study of cut sequences originally modeled using the MULSIM/NL computer program. Then, the ERR calculations are applied to a bump-prone mine in Southern Appalachia where a number of different pillar recovery cut sequences were used/analyzed in order to minimize the risk of bumps.

Incorporating the ERR calculations into the LaModel program further enhances the most widely used boundary-element model to allow for appropriate bump risk assessment. With this new analysis tool, engineers can adequately perform coal bump risk assessments with an increased margin of confidence. 


\section{Dedication}

This thesis and its accompanying research are dedicated to the miners and rescuers who lost their lives at the Crandall Canyon mine. Without its mainstream media attention, public outcry, and federal legislation, funding for this project would not have been used for the much needed research in the prediction of coal bumps and rock bursts. 


\section{Acknowledgements}

I would like to thank everyone who made this project possible. I would especially like to thank Dr. Keith Heasley, my advisor, whose hard work and guidance kept me on track through the countless hours involved in this project. In addition, I wish to acknowledge Dr. Syd Peng and Dr. Yi Luo for being committee members as well as instructors and mentors during both my undergraduate and graduate studies.

I would also like to thank Dr. Chris Mark who personally recommended me to be involved with this research. In addition, the ground control groups at the NIOSH Pittsburgh Research Laboratory and Spokane Research Laboratory, who provided funding, guidance, and support, are appreciatively recognized.

I would also like to thank my family, especially my father Casey Sears. Without his support, encouragement, and numerous years spent in the mining industry, I would not be where I am today. In addition, I want to thank my fiancée Kellie for her unconditional love and support. 


\section{Table of Contents}

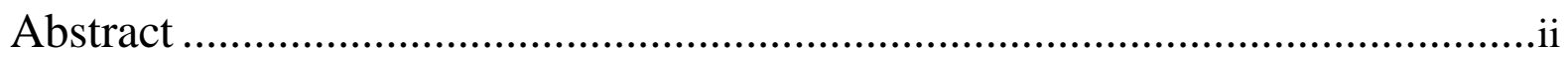

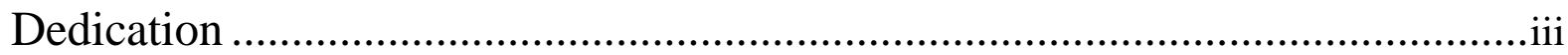

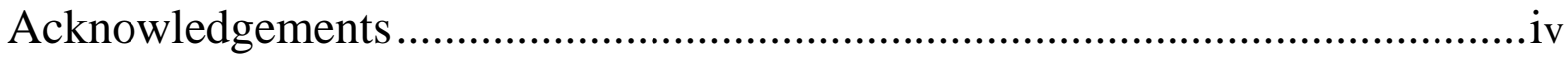

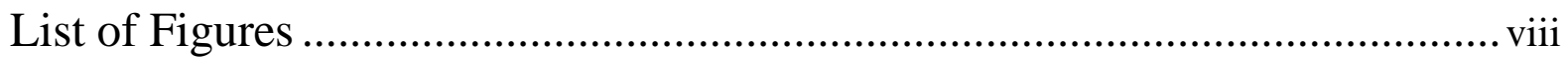

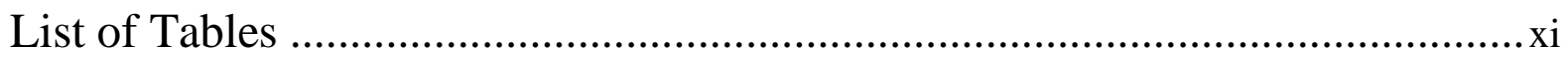

List of Symbols and Abbreviations.....................................................................

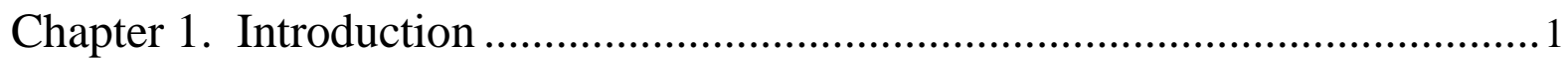

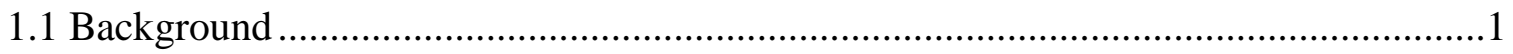

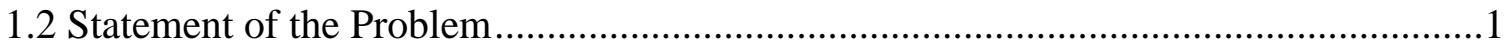

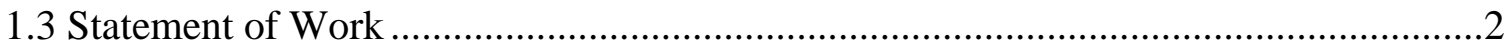

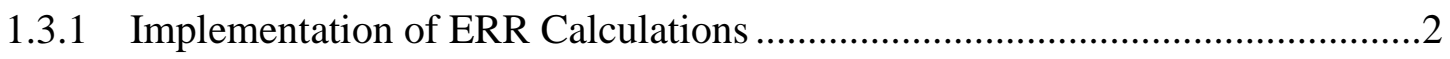

1.3.2 Validation of ERR Calculations...................................................................

1.3.3 Case Study Demonstration of ERR Calculations.................................................

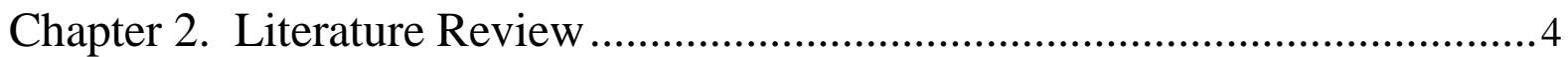

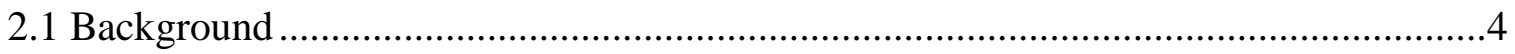

2.1.1 Salamon's Work....................................................................................

2.1.2 ERR Implementation into MULSIM/NL ....................................................9

Chapter 3. Implementation of Energy Release Calculations in LaModel ......... 17

3.1 Implementation of Static Energy Calculations into LaModel .....................................17 


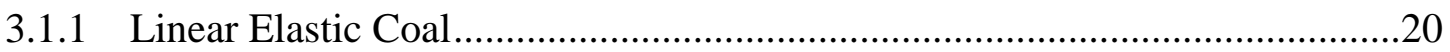

3.1.2 Strain Softening Coal ...............................................................................21

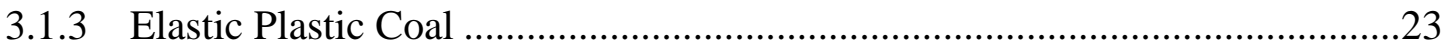

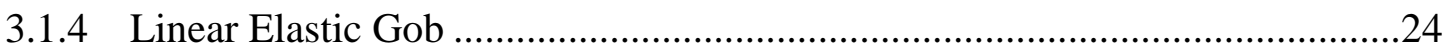

3.1.5 Strain Hardening Gob ............................................................................24

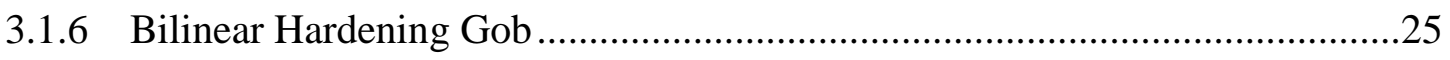

3.2 Implementation of Dynamic Energy Calculations into LaModel................................26

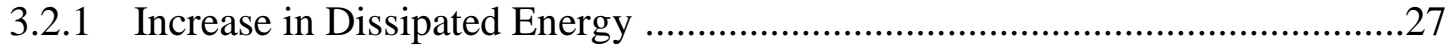

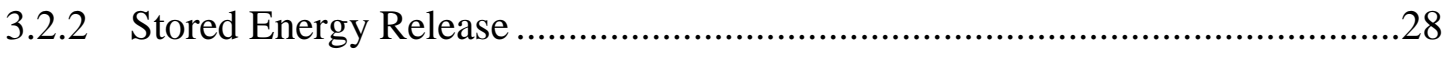

3.2.3 Kinetic Energy Release ………………………...................................29

3.2.4 Total Energy Release ………….............................................................

Chapter 4. Validation of the ERR Calculations ............................................... 32

4.1 Prior Research Using MULSIM/NL ....................................................................32

4.2 Cut Sequence Analysis with LaModel..................................................................34

Chapter 5. Case Study Demonstration of ERR Calculations............................. 40

5.1 Prior Research Using LaModel...............................................................................

5.2 Practical Application..........................................................................................

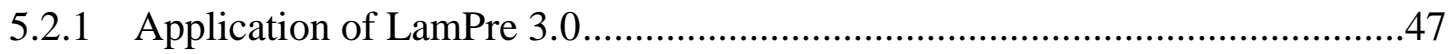

5.2.2 Application of LamPlt 3.0.......................................................................

5.3 Application of the LaModel ERR Calculations to the Case Study ............................52

5.3.1 Cut Sequences Modeled ...........................................................................52

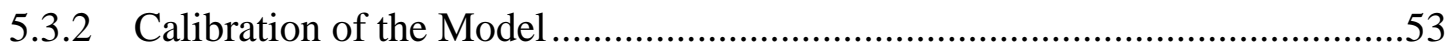

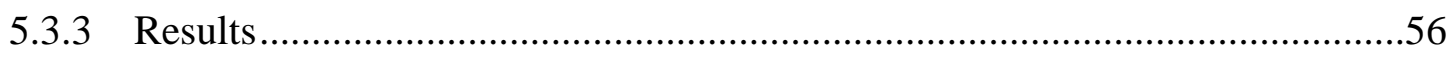

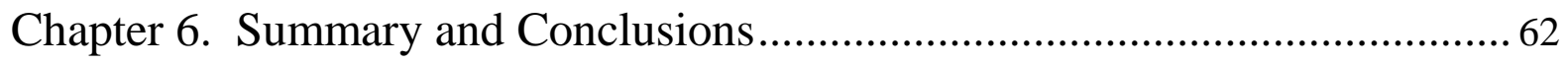

Chapter 7. Suggestions for Future Research..................................................63 


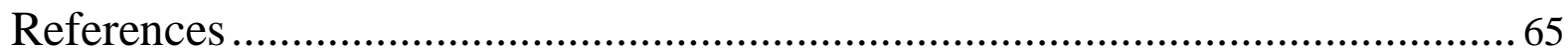

Appendix A. Derivation of the Energy for the Strain Hardening Gob Model...67

Appendix B. Verification of the ERR Programming Using Manual

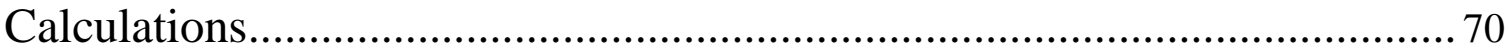

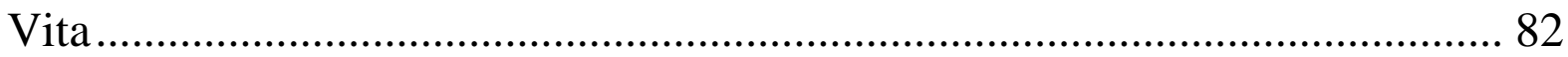




\section{List of Figures}

Figure 2.1: The definition of the work done in deforming the support (Salamon, 1984) ......6

Figure 2.2: Mining configuration and notations in the reference state, in state I (a), and after mining, state II (b), (after Salamon, 1984) .

Figure 2.3: Basic notation for energy calculations as mining progresses from state I to state II (Zipf, 1992)......

Figure 2.4: Step-size dependence of energy release components for radial expansion of a circular tunnel (Zipf, 1992)

Figure 2.5: The three special cases of mining progress from state I to state II showing how elements can undergo six different status changes between state I and state II (Zipf, 1992).

Figure 3.1: The material models available in LaModel (Heasley, 1998)

Figure 3.2: Static energy relationships for the six material models.

Figure 3.3: Increase in dissipated energy between step 1 (left) and step 2 (right) .28

Figure 3.4: Figure showing kinetic energy released from Salamon (left) and the extrapolation to the release from a material to material change (right).

Figure 4.1: Cut sequences modeled. .35

Figure 4.2: MULSIM/NL total energy released versus cut (after Zipf and Heasley, 1990). .36 
Figure 4.3: LaModel total energy released versus cut.

Figure 4.4: MULSIM/NL dissipated energy release versus cut (after Heasley and Zelanko, 1992). .38

Figure 4.5: LaModel dissipated energy release versus cut. .39

Figure 5.1: Close in 3 (Middle) retreat plan (hatching indicates bump location) (after Newman, 2008)

Figure 5.2: Close In 5 retreat plan (hatching indicates bump location) (after Newman, 2008).

Figure 5.3: Close In 4 (mirror of close in 2) retreat plan (hatching indicates bump location) (after Newman, 2008).

Figure 5.4: Close In 4 retreat plan with bump cut taken prior to retreat mining (after Newman, 2008)

Figure 5.5: Close In 5 retreat plan with bump cut taken prior to retreat mining (after Newman, 2008). .46

Figure 5.6: The Program Control Parameters form in LamPre 3.0. .48

Figure 5.7: LamPlt 3.0 Colored Square Plot Options

Figure 5.8: LamPlt 3.0 Dissipated Energy colored square plot .50

Figure 5.9: LamPlt 3.0 History Plot Options..... .51

Figure 5.10: LamPlt 3.0 Total Energy Released History Plot .52 
Figure 5.11: Energy release as a function of coal strength

Figure 5.12: Close in 3 (CI3) normalized energy release versus cut.................................56

Figure 5.13: Close in 4 (CI4) normalized energy release versus cut.................................57

Figure 5.14: Close in 5 (CI5) normalized energy release versus cut...................................58

Figure 5.15: Close in 4 Bump Cut (CI4 BC) normalized energy release versus cut..............59

Figure 5.16: Close in 5 Bump Cut (CI5 BC) normalized energy release versus cut..............60

Figure B.1: General Model Information ............................................................ 70

Figure B.2: Overburden / Rock Mass Parameters .......................................................... 71

Figure B.3: Seam Geometry and Boundary Conditions...............................................72

Figure B.4: Program Control Parameters ...................................................................... 74

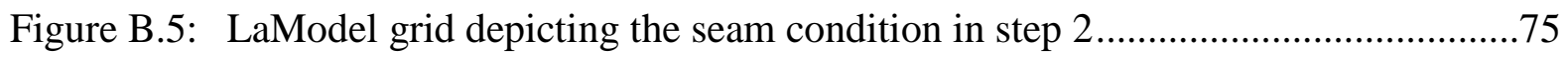

Figure B.6: LaModel grid depicting the seam condition in step 3 .................................76 


\section{List of Tables}

Table 5.1: Timing, Location, and Circumstances of Coal Bumps (after Newman, 2008)...41

Table B.1: LaModel material properties of the test case

Table B.2: LaModel stress and displacement values

Table B.3: Comparison between manual and program calculation of static energy values...78

Table B.4: Comparison between manual and program calculation of dynamic energy

values .79

Table B.5: Equations used to calculate respective energy quantity. .80 


\section{List of Abbreviations and Symbols}

$$
\begin{aligned}
& \text { BC - Bump Cut } \\
& \text { CIn - Close in } n \text { entry, where } n \text { is } 1-5 \\
& \text { ERR - energy release rate } \\
& \text { LMS - local mine stiffness } \\
& \text { OE - open ending } \\
& \mathrm{P} \& \mathrm{~W} \text { - pocket and wing } \\
& \text { SS\&F - single split and fender } \\
& \text { I }=\operatorname{step~(state)~} 1 \\
& \text { II }=\operatorname{step}(\text { state) } 2 \\
& \alpha=\text { nonlinearity parameter } \\
& \mathrm{V} \quad=\text { volume that remains unmined } \\
& \mathrm{V}_{\mathrm{m}} \quad \text { = volume of rock to be mined } \\
& \mathrm{U}=\text { strain energy in } \mathrm{V} \\
& \mathrm{U}^{\prime}=\text { train energy in } \mathrm{V}_{\mathrm{m}} \\
& \mathrm{W} \text { = work done by external and body forces } \\
& \mathrm{W}_{\mathrm{s}}=\text { work done on the permanent supports } \\
& \mathrm{n} \quad=\text { gob height factor } \\
& \mathrm{Q}_{\mathrm{i}} \quad=\text { primitive stress or traction vector } \\
& \mathrm{R}_{\mathrm{i}} \quad=\text { traction vector of the support } \\
& \mathrm{T}_{\mathrm{i}}^{(\mathrm{i})}=\text { indiced traction vector } \\
& \mathrm{R}=\text { gob (backfill) stress } \\
& \mathrm{S}=\text { surface area of the system } \\
& \mathrm{S}_{\mathrm{P}} \quad=\text { current location on the stress strain curve } \\
& \mathrm{S}_{\mathrm{M}}=\text { surface area mined } \\
& \mathrm{S}_{\mathrm{G}}=\text { surface area of gob } \\
& \mathrm{S}_{\mathrm{R}} \quad=\text { residual coal strength } \\
& \mathrm{S}_{\mathrm{I}} \quad=\text { insitu coal strength } \\
& \mathrm{T}=\text { rock mass } \\
& \mathrm{u} \quad=\text { displacement }
\end{aligned}
$$




$$
\begin{aligned}
\mathrm{X} & =\text { body force } \\
\mathrm{x} & =\text { distance from element center to free face } \\
\mathrm{h} & =\text { mining height } \\
\mathrm{W}_{\mathrm{R}} & =\text { total energy release } \\
\mathrm{W}_{\mathrm{RS}} & =\text { stored (strain) energy release } \\
\mathrm{W}_{\mathrm{RK}} & =\text { kinetic energy release } \\
\mathrm{W}_{\mathrm{S}} & =\text { stored elastic energy } \\
\mathrm{W}_{\mathrm{D}} & =\text { dissipated energy } \\
\mathrm{W}_{\mathrm{T}} & =\text { total input energy } \\
\sigma & =\text { stress } \\
\sigma_{\mathrm{p}} & =\text { peak stress } \\
\sigma_{\mathrm{r}} & =\text { residual stress } \\
\sigma_{\mathrm{u}} & =\text { ultimate stress } \\
\sigma_{\mathrm{O}} & =\text { offset stress } \\
\sigma_{\mathrm{e}-\mathrm{s}} & =\text { peak element stress } \\
\varepsilon & =\text { strain } \\
\varepsilon_{\mathrm{p}} & =\text { peak strain } \\
\varepsilon_{\mathrm{r}} & =\text { residual strain } \\
\varepsilon_{\mathrm{i}} & =\text { incremental strain } \\
\varepsilon_{\mathrm{O}} & =\text { offset strain } \\
\mathrm{E} & =\text { elastic modulus } \\
\mathrm{E}_{\mathrm{i}} & =\text { initial modulus } \\
\mathrm{E}_{\mathrm{f}} & =\text { final modulus } \\
\mathrm{E}_{\mathrm{p}} & =\text { plastic modulus } \\
\mathrm{E}_{\mathrm{h}} & =\text { hardening modulus } \\
\mathrm{LE} & =\text { linear elastic } \\
\mathrm{EP} & =\text { elastic plastic } \\
\mathrm{SS} & =\text { strain softening } \\
& =\text { strain hardening } \\
&
\end{aligned}
$$




\section{Chapter 1}

\section{Introduction}

\subsection{Background}

The fatal coal bump accidents at the Crandall Canyon Mine in August 2007 rapidly brought the insidious problem of coal bumps back into the public spotlight. Also, the continuing problem of bumps at the Aberdeen and West Ridge Mines, and the first time bump events at the Bowie and West Elk Mines further renewed interest in coal bump research. The old Bureau of Mines, and now NIOSH, and other researchers have performed bump research for many decades, and the industry's understanding of the conditions which can cause bumps and techniques for mitigating bumps have made significant strides (Maleki et al., 1995; Iannacchione and Zelanko, 1995). However, we are still a long way from accurately predicting exactly when and where coal bumps will occur. The exact mechanics that generate a coal bump are not understood.

One technique that has shown promise for analyzing the potential for coal bumps is calculation of the Energy Release Rate (ERR). The ERR calculation quantifies the "release" of the gravitational potential energy of the rock mass into the environment as mining progresses. This release of energy can occur passively in the form of heat and sound or dynamically in the form of pillar bumps or rock bursts. Large energy releases in a short period of time can be indicative of the timing and location of coal bumps or rock bursts. By modifying the mine plan, the energy releases can be distributed in time and space, theoretically minimizing the chance of dynamic failure.

\subsection{Statement of the Problem}

In the United States, the most recent use of ERR was with the MULSIM/NL program, and several studies were done with reasonable results. Heasley and Zelanko (1992) found the energy release rate values to correlate with the occurrence of coal bumps and Zipf and Heasley (1990) used the ERR to optimize retreat mining cut sequences to decrease the risk of coal bumps in room-and-pillar operations. In more recent years, the MULSIM/NL program has primarily been replaced by the LaModel program for boundary-element modeling of coal mines; however, the LaModel program has never incorporated Energy Release Rate calculations. 


\subsection{Statement of Work}

In this report, energy calculations are incorporated into the LaModel program to produce a modern coal mine modeling tool which can evaluate the bump proneness of a mining plan using energy principles. By upgrading LaModel with energy calculations, potential users will be able to leverage the present modern capabilities (automatic grid generation, overburden wizard, coal wizard, gob wizard, etc.) of the program to quickly and accurately produce energy release maps for minimizing the bump proneness of a mining plan.

\subsubsection{Implementation of ERR Calculations:}

For each of the material models in LaModel, a number of energy calculations are implemented. Specifically, the implemented energy calculations are divided into two major groups: Static (or input energy) and Dynamic (or released energy). The static energies are associated with the strain energy that has been input and/or stored in a seam material at a given strain level. The implemented static energies calculations are:

1) The total input energy,

2) The stored elastic energy, and

3) The dissipated energy.

The dynamic, or released, energy values are associated with energy changes in the materials that occur between mining steps. For the vast majority of elements, energy changes are associated with changes in the element's stress and deformation state while staying on the same material curve. For some elements, however, energy changes occur in conjunction with nearby mining when the element changing material types. For each element in the model, the implemented dynamic energy calculations are:

1) An increase in dissipated energy,

2) A stored energy release,

3) A kinetic energy release.

\subsubsection{Validation of ERR Calculations:}

After the energy calculations were implemented into LaModel, the mathematics and coding were validated (in addition to manual check calculations) by using four pillar cut sequences that were analyzed in previously published studies using the old MULSIM/NL program (Zipf and 
Heasley, 1990; Heasley and Zelanko, 1992). These four cut sequences were: open ending, pocket and wing, split and fender, and the Olga method. In the validation analysis, the same general trends observed in the previous analysis were also observed with the new LaModel ERR calculations, with some variation.

\subsubsection{Case Study Demonstration of ERR Calculations:}

Finally, the energy release calculations implemented in LaModel are applied to a case study which demonstrates the utility and accuracy of the calculations. In this case study analysis, a number of different pillar recovery cut sequences that were attempted at a bump-prone mine in Southern Appalachia (Newman, 2008) are modeled. These cut sequences were originally analyzed by Newman using the pillar stress distributions to compare with field observations. In this report, the LaModel energy calculations for these cut sequences are shown to correlate somewhat well with the field observations and with Newman's original stress analyzes, and the energy calculations provide a quantifiable index of bump potential. 


\section{Chapter 2 \\ Literature Review}

\subsection{Background}

The former U.S. Bureau of Mines and more recently the mining health and safety arm of NIOSH have been studying the problem of coal bumps (the sudden, violent expulsion of coal from a rib or active coal face into an adjacent entry or entries) for many years. As part of this research in the early 90's (Zipf and Heasley, 1990; Heasley 1991; Heasley and Zelanko, 1992), an investigation of the geologic strain energy released in association with coal bumps was initiated. It was hypothesized that calculated energy values may provide better insight, or even a certain predictive capability, regarding the occurrence of coal bumps. For many years, it has been understood that energy changes occur in the rock mass during mining. Basically, the very act of creating an opening underground causes the gravitational potential and tectonic strain energy of the rock mass to be redistributed. Part of this redistributed energy goes to increasing the elastic strain energy of the nearby rock mass while another part of the redistributed energy is dissipated or released. This released energy can take a passive form such as heat, sound, etc, or it may appear as dynamic energy driving a damaging rock burst or coal bump.

It is not surprising, then, to find that in the past the Energy Release Rate (ERR) has been found to correlate with the incidence or risk of damaging rock bursts. In the 1960's, the concept of ERR as an indicator of burst potential was pioneered in deep hard-rock mines in South Africa (Cook et al., 1966; Salamon, 1963; Hodgson and Joughin, 1966). More recently, energy release rate computation and application have improved (Salamon, 1984), and use of the ERR concept at burst-prone hard-rock mines has become common. However, the application of energy concepts to bump-prone coal mines has been limited. Crouch and Fairhurst (1973) applied a displacement-discontinuity model with an energy release calculation to simulated coal mining sequences and demonstrated a technique for selecting an optimum cut sequence for bump control based on the energy values. Maleki et al. (1987) used energy calculations in conjunction with stress and displacement calculations to analyze and recommend alternative mining plans for an active mine experiencing bump problems. At the U.S. Bureau of Mines, in a fashion similar to Crouch and Fairhurst, Zipf and Heasley (1990) applied an energy calculation to a set of idealized 
cut sequences for deep-cover pillar retreat mining and demonstrated the superiority of a unique cut sequence for maintaining a uniform energy release; and therefore, minimizing bump potential. Subsequently, Heasley (1991) back analyzed an actual bump event using energy release and found a good correlation with the observed bump behavior, and Heasley and Zelanko (1992), evaluated the dissipated energy from the longwall gate pillars and tailgate corner in several different multiple seam mining scenarios and found a fair correlation with coal bumps.

All of the energy release rate calculations performed by Bureau of Mine's personnel in the 90's were done using the MULSIM/NL program (Zipf, 1992). This code uses the displacementdiscontinuity variation of the boundary-element method (BEM) with an elastic homogeneous overburden model to calculate three-dimensional stresses and displacements caused by mining tabular deposits such as coal seams. From these stresses and displacements, MULSIM/NL calculates energy quantities for the seam materials. In the last decade, the MULSIM/NL program has largely been replaced by the LaModel program (Heasley, 1998) for modeling stresses and displacements in single and multiple-seam coal mines. The LaModel program uses a laminated overburden model that has been found to be more accurate for calculating stresses and displacements associated with horizontally bedded sedimentary rocks, as found in U. S. coal mining districts. Also, in contrast to MULSIM/NL, the LaModel program has been continually modernized and upgraded as operating systems and programming languages have evolved over time. However, LaModel has never had energy release rate calculations built into the program.

\subsubsection{Salamon's Work:}

Since its conception in South Africa, the Energy Release Rate (ERR) has shown a significant correlation to the risk of dangerous bumps and rock outbursts. From the beginning with Cook et al. (1966), who determined that significant energy changes occur during mining, through widened discussions with others, many energy calculations (including the ERR) were developed providing tools to engineers and professionals attempting to combat bumps and rockbursts. Although Cook and others laid a foundation for the study of the ERR, they failed to publish an acceptably rigorous derivation (Salamon, 1984).

The first rigorous examination concerning energy calculation and the ERR was presented by Salamon in 1984, over twenty years after Cook called attention to these energy quantities. In his synopsis, he states that the first component of the energy balance corresponds to all known 
modes of energy expenditure while the second component accounts for the energy surplus that must be released and dissipated in some form. This released energy can be either passive (sound, heat, etc.) or kinetic (bumps).

In his paper, Salamon describes in great detail several energy quantities that are needed to assess the ERR. Namely, the work done by the external and body forces when acting through the induced displacements $(\mathrm{W})$, the strain energy content of the volume $\left(\mathrm{V}_{\mathrm{m}}\right)$ of rock to be mined $\left(U^{\prime}\right)$, the change in strain energy in the volume (V) of the system that remains unmined (U), and the total work done by the contact and body forces on the permanent supports $\left(\mathrm{W}_{\mathrm{s}}\right.$ ) (see Figure 2.1. Figure 2.2 shows Salamon's notations, some of which ( $V$ and $\left.V_{m}\right)$ were verbally described above. In addition, $S_{0}$ and $S_{m}$ refer to the area in state I and state II respectively while $V_{0}$ is volume on the opening in state I.

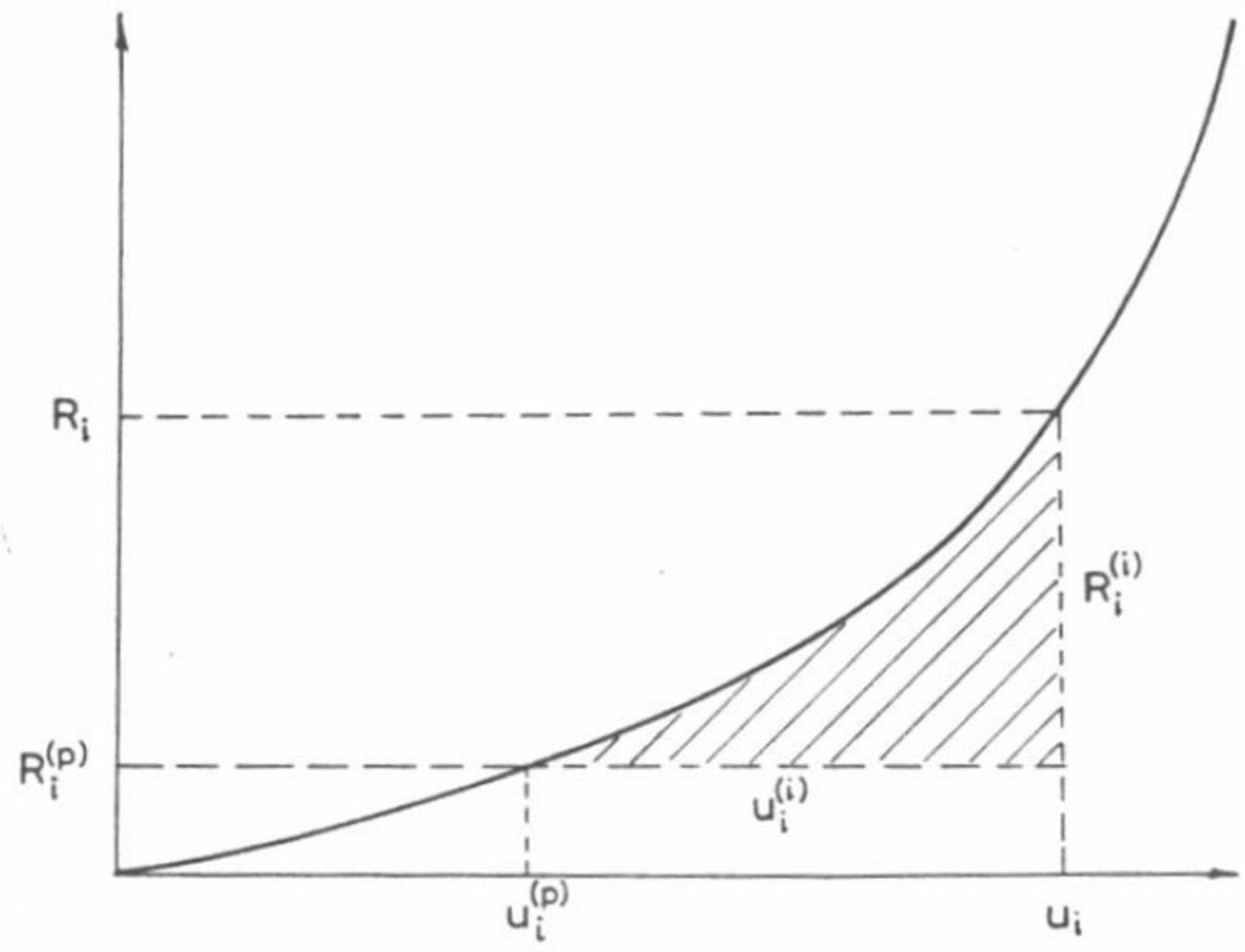

Figure 2.1: The definition of the work done in deforming the support (Salamon, 1984). 


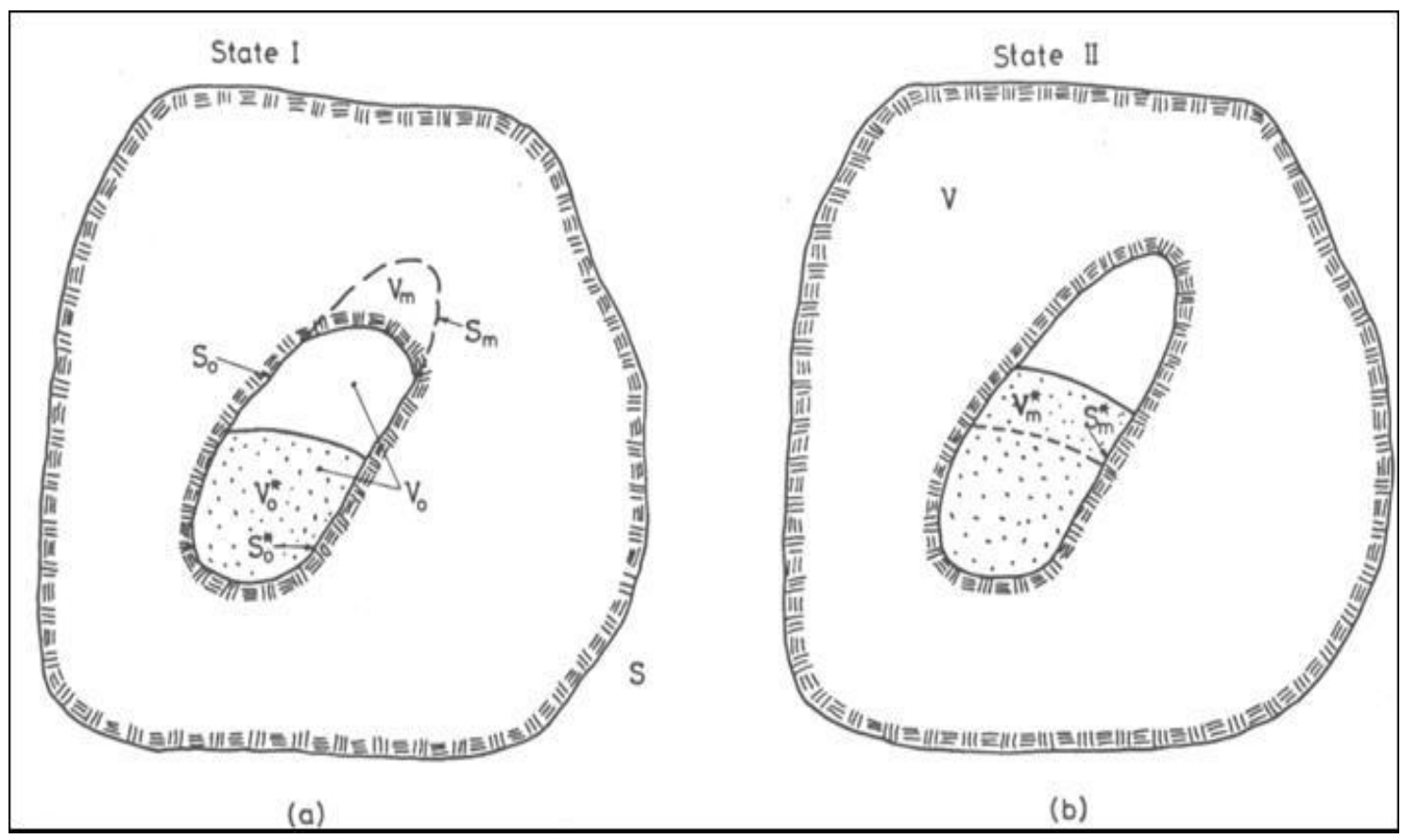

Figure 2.2: Mining configuration and notations in the reference state, in state I (a), and after mining, state II (b), (after Salamon, 1984).

The work done in deforming the permanent supports is modeled as nonlinear with a strain hardening response.

Based on these energy quantities, the released energy $\left(\mathrm{W}_{\mathrm{R}}\right)$ can be calculated with the following equality for tabular excavations:

$$
\mathrm{W}_{\mathrm{R}}=\mathrm{W}-\left[\left(\mathrm{U}-\mathrm{U}^{\prime}\right)+\mathrm{W}_{\mathrm{s}}\right]
$$

Salamon also described the methods for application to tabular excavations. In general, he utilizes the displacement discontinuity, or "slit" concept for this application. He feels that there are four advantages to using the displacement discontinuity model in energy analysis: 
1) While the displacements are discontinuous when moving perpendicularly across the seam, say from the roof to the floor of the excavation, the stresses remain continuous.

2) The weights of the extracted rock and of the backfill are neglected, and their volumes are taken to be zero.

3) As a result of (1) and (2), the induced traction, $T_{i}^{(i)}$, can be taken to be zero on $S$, which is on the surface enveloping the whole system.

4) A further consequence of (1) and (2) is that the work done by forces acting on the surfaces of excavations can be expressed as an integral of the forces acting through the relative displacement on the roof and floor.

After completion of the derivation of the total released energy, the final expression developed by Salamon can be described as a function of the primitive stress or traction vector $\left(\mathrm{Q}_{i}\right)$. This expression proves to have a vital role in the calculation of energy release rates for tabular deposits.

$$
\mathrm{W}_{\mathrm{R}}=\frac{1}{2}\left[\int_{\mathrm{A}} \mathrm{Q}_{\mathrm{i}} \mathrm{s}_{\mathrm{i}} \mathrm{dA}+\int_{\mathrm{B}}\left(1-\alpha_{\mathrm{i}}\right) \mathrm{R}_{\mathrm{i}} \mathrm{s}_{\mathrm{i}} \mathrm{dA}\right]
$$

Where:

$$
\begin{array}{ll}
\mathrm{W}_{\mathrm{R}} & =\text { total energy release } \\
\mathrm{R}_{\mathrm{i}} & =\text { traction vector of the support } \\
\mathrm{s}_{\mathrm{i}} & =\text { displacement vector } \\
\alpha_{\mathrm{i}} & =\text { nonlinearity parameter } \\
\mathrm{dA} & =\text { elementary area }
\end{array}
$$

Although Salamon's derivation of the released energy is correct and thorough, there are a couple issues where one might question its validity. As the size of the mined volume $\left(\mathrm{V}_{\mathrm{m}}\right)$ becomes smaller, so does the energy released. This means that in the limit as $\mathrm{V}_{\mathrm{m}}$ approaches zero, so does the energy released. To alleviate this issue, the assumption of an equal step sizes must be made. Once a standard step size has been chosen, then a comparison of the energy release and the associated ERR can be utilized without the worry of theoretical validity. Another issue with Salamon's work is the assumption of elasticity of the seam material. While an elastic model for use with deep South African hard rock mines may be valid, the use of this model with 
respect to highly stressed coal is questionable. The following section on the incorporation of the ERR into the MULSIM/NL program will address this issue.

Looking forward, the strain energy (stored energy release) discussed above remains the same in the LaModel 3.0 program while the kinetic energy and energy released in deforming the supports are modified for use in LaModel 3.0. The kinetic energy used by Salamon assumes that a linear elastic material changes linearly to an opening with zero stress. In LaModel 3.0, the element is allowed to change from any material to any other material or opening using the same linear shift assumption. The equation for energy released in deforming the supports (gob energy in our case) is also modified dropping the linear shift assumption and the non-linearity factor $(\alpha)$ in favor of a direct calculation using the gob energy equation (See Appendix A).

\subsubsection{ERR Implementation into MULSIM/NL:}

While the ERR calculation was not previously included in the LaModel software package, it was available in its predecessor, MULSIM/NL. The ERR calculations in MULSIM/NL used the equations as derived by Salamon for use with the displacement discontinuity model as adapted by Zipf (1992) in equation 2.3. In this equation, the first and second bracketed terms represent the stored energy release $\left(\mathrm{W}_{\mathrm{RS}}\right)$ and the kinetic energy release $\left(\mathrm{W}_{\mathrm{RK}}\right)$, respectively. The first term in the stored energy release calculation is the elastic energy stored in the elements at step I that is released when the elements are mined between steps I and II. The second term in the stored energy release calculation is from the body forces in the elements which are generally considered to be zero in the displacement discontinuity method. In the kinetic energy release calculation in the second bracket, the first term quantifies the gravitational potential energy that is input into each mined element in going from step I to step II, but is not stored in the element. The second term in the kinetic energy calculation quantifies the kinetic energy release from compressing the non-linear gob area.

$$
\mathrm{W}_{\mathrm{R}}=\left[\frac{1}{2} \int_{\mathrm{S}_{\mathrm{M}}} \mathrm{T}_{\mathrm{I}} \mathrm{u}_{\mathrm{I}} \mathrm{ds}-\frac{1}{2} \int_{\mathrm{V}_{\mathrm{M}}} \mathrm{X}_{\mathrm{I}} \mathrm{u}_{\mathrm{I}} \mathrm{dv}\right]+\left[\frac{1}{2} \int_{\mathrm{S}_{\mathrm{M}}} \mathrm{T}_{\mathrm{I}} \Delta \mathrm{uds}+\frac{1}{2} \int_{\mathrm{S}_{\mathrm{GII}}}(1-\alpha) \Delta \mathrm{R} \Delta \mathrm{uds}\right]
$$


Where:

$\mathrm{T}_{\mathrm{I}} \quad=$ rock mass stress in state $\mathrm{I}$

$\mathrm{u}_{\mathrm{I}} \quad=$ displacements in state $\mathrm{I}$

$\Delta \mathrm{u}=$ change in displacement from state I to state II

$\Delta \mathrm{R}=$ change in gob (backfill) stress from state I to state II

$\mathrm{X}_{\mathrm{I}}$ = body force in state $\mathrm{I}$

$\mathrm{S}_{\mathrm{M}}=$ surface area mined this step

$\mathrm{V}_{\mathrm{M}}=$ volume mined this step

$\mathrm{S}_{\mathrm{GII}}=$ surface area of gob (backfill) in state II

$\alpha=$ a nonlinearity factor for the gob and/or backfill material (for linear materials, $\alpha=1$, and for strain-hardening materials, $\alpha<1$ )

ds $=$ differential area

$\mathrm{dv}=$ differential volume

Zipf's basic notation as mining progresses from state I to state II can be seen in figure 2.3. Zipf notes that as an analogy, it was presumed that not only could the ERR be a quantitative measure of rock burst potential, but also coal bump potential. He also acknowledges Salamon's conclusion of step size dependence in the ERR calculation and shows that as the mining step approaches zero, the kinetic energy released approaches zero. This means that as the step size approaches zero, the total released energy becomes the strain energy released from the mined out material and the kinetic energy release goes to zero very fast (see Figure 2.4). 

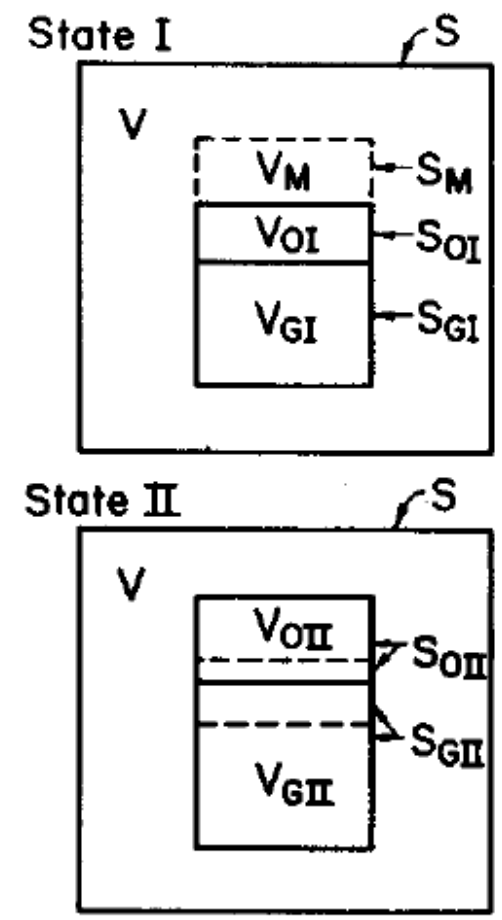

KEY

$\mathrm{V}$ Rock mass volume

$V_{\text {OI }}$ Volume open in state I

VoII Volume open in state II

$V_{G I}$ Volume of backfill in state I

$V_{G I I}$ Volume of backfill in state II

$V_{M} \quad$ Volume mined this step

$S \quad$ Rock mass boundary orea

SoI Surface area open in state I

SoII Surface area open in state II

$S_{\mathrm{GI}}$ Surface area of backfill in state $I$

$S_{\text {GII }}$ Surface area of bockfill in state II

$S_{M} \quad$ Surfoce oreo mined this step

Figure 2.3: Basic notation for energy calculations as mining progresses from state I to state II (Zipf, 1992). 


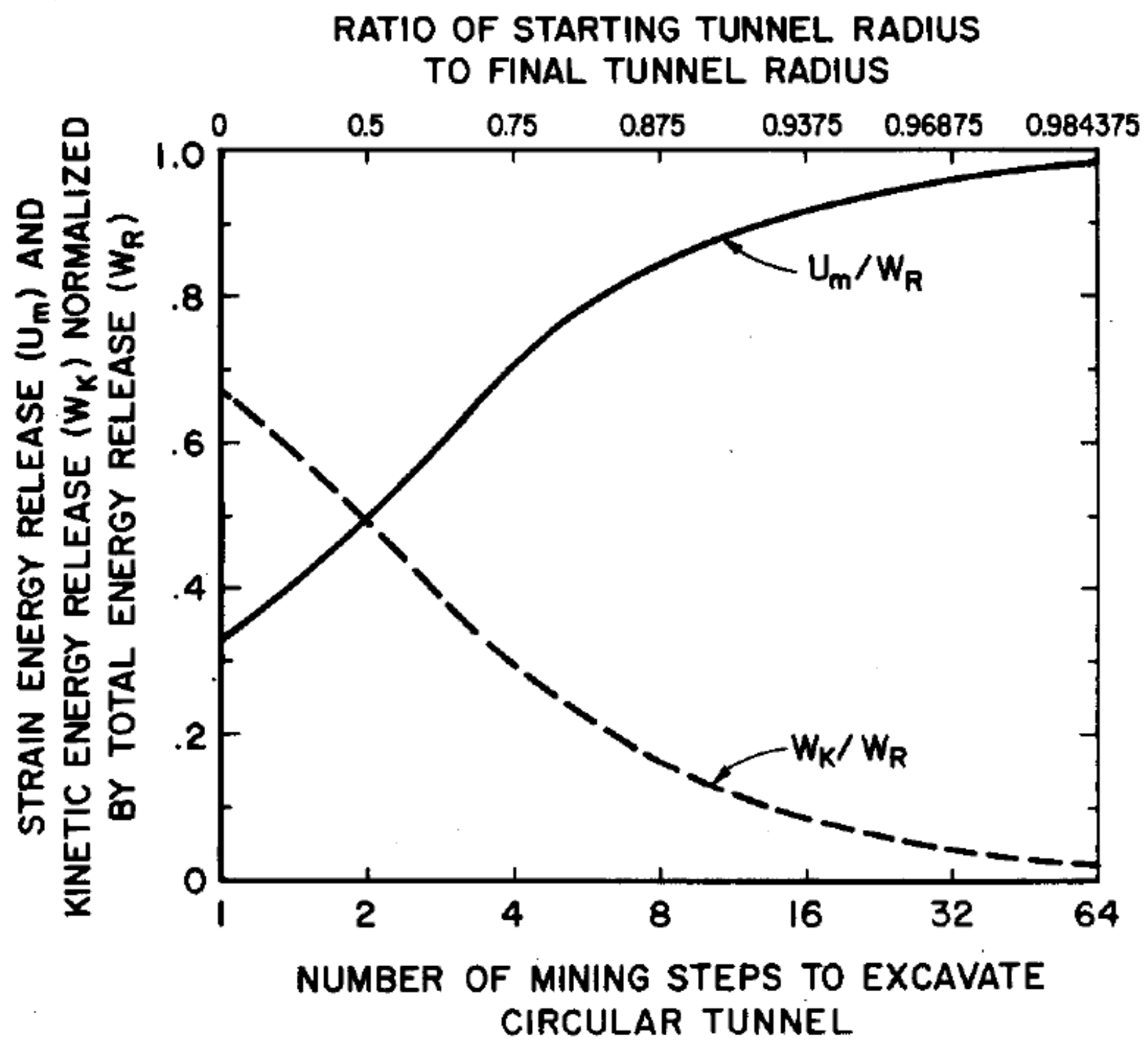

Figure 2.4: Step-size dependence of energy release components for radial expansion of a circular tunnel (Zipf, 1992).

In the calculation of the energy quantities in MULSIM/NL, three special cases can arise which complicate the math involved. In case A, the newly-mined area (of arbitrary geometry) exactly balances the newly gob/backfilled area and the open area in state I equals the open area in state II. In case B, the gob/backfilling lags the mining and the open area increases, where in case $\mathrm{C}$, the gob/backfilling exceeds the mining and the open area decreases (see Figure 2.5). 

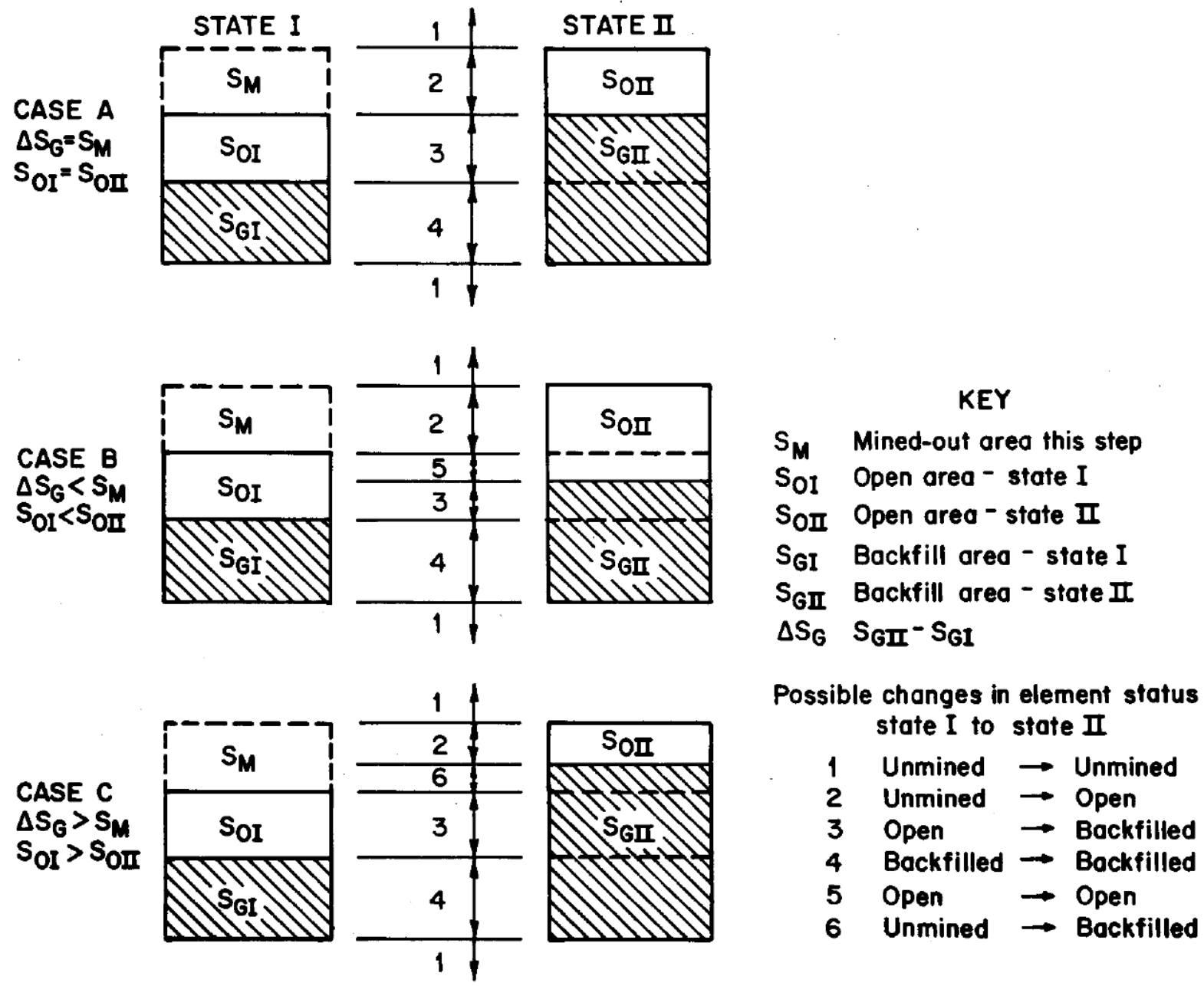

Figure 2.5: The three special cases of mining progress from state I to state II showing how elements can undergo six different status changes between state I and state II (after Zipf, 1992).

The ERR subroutine in MULSIM/NL calculates six energy quantities for each element. Three dynamic energy quantities:

1) Strain Energy Release (Stored Energy Release)

2) Kinetic Energy Release

Linear component (gravitational)

Nonlinear component (backfill and/or gob)

3) Total Energy Release 
and three static energy quantities (See Figure 3.2):

1) Total Strain Energy: This is the entire area under the stress strain curve for a given material. It is the energy required to strain the material from zero strain to the current strain value. It is the sum of the stored and dissipated strain energies.

2) Recoverable Strain Energy: This is the energy that is stored in the material as elastic strain energy. This value represents the energy that is recoverable from the material if the material were to be unloaded to zero strain. It is the difference between the total input energy and the dissipated energy.

3) Dissipated Strain Energy: This is the strain energy that is input to the material but is not stored in the material. This energy is assumed to have been dissipated by the element to the environment either nonviolently through rock failure, cracking, friction, and heat generation or violently with dynamic ejection of the material (coal bump or rock burst).

The first three quantities are determined by applying equation 2.3 on each element of the model. The energy changes for the elements within the mined area, $S_{m}$, are calculated for the strain energy release for a linear element (Equation 2.4) and the linear part of the kinetic energy release (Equation 2.5).

$$
\begin{aligned}
& \mathrm{W}_{\mathrm{RS}}=\frac{1}{2} \mathrm{~T}_{\mathrm{I}} \mathrm{u}_{\mathrm{I}} \\
& \mathrm{W}_{\mathrm{RK}}=\frac{1}{2} \mathrm{~T}_{\mathrm{I}} \Delta \mathrm{u}
\end{aligned}
$$

Where:

$\mathrm{W}_{\mathrm{RS}}=$ strain energy release for a linear element

$\mathrm{W}_{\mathrm{RK}}=$ linear part of kinetic energy release

$\mathrm{T}_{\mathrm{I}} \quad=$ rock mass stress in state $\mathrm{I}$

$\mathrm{u}_{\mathrm{I}} \quad=$ displacement in state $\mathrm{I}$

$\Delta \mathrm{u}=$ change in displacement from state I to state II 
The elements in the gob and/or backfill area, $\mathrm{S}_{\mathrm{GII}}$, are calculated as the nonlinear part of the kinetic energy.

$$
\mathrm{W}_{\mathrm{RK}}=\frac{1}{2}(1-\alpha) \Delta \mathrm{R} \Delta \mathrm{u}
$$

Where:

$\mathrm{W}_{\mathrm{RK}}=$ non-linear part of kinetic energy release

$\Delta \mathrm{R}=$ change in gob (backfill) stress from state I to state II

$\alpha=$ a nonlinearity factor for the gob and/or backfill (for linear materials, $\alpha=1$, and for strain-hardening materials, $\alpha<1$ )

Following this, the total energy release is calculated on an elemental basis. The energy release for the elements within $S_{m}$ is calculated as the sum of equations 2.4 and 2.5 while the energy release for the elements within $\mathrm{S}_{\mathrm{GII}}$ is calculated with equation 2.6. If a special case should arise where an element is within both $S_{m}$ and $S_{\mathrm{GII}}$, the total energy release for that element is simply the sum of all three energy quantities.

The total strain energy, recoverable strain energy, and dissipated energy are then calculated for each unmined element in the model. With slight modification of Salamon's original equations for linear strain energy release, equations can be derived to account for the nonlinear stress-strain behaviors available as material models in the MULSIM/NL program. Assuming that the initial loading and unloading modulus is the same for the nonlinear models, the strain energy release from the mined material must equal the recoverable strain energy. The difference in total strain energy and recoverable strain energy is the dissipated strain energy which is dissipated by the element to the environment.

With the material models available in MULSIM/NL (and LaModel) and considering Case A in Figure 2.5, four general types of potential material changes exist. Type 1 elements (See Figure 2.5) are unmined in state I and state II and the total strain energy, recoverable strain energy, and dissipated strain energy are calculated for each. Type 2 elements are mined out in going from state I to II and the strain energy release is computed as the recoverable strain energy. Combined with the linear kinetic energy release (Equation 2.5), the total energy release for these 
elements can be determined. Type 3 and 4 materials are open or backfilled, respectively, in state I and change to, or remain, backfilled in state II. For these elements, the total energy release is calculated as the non-linear component of the kinetic energy release (Equation 2.6). The only difference between type 3 and 4 elements is the stress at state I which is zero and nonzero respectively.

In case B, elements exist as type 1 through 4 just as with case A. Also, in this case, a fifth element type emerges, type 5 material was mined and open in state I and remains open in state II. These type 5 elements contribute zero energy to the energy release and do not contain stored elastic strain energy.

In case $C$, the opposite of case B occurs. Here, elements exist as type 1 through 4 and type 6. These type 6 elements go from unmined in state I to gob/backfill in state II without an intermediate open step and are contained in both $S_{M}$ and $S_{\mathrm{GII}}$. For these elements, the total energy release is calculated as the sum of the recoverable strain energy (Equation 2.4), the linear component of the kinetic energy release (Equation 2.5), and the nonlinear component of the kinetic energy release (Equation 2.6).

Looking forward again, one can see that the LaModel program calculates the energy quantities similarly to MULSIM/NL. The MULSIM/NL program has applied the energy calculation to non-linear materials and calculates the kinetic energy release for any material change. This is exactly what is done in the LaModel program. The only difference being the form in which the energy equations are presented and a new derivation of the Strain Hardening Gob energy equations, eliminating the need for a non-linearity factor. 


\section{Chapter 3}

\section{Implementation of Energy Release Calculations in LaModel}

\subsection{Implementation of Static Energy Calculations into LaModel}

In order to apply ERR calculations to the analysis of bump potential in some recent bump events, the LaModel displacement-discontinuity program has been enhanced with newly programmed energy calculations. Almost identical to Zipf's calculations in MULSIM/NL, the static and dynamic energy calculations for each seam material are described by seam material. In the original LaModel (as in MULSIM/NL), six material models were available: Linear Elastic Coal, Strain-Softening Coal, Elastic Plastic Coal, Linear Elastic Gob, Strain-Hardening Gob, and Bilinear Hardening Gob (see Figure 3.1).

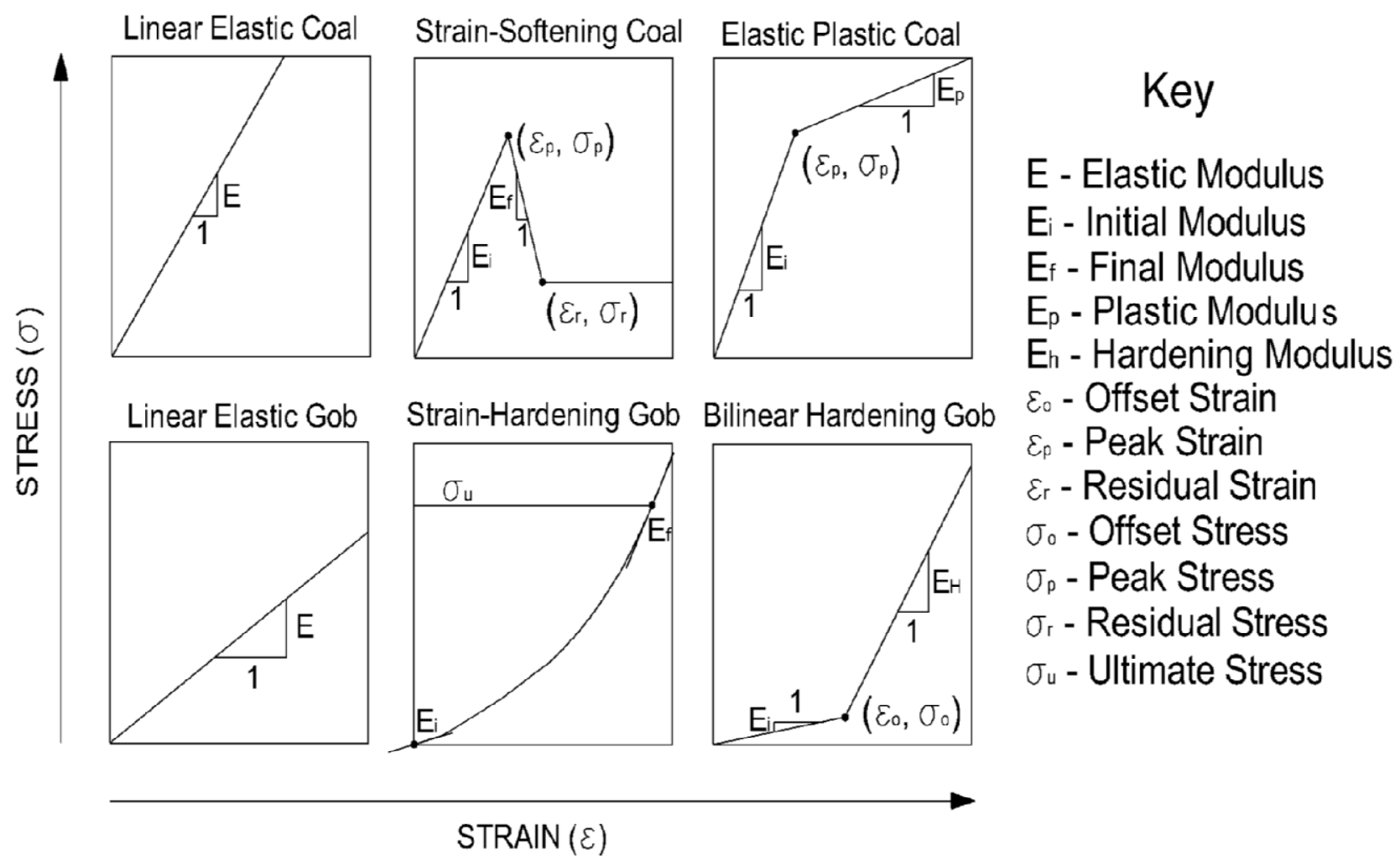

Figure 3.1: The material models available in LaModel (Heasley, 1998). 
For each of these material models, a number of energy values can be calculated, as previously shown by Zipf and Heasley (1990) with MULSIM/NL. In the latest LaModel program, these calculated energy quantities are divided into two major groups: Static (or input energy) and Dynamic (or released energy). The static energies are associated with the strain energy that has been input and/or stored in a seam material at a given strain level (just as in MULSIM/NL). The input energies include the total input energy, stored elastic energy, and the dissipated energy (see Figure 3.2):

1) Total Input Energy $\left(\mathrm{W}_{\mathrm{T}}\right)$ : Zipf (1992) refers to this as the Total Strain Energy. This is the entire area under the stress strain curve for a given material. It is the energy required to strain the material from zero strain to the current strain value. It is the sum of the stored and dissipated strain energies.

2) Stored Elastic Energy ( $\mathrm{W}_{\mathrm{S}}$ ): Zipf (1992) refers to this as the Recoverable Strain Energy. This is the energy that is stored in the material as elastic strain energy. This value represents the energy that is recoverable from the material if the material were to be unloaded to zero strain. It is the difference between the total input energy and the dissipated energy.

3) Dissipated Strain Energy $\left(\mathrm{W}_{\mathrm{D}}\right)$ : This is the strain energy that is input to the material but is not stored in the material. This energy is assumed to have been dissipated by the element to the environment either nonviolently through rock failure, cracking, friction, and heat generation or violently with dynamic ejection of the material (coal bump or rock burst). 


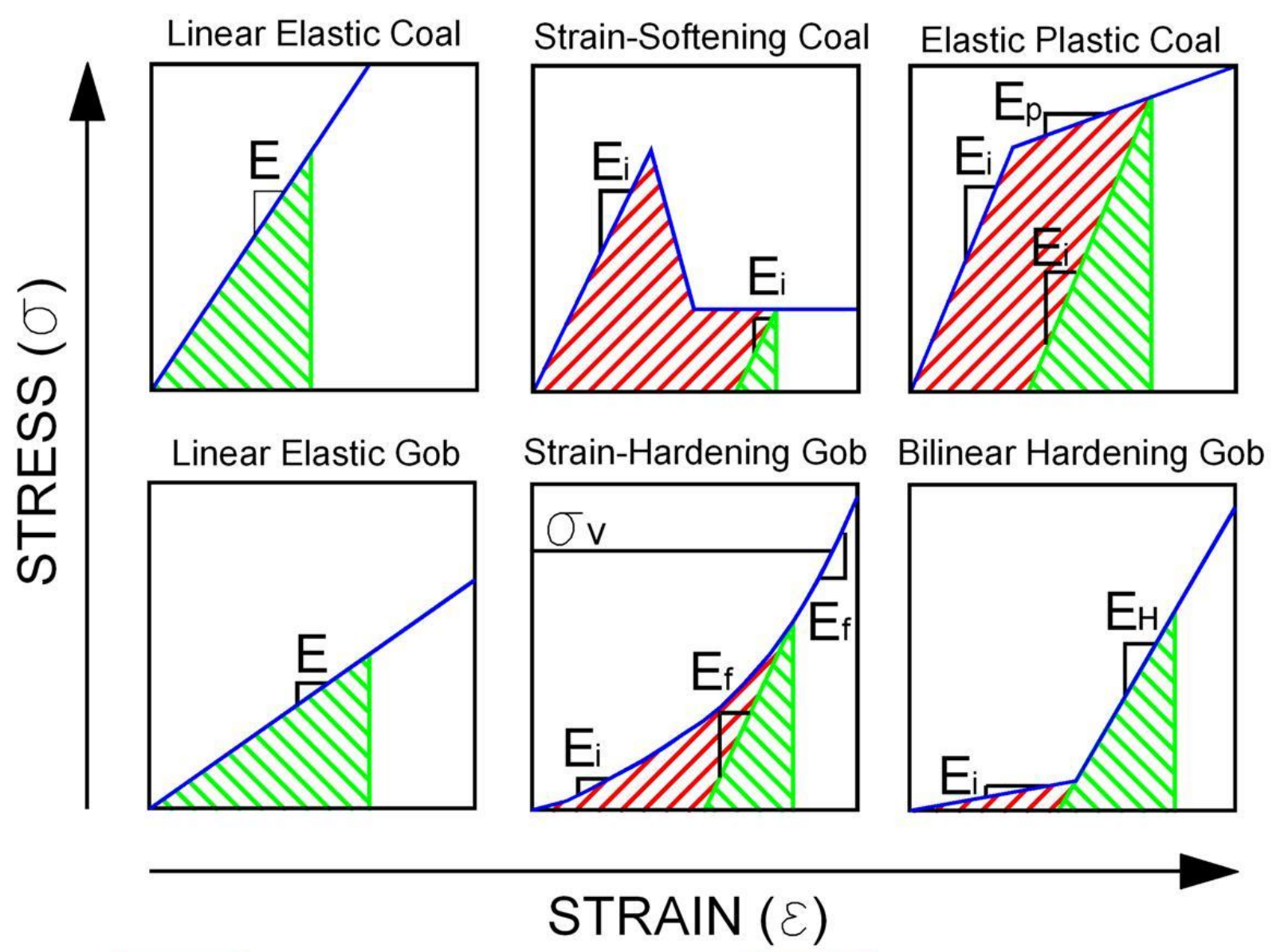

Dissipated Strain Energy

Stored Elastic Energy

Figure 3.2: Static energy relationships for the six material models.

In order to actually calculate these static energy values, a number of necessary assumptions were made. For the Strain-Softening and Elastic-Plastic Coal, the unloading modulus was assumed to be equal to the initial elastic modulus. For the Strain-Hardening Gob, the unloading modulus was assumed to be equal to the Final Modulus, and for the Bilinear Hardening Gob material, the unloading modulus was assumed to be equal to the Hardening Modulus (see Figures 3.1 and 3.2). The equations needed to calculate the static energy quantities for each material model are described in detail below. 


\subsubsection{Linear Elastic Coal:}

The static energy equations for all linear elastic materials are the same. The static energy equations for Linear Elastic Coal and Linear Elastic Gob are shown in the following equations.

$$
\begin{aligned}
& \mathrm{W}_{\mathrm{S}}=\frac{\sigma}{2} \mathrm{~S}_{\mathrm{M}} \varepsilon \mathrm{h} \\
& \mathrm{W}_{\mathrm{D}}=0 \\
& \mathrm{~W}_{\mathrm{T}}=\mathrm{W}_{\mathrm{S}}
\end{aligned}
$$

Where:

$$
\begin{array}{ll}
\mathrm{W}_{\mathrm{S}} & =\text { stored elastic energy } \\
\mathrm{W}_{\mathrm{D}} & =\text { dissipated energy } \\
\mathrm{W}_{\mathrm{T}} & =\text { total input energy } \\
\sigma & =\text { element stress } \\
\mathrm{S}_{\mathrm{M}} & =\text { the surface area of the element } \\
\varepsilon & =\text { strain } \\
\mathrm{h} & =\text { mining height }
\end{array}
$$

and where the displacement $(\mathrm{u})$ of the element is equal to the element strain $(\varepsilon)$ times the mining height (h):

$$
\mathrm{u}=\varepsilon \mathrm{h}
$$

Equation 3.1 is essentially equal to equation 2.4 and the first term of the stored energy release in equation 2.3. 


\subsubsection{Strain Softening Coal:}

This is the second coal material available in LaModel. In this material model, stress again increases on the linear curve until the peak stress and peak strain is reached. From here, the stress decreases while the strain increases until the residual stress is reached. At this point, the strain increases at a constant residual stress (see Figure 3.2). With this material, it is advantageous to calculate the dissipated energy as the difference between the total input energy and the stored elastic energy. Depending on the location on the curve, the following equations are used to calculate the static energy quantities. If the location on the stress - strain curve is less than or equal to the peak strain $\left(\varepsilon \leq \varepsilon_{\mathrm{p}}\right)$, that is the location is on the linear portion of the cure, the triangular are under the curve is calculated. In this case, the same equations used for the linear material models, equations 3.5a are used.

$$
\begin{aligned}
& \mathrm{W}_{\mathrm{S}}=\frac{\sigma}{2} \mathrm{~S}_{\mathrm{M}} \varepsilon \mathrm{h} \\
& \mathrm{W}_{\mathrm{D}}=0 \\
& \mathrm{~W}_{\mathrm{T}}=\mathrm{W}_{\mathrm{S}}
\end{aligned}
$$

If the material is on the strain softening portion of the curve then the strain level is between the peak strain and residual strain $\left(\varepsilon_{\mathrm{p}} \leq \varepsilon \leq \varepsilon_{\mathrm{r}}\right)$. To help with the calculation, the amount of incremental strain $\left(\varepsilon_{i 1}\right)$ past the peak strain is determined. In this case, the area under the curve becomes the summation of the energy input up to the peak strain and the energy input between the peak strain and the present strain level. Assuming the loading and unloading follow the same modulus, equations $3.5 \mathrm{~b}$ give the energy values for the strain-softening part of the curve.

$$
\begin{gathered}
\varepsilon_{\mathrm{i} 1}=\varepsilon-\varepsilon_{\mathrm{p}} \\
\mathrm{W}_{\mathrm{S}}=\frac{\sigma^{2}}{2 \mathrm{E}_{\mathrm{i}}} \mathrm{S}_{\mathrm{M}} \mathrm{h}
\end{gathered}
$$




$$
\begin{gathered}
\mathrm{W}_{\mathrm{T}}=\left[\left(\frac{\sigma_{\mathrm{p}}}{2} \varepsilon_{\mathrm{p}}\right)+\left(\frac{\sigma+\sigma_{\mathrm{p}}}{2}\right) \varepsilon_{\mathrm{i} 1}\right] \mathrm{S}_{\mathrm{M}} \mathrm{h} \\
\mathrm{W}_{\mathrm{D}}=\mathrm{W}_{\mathrm{T}}-\mathrm{W}_{\mathrm{S}}
\end{gathered}
$$

If the material is on the residual portion of the stress - strain curve, then the strain level is beyond the residual strain $\left(\varepsilon>\varepsilon_{\mathrm{r}}\right)$. In this case, the total energy is the sum of the energy input into all three portions to the curve, and to help with the calculations the amount of incremental strain between the peak and residual strain $\left(\varepsilon_{\mathrm{i} 1}\right)$ and the amount of incremental past $\left(\varepsilon_{\mathrm{i} 2}\right)$ past the residual strain are determined. Again, the loading modulus and unloading modulus are assumed equal.

$$
\begin{gathered}
\varepsilon_{\mathrm{i} 1}=\varepsilon_{\mathrm{r}}-\varepsilon_{\mathrm{p}} \\
\varepsilon_{\mathrm{i} 2}=\varepsilon-\varepsilon_{\mathrm{r}} \\
\mathrm{W}_{\mathrm{S}}=\frac{\sigma^{2}}{2 \mathrm{E}_{\mathrm{i}}} \mathrm{S}_{\mathrm{M}} \mathrm{h} \\
\mathrm{W}_{\mathrm{T}}=\left[\left(\frac{\sigma_{\mathrm{p}}}{2} \varepsilon_{\mathrm{p}}\right)+\left(\frac{\sigma_{\mathrm{r}}+\sigma_{\mathrm{p}}}{2}\right) \varepsilon_{\mathrm{i} 1}+\left(\sigma_{\mathrm{r}} \varepsilon_{\mathrm{i} 2}\right)\right] \mathrm{S}_{\mathrm{M}} \mathrm{h} \\
\mathrm{W}_{\mathrm{D}}=\mathrm{W}_{\mathrm{T}}-\mathrm{W}_{\mathrm{S}}
\end{gathered}
$$

Where:

$$
\begin{aligned}
& \sigma_{\mathrm{p}}=\text { peak stress } \\
& \sigma_{\mathrm{r}}=\text { residual stress }
\end{aligned}
$$




$$
\begin{array}{ll}
\varepsilon_{\mathrm{p}} & =\text { peak strain } \\
\varepsilon_{\mathrm{r}} & =\text { residual strain } \\
\varepsilon_{\mathrm{i} 1} & =\text { first incremental strain } \\
\varepsilon_{\mathrm{i} 2} & =\text { second incremental strain } \\
\mathrm{E}_{\mathrm{i}} & =\text { initial modulus }
\end{array}
$$

\subsubsection{Elastic Plastic Coal:}

This material is probably the most widely used material model currently available to simulate coal since it has been incorporated into the LamPre (the LaModel preprocessor program) material wizard. In this material model, stress increases on the initial linear portion of the curve until the peak stress is reached where it continues on the plastic curve (see Figure 3.2). When the stress is on the initial linear portion of the curve, the static energy values are calculated using the same equations as for any linear elastic material. Equation 3.6a shows the static energy calculations for the elastic plastic material when the strain level is less than the plastic strain $\left(\varepsilon \leq \varepsilon_{\mathrm{p}}\right)$.

$$
\begin{gathered}
\mathrm{W}_{\mathrm{S}}=\frac{\sigma}{2} \mathrm{~S}_{\mathrm{M}} \varepsilon \mathrm{h} \\
\mathrm{W}_{\mathrm{D}}=0 \\
\mathrm{~W}_{\mathrm{T}}=\mathrm{W}_{\mathrm{S}}
\end{gathered}
$$

If the material is on the plastic portion of the stress - strain curve, that is the strain value is greater than the plastic strain $\left(\varepsilon>\varepsilon_{\mathrm{p}}\right)$, then the total input energy is the triangular area under the linear portion of the curve plus the area under the plastic portion under the curve. Equations 3.6b shows the static energy calculations for the plastic portion of the curve.

$$
\mathrm{W}_{\mathrm{S}}=\frac{\sigma_{\mathrm{p}}}{2} \mathrm{~S}_{\mathrm{M}} \varepsilon_{\mathrm{p}} \mathrm{h}
$$




$$
\begin{gathered}
\mathrm{W}_{\mathrm{D}}=\sigma_{\mathrm{p}} \mathrm{S}_{\mathrm{m}}\left(\varepsilon-\varepsilon_{\mathrm{p}}\right) \mathrm{h} \\
\mathrm{W}_{\mathrm{T}}=\mathrm{W}_{\mathrm{S}}+\mathrm{W}_{\mathrm{D}}
\end{gathered}
$$

Where:

$$
\begin{aligned}
& \sigma_{\mathrm{p}}=\text { peak stress } \\
& \varepsilon_{\mathrm{p}}=\text { peak strain }
\end{aligned}
$$

\subsubsection{Linear Elastic Gob:}

The linear elastic gob material is very similar to the linear elastic coal material, with the addition of the gob height factor. For calculating the static energy quantities, the following equations show the static energy calculation for either material.

$$
\begin{gathered}
\mathrm{W}_{\mathrm{S}}=\frac{\sigma}{2} \varepsilon \mathrm{S}_{\mathrm{M}} \mathrm{h} \\
\mathrm{W}_{\mathrm{D}}=0 \\
\mathrm{~W}_{\mathrm{T}}=\mathrm{W}_{\mathrm{S}}
\end{gathered}
$$

\subsubsection{Strain Hardening Gob:}

This material model is the most widely used gob material since it is incorporated into the Gob Wizard in the current LamPre program. This gob material is a non-linear model where the material hardens as the stress increases. The following equation gives the total input energy to this material, which is equal to the area under the associated stress-strain curve (see Figure 3.2). The derivation of this equation can be found in Appendix A. 


$$
\int_{0}^{S_{p}} \sigma d \varepsilon=\frac{E_{i}}{n}\left[\frac{n \sigma_{u}}{E_{f}-E_{i}}\right]^{2} e^{\frac{E_{f}-E_{i}}{n \sigma_{u}} S_{p}}-\frac{E_{i}}{n}\left[\frac{n \sigma_{u}}{E_{f}-E_{i}}\right] S_{p}-\frac{E_{i}}{n}\left[\frac{n \sigma_{u}}{E_{f}-E_{i}}\right]^{2}
$$

Where:

$\sigma_{\mathrm{u}}=$ ultimate stress

$\mathrm{E}_{\mathrm{i}}=$ initial modulus

$\mathrm{E}_{\mathrm{f}}=$ final modulus

$\mathrm{S}_{\mathrm{p}}=$ current strain

$\mathrm{n}=$ gob height factor

With this equation, the total energy input to the element $\left(\mathrm{W}_{\mathrm{T}}\right)$ can be determined as equation 3.10 multiplied by the element area $\left(\mathrm{S}_{\mathrm{M}}\right)$ and the seam height $(\mathrm{h})$. Then, if the unloading modulus is assumed to be equal to the final modulus (Ef) and we are using effective stress and strain values, the static energy quantities for the strain hardening gob can be written as:

$$
\begin{gathered}
W_{S}=\frac{\sigma^{2}}{2 E_{f}} S_{M} h \\
W_{T}=\left(\frac{E_{i}}{n}\left[\frac{n \sigma_{u}}{E_{f}-E_{i}}\right]^{2} e^{\frac{E_{f}-E_{i}}{n \sigma_{u}} S_{P}}-\frac{E_{i}}{n}\left[\frac{n \sigma_{u}}{E_{f}-E_{i}}\right] S_{P}-\frac{E_{i}}{n}\left[\frac{n \sigma_{u}}{E_{f}-E_{i}}\right]^{2}\right) S_{M} h \\
W_{D}=W_{T}-W_{S}
\end{gathered}
$$

\subsubsection{Bilinear Hardening Gob:}

This gob material allows for the initial hardening to occur along one linear portion of the curve until the offset stress is reached. At this point, the gob hardens at a faster rate along the final linear portion of the curve. If the strain level is on the initial hardening portion of the curve, that is $\left(\varepsilon \leq \varepsilon_{0}\right)$, equations $3.14 \mathrm{a}$ are used to calculate the energy values. 


$$
\begin{gathered}
\mathrm{W}_{\mathrm{S}}=\frac{\sigma}{2} \mathrm{~S}_{\mathrm{M}} \varepsilon \mathrm{h} \\
\mathrm{W}_{\mathrm{T}}=\mathrm{W}_{\mathrm{S}} \\
\mathrm{W}_{\mathrm{D}}=0
\end{gathered}
$$

If the material is on the final hardening portion of the stress - strain curve $\left(\varepsilon>\varepsilon_{0}\right)$, the total input energy is calculated as the total area under both parts the curve. In this case, the unloading modulus is assumed equal to the hardening modulus and the energy values are defined by equations $3.14 \mathrm{~b}$.

$$
\begin{gathered}
\mathrm{W}_{\mathrm{S}}=\frac{\sigma^{2}}{2 \mathrm{E}_{\mathrm{f}}} \mathrm{S}_{\mathrm{M}} \mathrm{h} \\
\mathrm{W}_{\mathrm{T}}=\left[\left(\frac{\sigma_{0}}{2}\right) \varepsilon_{0}+\left(\frac{\sigma+\sigma_{0}}{2}\right)\left(\varepsilon-\varepsilon_{0}\right)\right] \mathrm{S}_{\mathrm{m}} \mathrm{h} \\
\mathrm{W}_{\mathrm{D}}=\mathrm{W}_{\mathrm{T}}-\mathrm{W}_{\mathrm{S}}
\end{gathered}
$$

Where:

$$
\begin{aligned}
& \sigma_{\mathrm{o}}=\text { offset stress } \\
& \varepsilon_{\mathrm{o}}=\text { offset strain }
\end{aligned}
$$

\subsection{Implementation of Dynamic Energy Calculations into LaModel}

The dynamic, or released, energy values are associated with energy changes in the materials that occur between mining steps. For the vast majority of elements, energy changes are associated with changes in the element's stress and deformation state while staying on the same 
material curve. For some elements, however, energy changes occur in conjunction with one of three major material changes that can happen to that element between steps:

1) The element can change from one material to another (a cut can be taken nearby and the element changes to a weaker element, or a coal element can change to a gob element after it is mined);

2) The element changes from a material to an opening (typically immediately after it is mined), or;

3) The element changes from an opening to a material (typically a gob material as the element moves into the gob).

For each element in the model, there are specific dynamic energy changes that occur. These dynamic energy changes are:

1) An increase in dissipated energy,

2) A stored energy release (Zipf's strain energy release),

3) A kinetic energy release, and

4) A total energy release

\subsubsection{Increase in Dissipated Energy:}

The increase in dissipated energy only applies to an element that stays the same material between one step and another, and it is equal to the change in the dissipated energy of the element between the first step and the second. This increase in dissipated energy equals the difference between the energy input into the element along the stress-strain curve between the steps and the change in energy stored in the element between the steps (see Equation 3.15). It is calculated by subtracting the dissipated strain energy in the first step (see Figure 3.3A) from the dissipated strain energy in the second step (see Figure 3.3B).

$$
\Delta \mathrm{W}_{\mathrm{D}}=\mathrm{W}_{\mathrm{DII}}-\mathrm{W}_{\mathrm{DI}}
$$

Where:

$$
\begin{aligned}
& \Delta \mathrm{W}_{\mathrm{D}}=\text { change in dissipated energy } \\
& \mathrm{W}_{\text {DII }}=\text { step two dissipated energy }
\end{aligned}
$$


$\mathrm{W}_{\mathrm{DI}}=$ step one dissipated energy

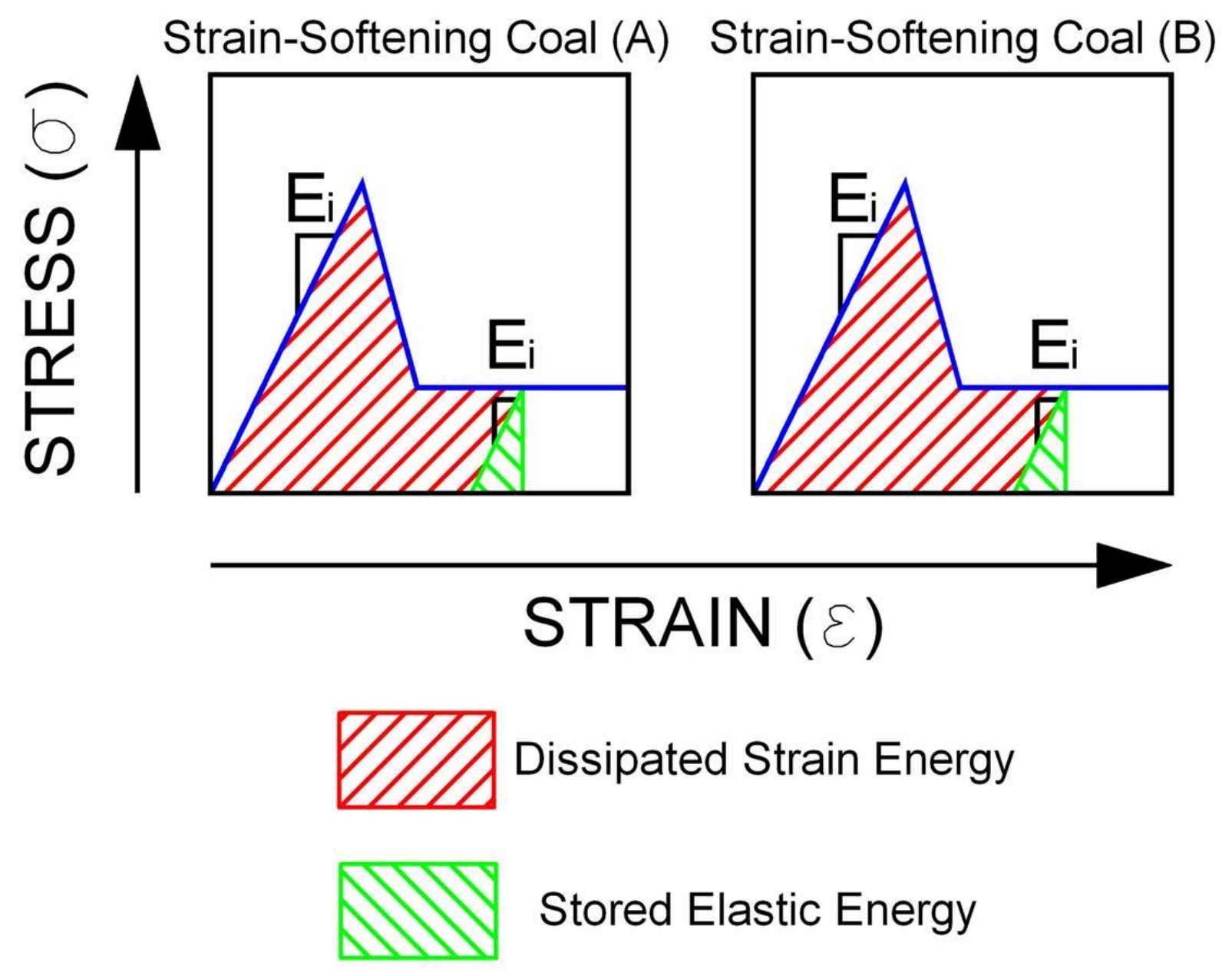

Figure 3.3: Increase in dissipated energy between step 1 (left) and step 2 (right).

\subsubsection{Stored Energy Release:}

The stored energy release is the difference in stored elastic energy between the first and second step. It is equal to the negative of the change in stored energy. This energy value can be calculated for all elements whether the element stays the same material or whether the element changes to another material between steps.

$$
-\Delta \mathrm{W}_{\mathrm{S}}=\mathrm{W}_{\mathrm{RS}}=-\left(\mathrm{W}_{\mathrm{SII}}-\mathrm{W}_{\mathrm{SI}}\right)
$$


Where:

$\Delta \mathrm{W}_{\mathrm{S}}=$ the change in stored energy

$\mathrm{W}_{\mathrm{RS}}=$ stored energy release

$\mathrm{W}_{\mathrm{SI}}=$ step one stored energy

$\mathrm{W}_{\text {SII }}=$ step two stored energy

\subsubsection{Kinetic Energy Release:}

The kinetic energy is the energy input to an element in going from one stress/strain location on one material curve to another stress/strain location on another material curve. In Salamon's (1984) original work, he was primarily concerned with the energy released from elastic elements changing to an opening (see Figure 3.4A). In this case, the elastic element was originally at point B on the material's elastic stress-strain curve and in the step it was mined, it moved to point D (an opening with zero stress and generally increased displacement/strain). For this material change, the stored energy release is equal to the total stored energy in the first step (area $\mathrm{ABC}$ ) minus the total stored energy in the second step (zero). The kinetic energy input to the element in the change between steps is equal to the average stress times the displacement between the steps (area BCD). This is the gravitational potential energy from the overburden that is input to the element as the roof converges. It is thought that this energy Since the element is an opening in the second step and does not have any stored energy, the kinetic energy release is equal to the total kinetic energy input between the steps (area BCD). The total energy release for this element is then area ABD.

In the more general case of calculating the kinetic energy release, an element can change from one material curve to another, the kinetic energy and kinetic energy release values are calculated in a similar manner to that describe above for the removal of an elastic element. For instance, consider the case where an elastic coal element changes to an elastic gob element (see Figure 3.4B). In this case, the element is at point B on the coal material's elastic stress-strain curve and after the element is mined, it ends at point $\mathrm{E}$ on the gob material's elastic stress-strain curve. For this material change, the stored energy release is equal to the total stored energy in the first step (area $A B C$ ) minus the total stored energy in the second step (area ADE). The kinetic energy input to the element in the change between steps is equal to the average stress 
times the displacement between the steps (area BCDE) (see equation 3.17). Since the gob element does have some final stored elastic energy, the total energy released from the element is equal to the total energy input to the element (area ABED, which is the initial stored energy plus the input kinetic energy) minus the final stored energy (area ADE). Therefore, the kinetic energy release is equal to the total energy release minus the stored energy release. The kinetic energy release calculation only applies to elements that change material codes, and in changing materials, it is assumed that the change between the two stress/strain location between the two material curves is linear

$$
\mathrm{W}_{\mathrm{RK}}=\frac{1}{2}\left(\sigma_{\mathrm{I}}+\sigma_{\mathrm{II}}\right) \Delta \mathrm{u}
$$

Where:

$$
\begin{aligned}
& \mathrm{W}_{\mathrm{RK}}=\text { input kinetic energy } \\
& \sigma_{\mathrm{I}}=\text { stress at step one } \\
& \sigma_{\mathrm{II}}=\text { stress at step two } \\
& \Delta \mathrm{u}=\text { change in displacement }
\end{aligned}
$$




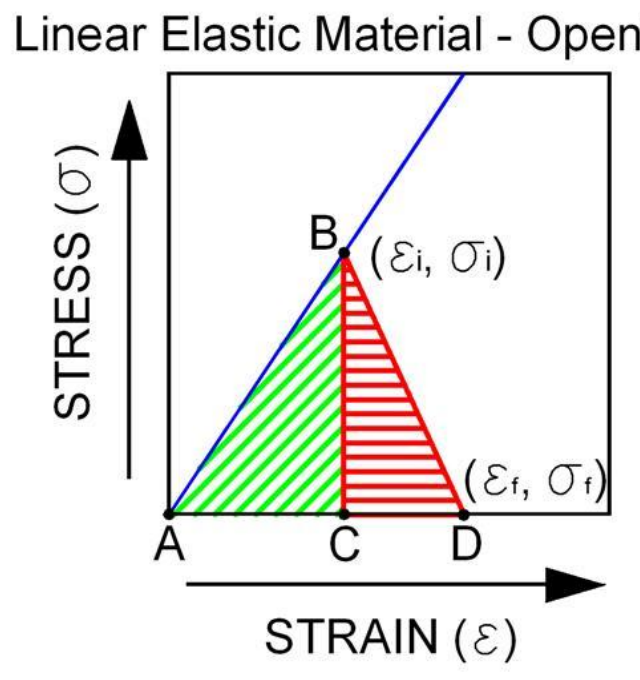

Stored Elastic Energy Kinetic Energy Released
Linear Elastic Coal - Gob (B)

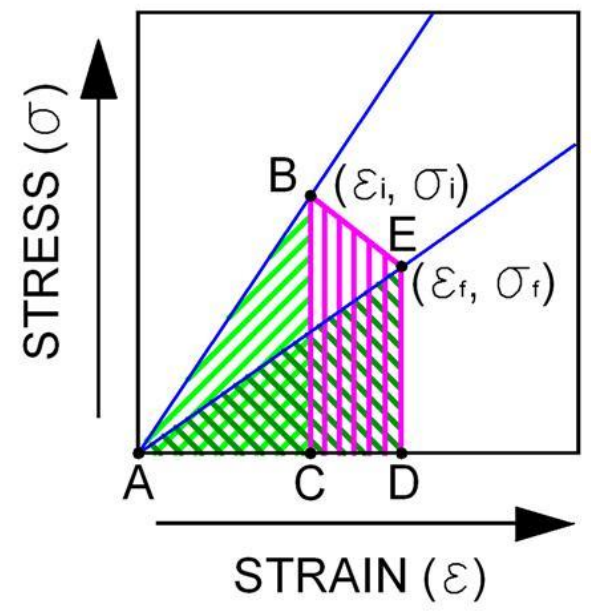

Coal Stored Elastic Energy Gob Stored Elastic Energy Input Kinetic Energy

Figure 3.4: Figure showing kinetic energy released from Salamon (left) and the extrapolation to the release from a material to material change (right).

\subsubsection{Total Energy Release:}

Once the three types of energy release have been calculated for an element, then the total energy release is the sum of all of the energies released from an element between mining steps. For an element that stays on the same material curve, the total energy release $\left(E_{R}\right)$ is just the increase in dissipated energy between steps.

$$
\mathrm{W}_{\mathrm{R}}=\Delta \mathrm{W}_{\mathrm{D}}
$$

For an element that changes material curves, the total energy release is the sum of the stored energy release and the kinetic energy release between the given steps.

$$
\mathrm{W}_{\mathrm{R}}=\mathrm{W}_{\mathrm{RS}}+\mathrm{W}_{\mathrm{RK}}
$$




\section{Chapter 4 \\ Validation of the ERR Calculations}

\subsection{Prior Research using MULSIM/NL:}

There have been several bump related case studies utilizing the non-linear boundary element MULSIM/NL program. The particular case that will be reexamined with LaModel in this thesis was a generic study of pillar recovery cut sequences published by the former US Bureau of Mines based on data from the Olga Mine in southern West Virginia (Zipf and Heasley, 1990). In this study, it was presumed that modification of cut sequences when recovering pillars could result is differing changes in the ERR. By modeling various cut sequences, the changes in the maximum ERR and the uniformity of the ERR over time can be charted. The cut sequences modeled in this study include; the single split and fender, pocket and wing, open ending, and the Olga Mine method (see Figure 4.1). The object of the initial study was to determine what cut sequence, if any, was the least bump prone based on the energy release rate calculation in MULSIM/NL.

This initial study commenced in two phases: first a linear elastic coal model was used and then a non-linear coal model. The material properties for the coal models were determined from back calculation from field data taken from the mine in 1989 by Campoli (Zipf and Heasley, 1990). The results of this study determined that the non-linear coal model was probably the more accurate representation. It also concluded that the Olga Mine method for recovering pillars was only marginally better than the other methods with respect to maximum observed ERR, but was highly advantageous with respect to ERR uniformity. Based on this result and the success of the Olga Mine method in the field, it was concluded that the uniformity of the ERR should be considered in conjunction with the absolute magnitude.

Zipf and Heasley (1990) again address the potential pitfalls of the ERR calculations, by stating that the area mined per step must remain constant due to the step size dependence originally highlighted by Salamon. With an unequal step size, comparisons between cut sequences would be invalid. It should be noted that the ERR criteria may not provide a clear distinction regarding the relative superiority of various mining methods or cut sequences because the ERR, for a given step, is an average of the energy release for all the elements extracted in 
that step. The larger the extraction area, the more likely it is to mask energy release spikes within the step resulting in a false impression of uniformity. In an ideal modeling situation, each mining step should extract the smallest area possible. While it is nearly impossible to extract one element at a time, one must balance the concept with the practicality of the available computing resources. It should also be noted that non-linear material models are required for a model to represent the actual coal yielding and load transfer observed in the field. Furthermore, it tends to be quite difficult to determine which method may actually be best based on the maximum ERR since changes in its magnitude are usually small (typically $<10 \%$ ). It seems to be easier (and perhaps better) to determine cut sequence superiority based on uniformity of the ERR (in time and space). Large increases in the ERR are usually observed during the extraction of the highly stressed pillar core (splitting the pillar). As we will see in Chapter 5, deliberately taking these highly stressed cuts into the core prior to full extraction has the potential to reduce the chances of a bump.

Second, viable comparisons between different models must always use the same rock mass modulus. This results as a paradox regarding the ERR when applied to coal mine bumps. Most would agree that coal bumps are most likely to occur in seams surrounded by massive competent strata such as thick sandstone and least likely to occur in seams surrounded by less competent strata such as shale. Typically, sandstone equates to a high rock mass modulus while shale equates to a lower rock mass modulus. However, in Boundary Element Model (BEM) calculations, the ERR varies inversely with the rock mass modulus. This would mean that seams surrounded by softer rock, "shale," would represent a higher bump risk than seams surrounded by sandstone. Obviously, this is not the case. In practice, this paradox does not discredit the usefulness of the ERR calculation. Assuming the same rock mass modulus would make comparisons between different cut sequence models appropriate. Also, this means that the ERR value (as presently) cannot provide a universal threshold value above which bumps would be known to occur.

Overall, the case study by Zipf and Heasley (1990) concludes that the Olga Mine method for pillar recovery is superior to the other pillar recover methods for use in a bump prone mine. The Olga Mine method gradually reduces pillar stiffness several rows ahead of the advancing gob line. Progressively softening these pillars tends to decrease the overall strain energy and provides for a mechanism for keeping the ERR uniform. Based on what has been described 
above, a nonlinear BEM such as MULSIM/NL using nonlinear material models can be used to evaluate different mining cut sequences to help decrease coal bump risk, provided that the precautions listed above are adequately considered.

\subsection{Cut Sequence Analysis with LaModel:}

Validation of the ERR calculations added to LaModel, in addition to manual test calculations (see Appendix B), included duplicating the analysis of four pillar retreat cut sequences that were analyzed and previously published (Zipf and Heasley, 1990; Heasley and Zelanko, 1992). These cut sequences were originally analyzed using the MULSIM/NL boundary element program, which is based on a homogeneous overburden model as opposed to the LaModel program, which is based on a laminated overburden model. Because of this fundamental difference in the programs' formulations, it was not expected that the LaModel energy results would exactly match the previous MULSIM/NL results; however, it was anticipated that very similar trends would be observed. Specifically, both programs were used to analyze the Open Ending (OE), Pocket and Wing (P\&W), Single Split and Fender (SS\&F), and Olga cut sequences as shown in Figure 4.1 (Zipf and Heasley, 1990; Heasley and Zelanko, 1992). 


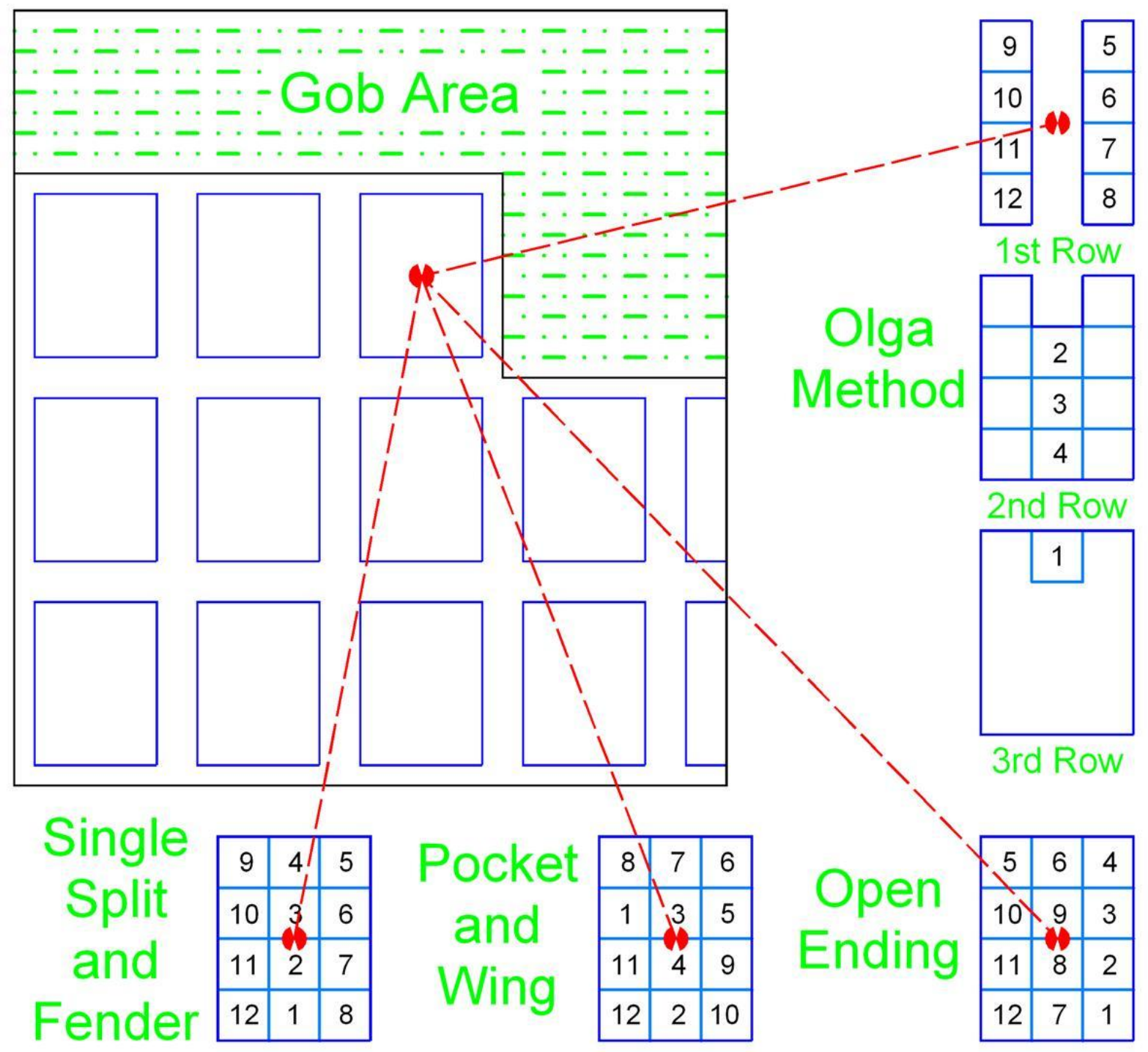

Figure 4.1: Cut sequences modeled.

The first verification study with the different cut sequences analyzes the total energy released from the four different pillar retreat cut sequences and duplicates the elastic material models developed by Zipf and Heasley (1990). In this case, the total energy release was calculated as the total over the area of the pillar being extracted. In the case of the Olga cut sequence, where cuts were being taken into multiple pillars, the respective pillar with a cut that step was analyzed. The same general trends observed by Zipf and Heasley with MULSIM/NL were observed with LaModel with some variation (see Figures 4.2 and 4.3). First, the magnitude of the total energy 
release with LaModel is approximately half of that which was observed with MULSIM/NL. This difference is probably due to a fundamental difference in roof stiffness between the two model's input parameters. With both programs, the Olga cut sequence had the highest peak energy releases and the open ending cut sequence had the lowest peak energy releases. With both programs, the Olga cut sequence and the split and fender cut sequence had very similar energy release curves. Differences between the two programs' results appeared to be due to slight difference in the location of element stresses and the timing of element failure, assumedly due to the different overburden responses. As we see later, small changes in coal behavior can significantly shift the timing and location of calculated energy releases.

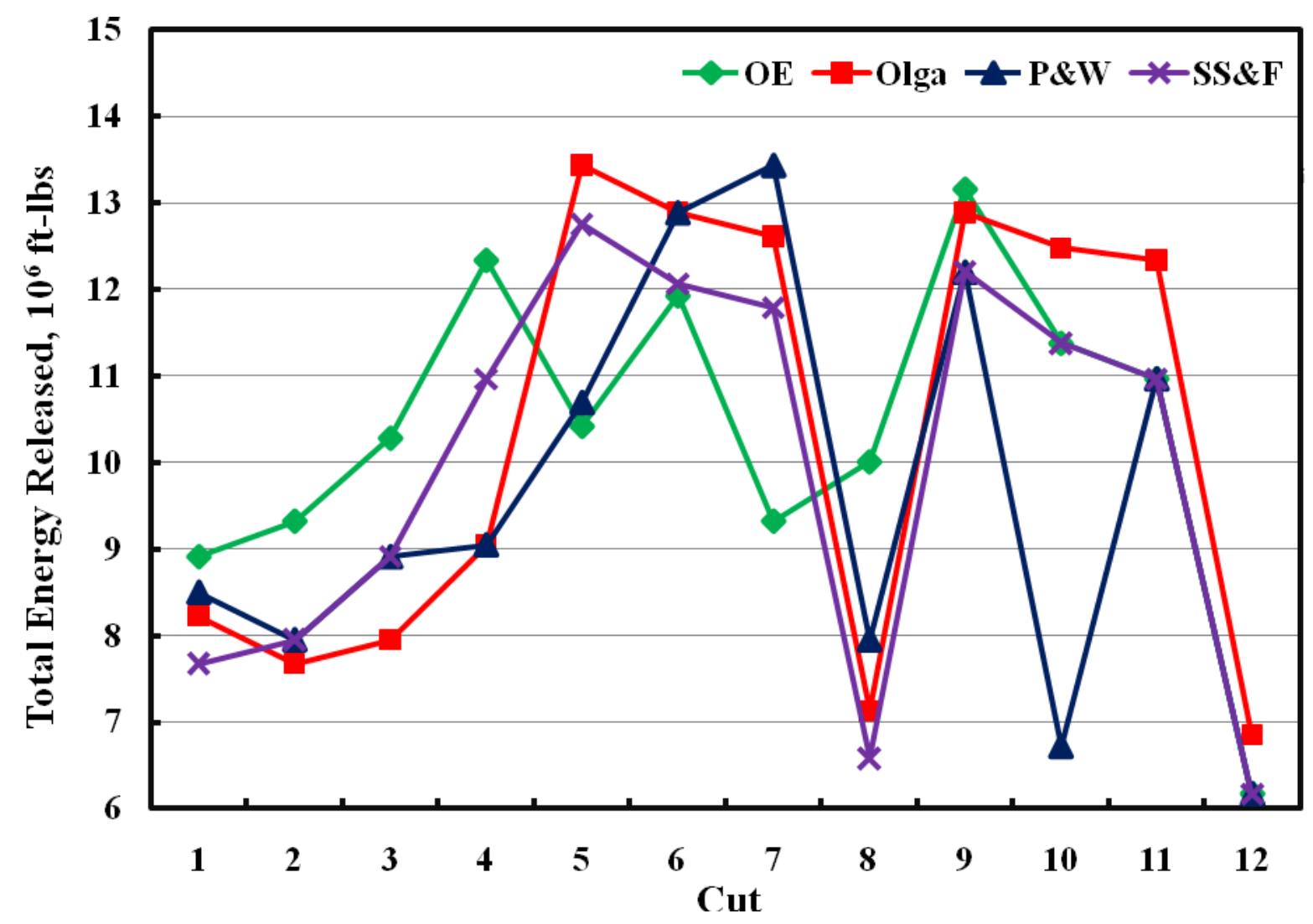

Figure 4.2: $\quad$ MULSIM/NL total energy released versus cut (after Zipf and Heasley, 1990). 


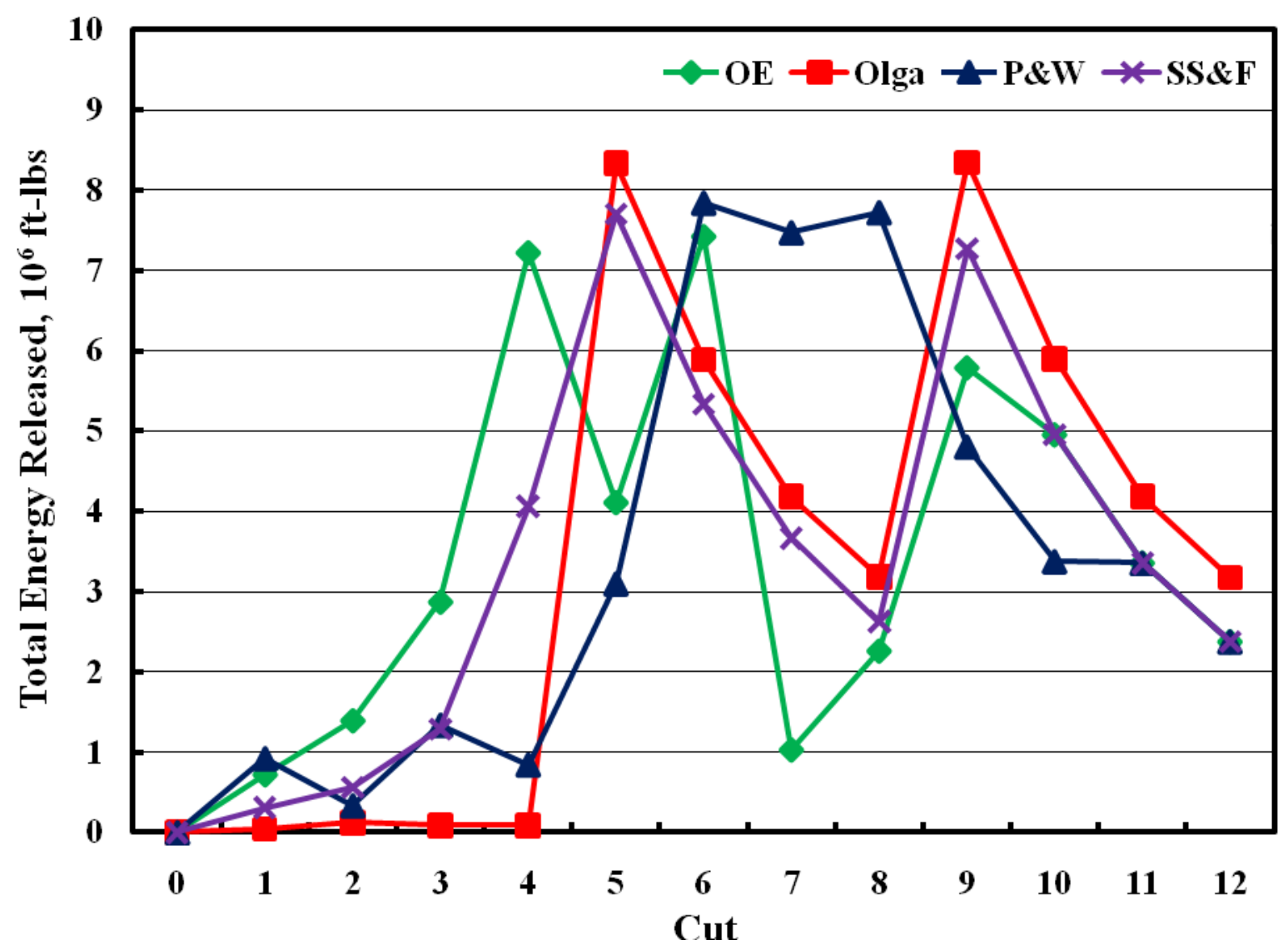

Figure 4.3: LaModel total energy released versus cut.

The second verification study investigates the change in dissipated energy between the mining steps for the four cut sequences and uses the strain-softening coal properties developed for the Olga Mine by Heasley and Zelanko (1992). In this case, the change in dissipated energy was calculated as the total over the entire model area. Again, the same trends observed with the MULSIM/NL analysis were observed with the LaModel analysis with some slight variation. Again, the energy values calculated with MULSIM/NL are higher than those calculated with LaModel, in this case, approximately four times higher. In both programs, the first three steps of the cut sequences have the highest dissipated energy releases. In both models, the open ending cut sequence has the lowest peak energy releases and distributes significant energy release after cut 4 . In the LaModel analysis, the highest dissipated energy generally occurs in cut 1 rather than in cut 2 cut as observed with MULSIM/NL. Also, the peak dissipated energies between the two models are a bit scrambled. Again, the small differences between the two programs' results 
can probably be explained by a slight difference in the location of element stresses and the timing of element failure, assumedly due to the different overburden responses.

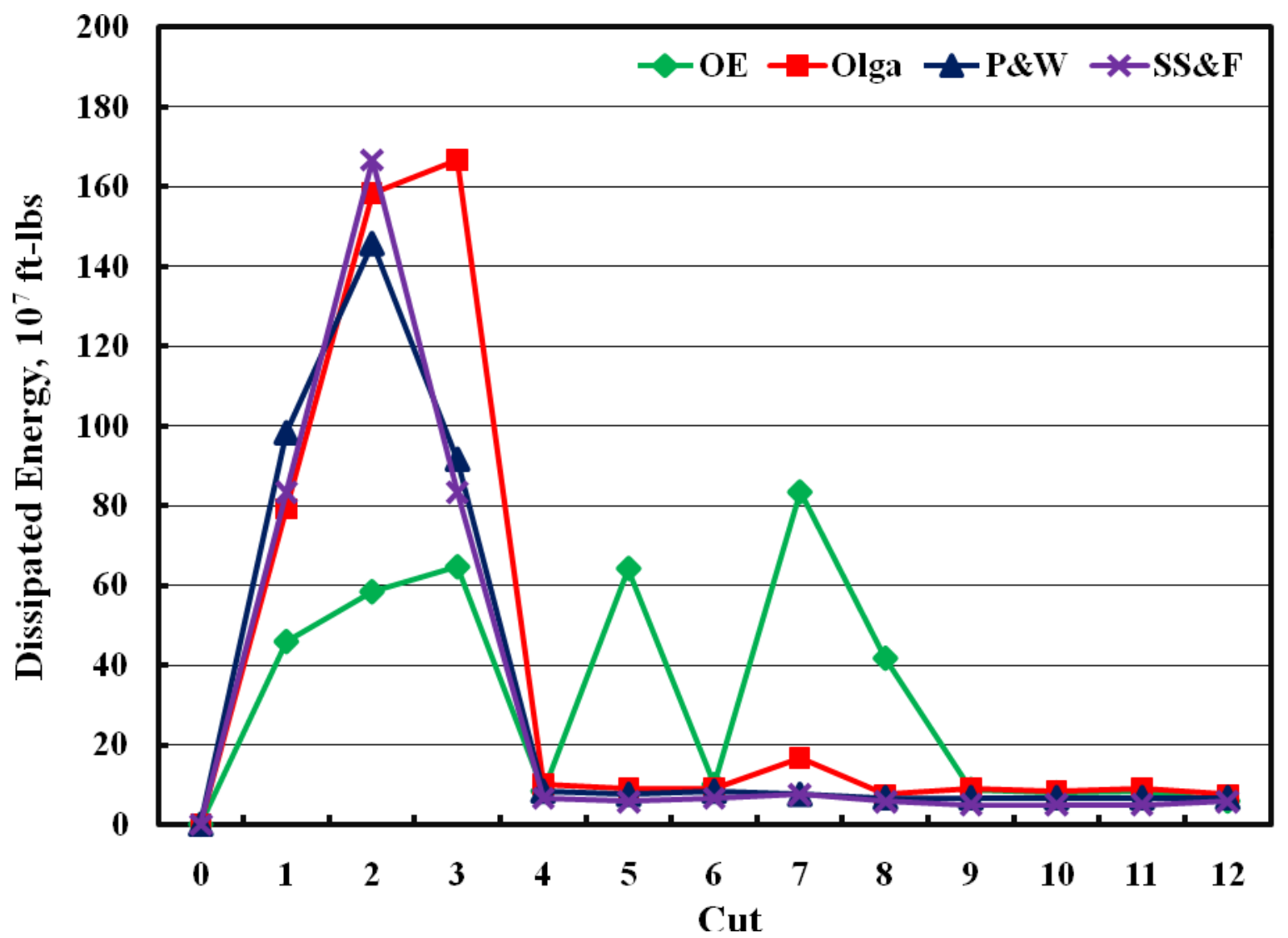

Figure 4.4: MULSIM/NL dissipated energy release versus cut (after Heasley and Zelanko, 1992). 


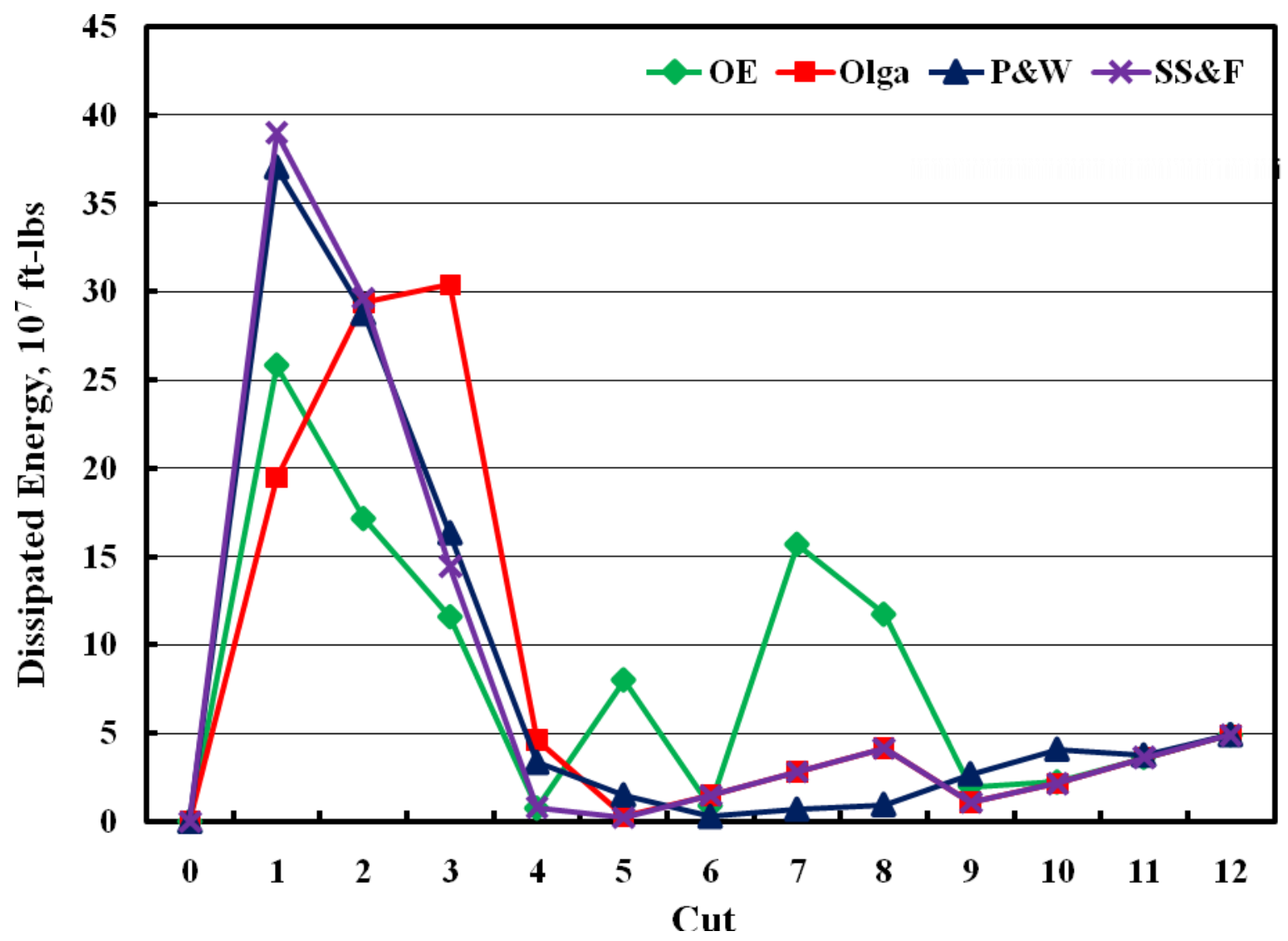

Figure 4.5: LaModel dissipated energy release versus cut. 


\section{Chapter 5}

\section{Case Study Demonstration of ERR Calculations}

\subsection{Prior Research Using LaModel}

Up until this research, the ERR calculation was not incorporated into the LaModel program as it was in MULSIM/NL. Although it has lacked this valuable tool for the assessment of bump potential, this has not stopped LaModel from being used for assessing potential. Newman (2008) described two cases in which the LaModel program was used to determine a safe pillar recover plan solely based on detailed stress analysis.

Both cases are located in the Darby Seam in Eastern Kentucky. The coal in this seam is of metallurgical grade with low sulfur, high BTU, and is suitable as a stoker coal. The coal itself is brittle and strong with an insitu strength of 984 psi, based on physical tests. The Darby seam has been mined extensively in Harlan County, Kentucky (the location of the case studies) as well as other locations and is known for coal bump occurrences. Coal bumps in this area are attributed to the unique geology, high topographic relief, and stiff overburden characteristics (Newman, 2008).

The immediate roof varies by location, but is typically about 50 feet of competent sandstone. The immediate floor is also competent rock typically consisting of hard shale or sandy shale. Long steep ridges characterize the local topography in the area with relief ranging from 1,800 to 2,000 feet. This means that even though mines typically access the coal seam from the outcrop, overburden depths from 1,000 to 1,500 feet can be reached very quickly.

Multiple seam mining is also practiced in the area and the ability to stack pillars is not typically possible. This situation occurs because different operators who do not wish to divulge proprietary information often conduct mining simultaneously, seams have different mineral owners who wish to maximize their own recovery, or old working may have random pillar layouts with remnant and/or irregularly shaped pillars. This means that the contributing mechanisms for coal bumps in the area can be: thick overburden, massive competent formations surrounding the coal seam, and stress concentrations multiple seam mining.

In the mine analyzed by Newman, full retreat mining was conducted with continuous haulage in 7,000 foot long panels. A five entry system was used with pillars spaced on 80 by 90 foot 
centers with an average mining height of 66 inches. Five different cut sequences were used at the mine in an attempt to overcome reaching limitations of the continuous haulage system and to alleviate the bumps that were occurring. Over the course of one year, eight bumps occurred (see Table 5.1)

\begin{tabular}{|c|c|c|c|c|c|c|c|}
\hline \multicolumn{7}{|c|}{ Mine No. 1 - History of Bump Events } \\
\hline Event & Date & Section & Cross-cut & Entry & Cover & Plan & Lift \\
\hline 1 & $4 / 9 / 2002$ & 5 -Lt. & $57-58$ & 4 & $1,800^{\prime}$ & Close in \#3 & $?$ \\
\hline 2 & $5 / 4 / 2002$ & $4-$-Lt. & $66-67$ & 3 & $1,850^{\prime}$ & Close in \#3 & $?$ \\
\hline 3 & $10 / 8 / 2002$ & $3-$-Lt. & $81-82$ & 3 & $1,950^{\prime}+$ & Close in \#3 & 9 A \\
\hline 4 & $1 / 7 / 2003$ & $2-$-Lt. & $79-80$ & 3 & $1,950^{\prime}+$ & Close in \#3 & 36 \\
\hline 5 & $2 / 21 / 2003$ & 1-Lt. & $74-75$ & 4 & $2,000^{\prime}$ & Close in \#5 & 28 \\
\hline 6 & $3 / 5 / 2003$ & 1-Lt. & $58-59$ & 4 & $1,400^{\prime}+$ & Close in \#4 & 36 \\
\hline 7 & $4 / 8 / 2003$ & $2-L t . ~$ & $11-12$ & 2 & $1,750^{\prime}+$ & Close in \#2 & 36 \\
\hline 8 & $4 / 10 / 2003$ & 1-Lt. & $45-46$ & 3 & $1,950^{\prime}$ & Key Cut & $?$ \\
\hline
\end{tabular}

Table 5.1: Timing, Location, and Circumstances of Coal Bumps (after Newman, 2008).

Initially, pillars were retreated with a "Close In 3" $(\mathrm{CI} 3)$ recovery plan (see Figure 5.1). With this plan, pillars are recovered from the outside toward the belt entry. This presents a problem where the last cuts, the half pillars on either side of the belt entry, are highly stressed and resulted in four of the eight bump occurrences. To avoid concentrating stress in these cuts, the plan was modified and changed to a "Close In 5" (CI5) plan (or mirror-image close in 1) (see Figure 5.2). In this sequence, the pillars are retreated in sequence from left to right. In the CI5 plan, bumps occurred when taking the first cuts into the last full pillar (step 28). This eliminated the highly stressed cuts from the middle of the previous plan, but limited access for the haulage system to the last cuts. In this case, a shuttle car was required. After trying the CI5 plan, a "Close In 4" (CI4) plan (or mirror-image close in 2) was adopted (see Figure 5.3). In this sequence, the fifth entry is originally retreated then the entries from 1 to 4 are mined, finishing 
with the last 2 half pillars around entry 4 . In the CI4 sequence, the bumps occurred when cutting these last two half pillars (step 36). This would allow the haulage system to reach all cuts, but again brought the stress associated with mining from both sides of the panel.

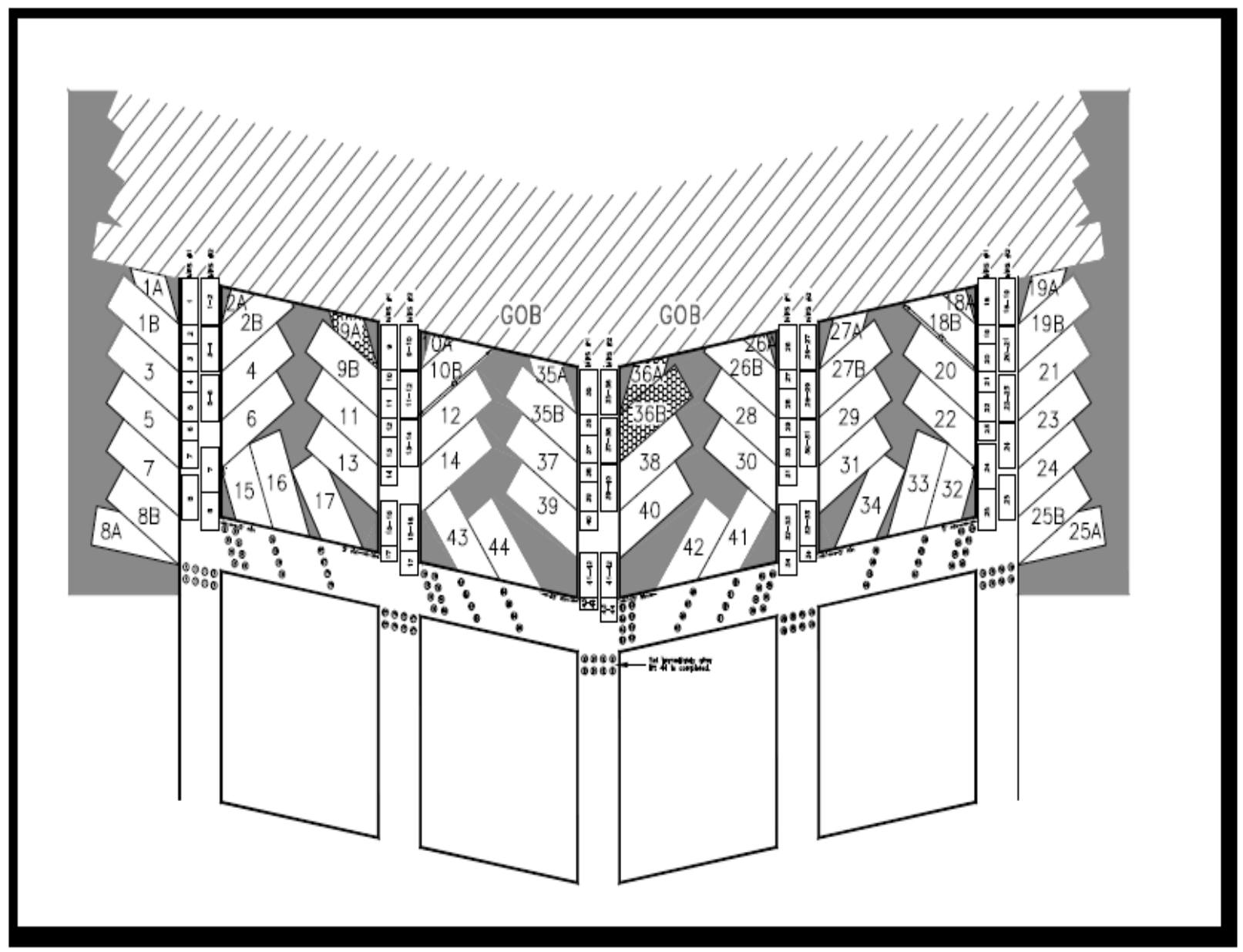

Figure 5.1: Close In 3 (Middle) retreat plan (hatching indicates bump location) (after Newman, 2008). 


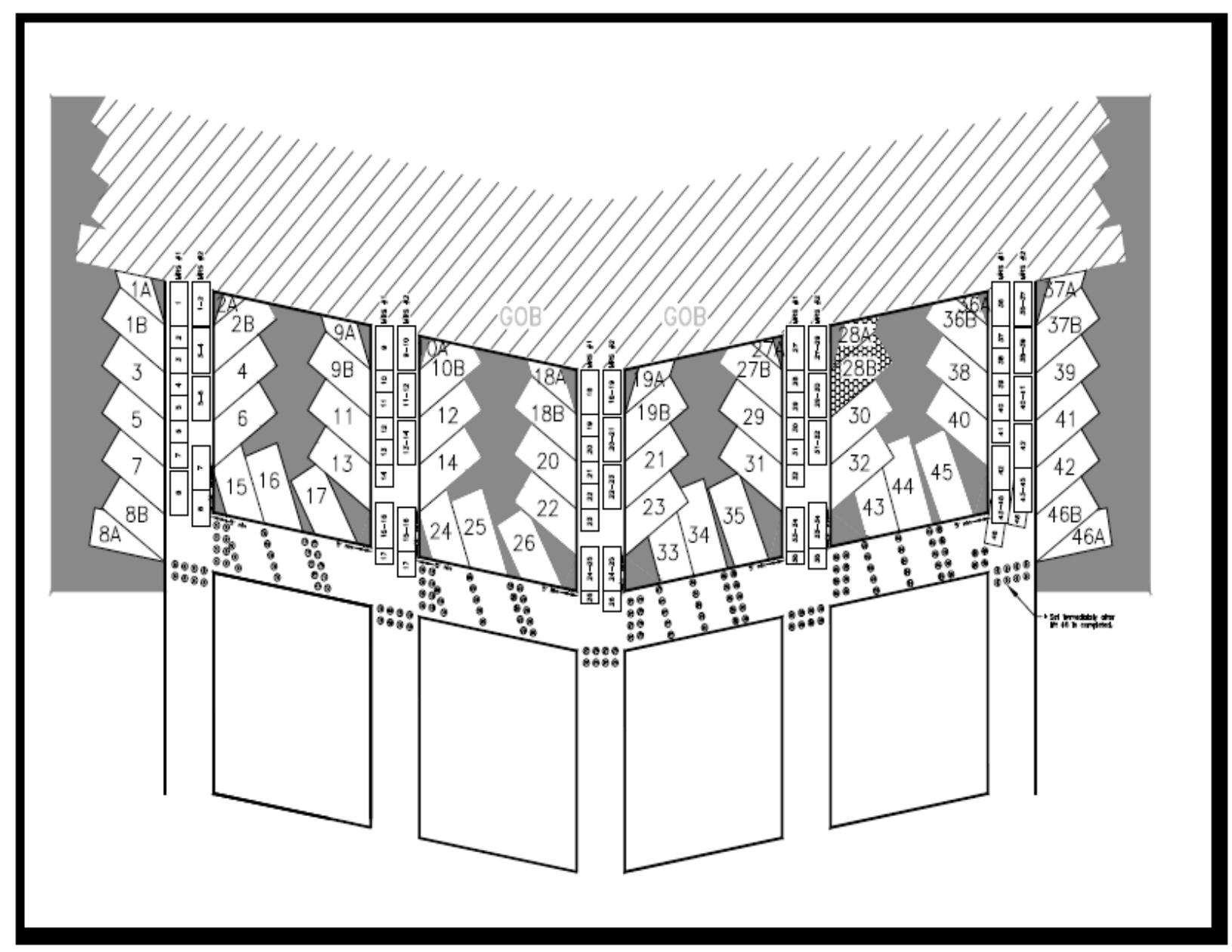

Figure 5.2: Close In 5 retreat plan (hatching indicates bump location) (after Newman, 2008). 


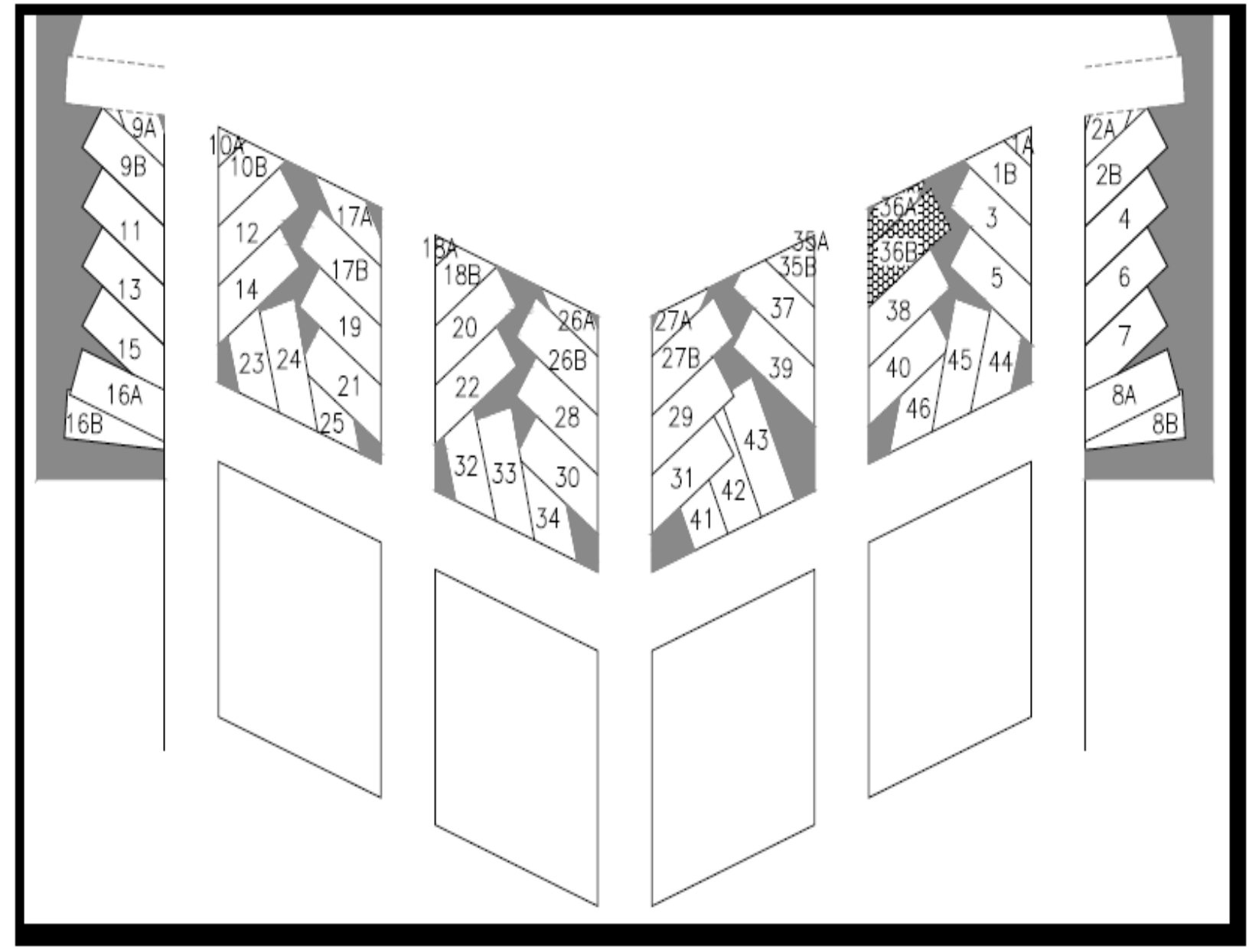

Figure 5.3: Close In 4 (mirror of close in 2) retreat plan (hatching indicates bump location) (after Newman, 2008).

At this point, Newman decided that the LaModel program should be used to numerically model previous and new retreat mining plans. These plans were modeled on a cut-by-cut basis to determine which cuts were highly stressed. The models were calibrated with information gathered from the field. The models incorporated physical data taken from 389 samples where testing had been conducted since 1986. These physical samples, cut sequence geometry, and thick overburden were inputs into the model. Other inputs were determined from field conditions. A large lamination thickness was used to simulate the stiff massive layers of overburden along with a hanging gob scenario, which simulated the cantilevering of the main roof over the gob. 
The use of "bump cuts," or cuts made into the center of the pillar in the outby crosscut as a method of destressing the pillars prior to extraction was also modeled. The Close in 4 with bump cuts (CI4 BC) sequence is nearly the same as the CI4 with the exception that bump cuts are taken in the outby pillar row during the mining sequence (cuts 19-22) (see Figure 5.4). The Close in 5 with bump cuts (CI5 BC) sequence is also the same as the CI5 except the bump cuts are taken in the active pillar row prior (cuts 1-4) prior to mining each entry from left to right (see Figure 5.5). A single bump event was recorded during the mining of a bump cut under 1950 feet of cover.

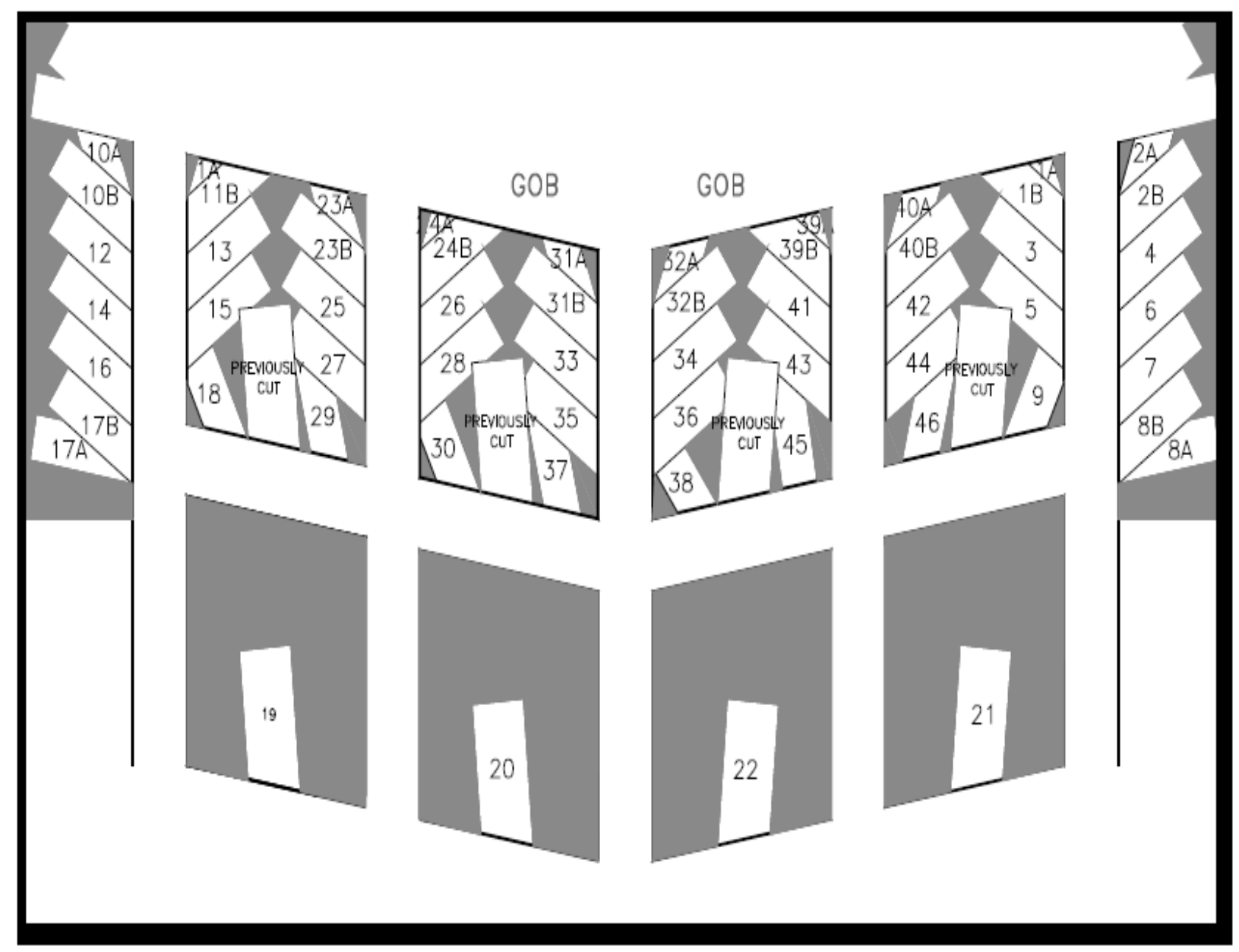

Figure 5.4: Close In 4 retreat plan with bump cut taken prior to retreat mining (after Newman, 2008). 


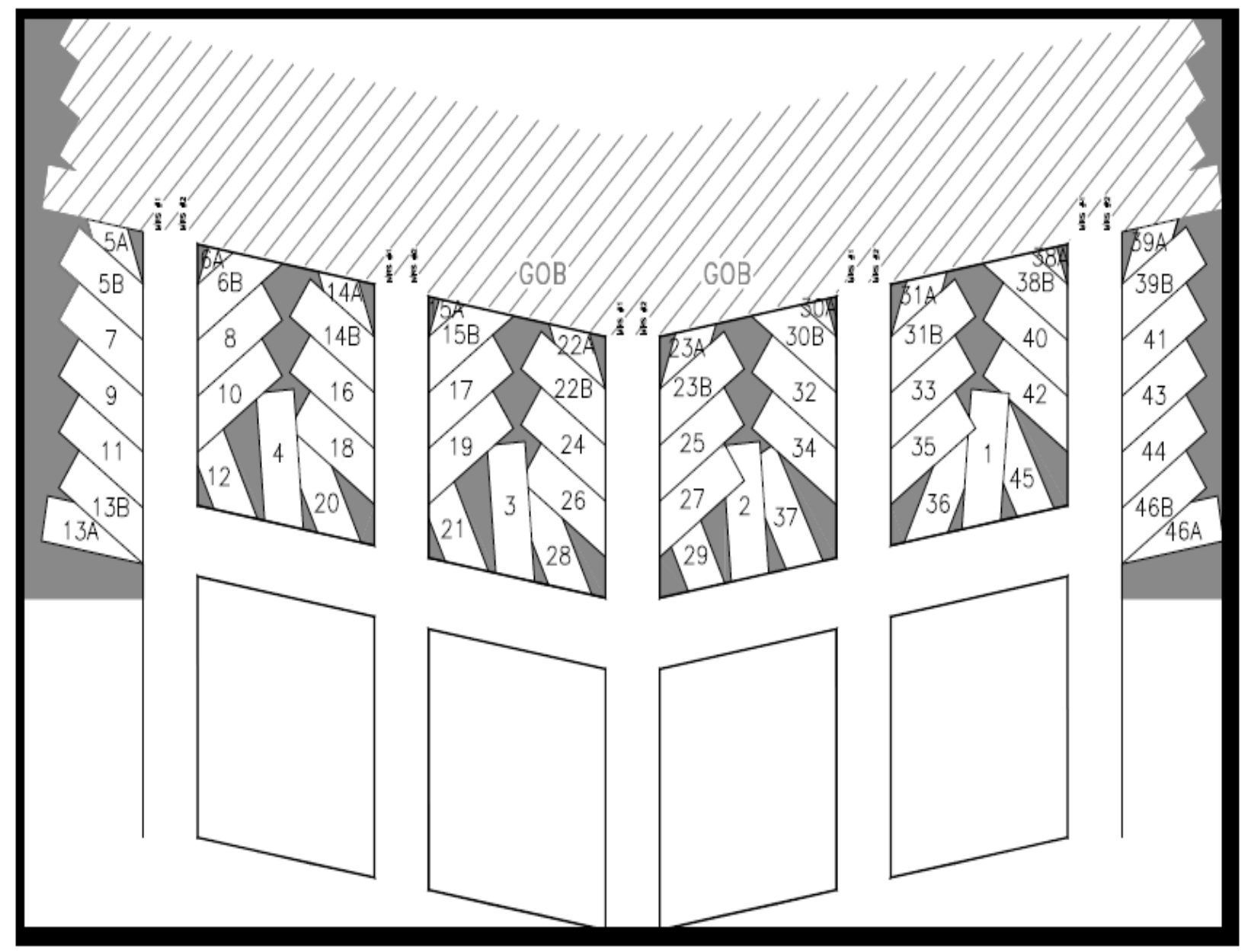

Figure 5.5: Close In 5 retreat plan with bump cut taken prior to retreat mining (after Newman, 2008).

Modeling using LaModel was done on the CI3, CI5 and the CI4 with and without the bump cuts. In addition, two methods of taking the bump cuts were modeled including taking the bump cuts in either the outby pillar row or the active pillar row prior to other retreat mining. All of these scenarios were evaluated under high average (1,784 feet) and high (2,000 feet) overburden and for both hanging and non-hanging gob models.

Results from the numerical modeling concluded that the CI3 and CI4 plans do concentrate front and side abutment pressures on the remaining pillars near the center of the panel. This results in more and larger highly stressed cuts being observed and is confirmed by the bump 
history at the mine (see Table 5.1). The results also showed that the CI5 plan was optimal from a bump control perspective, but required the shuttle car to be used.

The numerical modeling also showed that bump cuts are only effective when they are made prior to retreat mining. If the bump cuts are taken in cycle during the course of retreat mining, they do not dissipate the stress and actually, the models indicate that the bump cut is adjacent to a highly stressed area and is likely to induce a bump itself. With bump cuts made prior to retreat, both the CI5 and CI4 alternative seem to be effective in the models, but prove to be difficult to implement underground and require tramming the miner and bridge system across the section to make the cuts prior to mining. The company attempted this method and determined that it was not productive and therefore un-economical.

At this mine, the company ultimately decided to stop retreat mining in areas with overburden thicker than 1,700 feet and where the sandstone thickness was more than 50 feet. Larger barrier pillars between adjacent panels were also used to reduce side abutment pressures from the adjacent panels.

\subsection{Practical Application}

The process of applying the energy calculations in the LaModel 3.0 program requires the successful use of the LamPre 3.0 and LamPlt 3.0 programs. With respect to energy calculations, these programs remain quite similar to their LaModel 2.1 predecessors. However, a number of additional for options are available to the user.

\subsubsection{Application of LamPre 3.0}

The Program Control Parameters form of the LamPre program contains both the control and solution options for the model. The control options portion of the form in LamPre 3.0 remains unchanged from the previous LamPre 2.1 however, the solution options portion contains an additional check box (see Figure 5.6). In this form, checking the "Include Energy Calculations" check box directs the LaModel 3.0 program to perform the energy calculations as detailed in Chapter 3. 


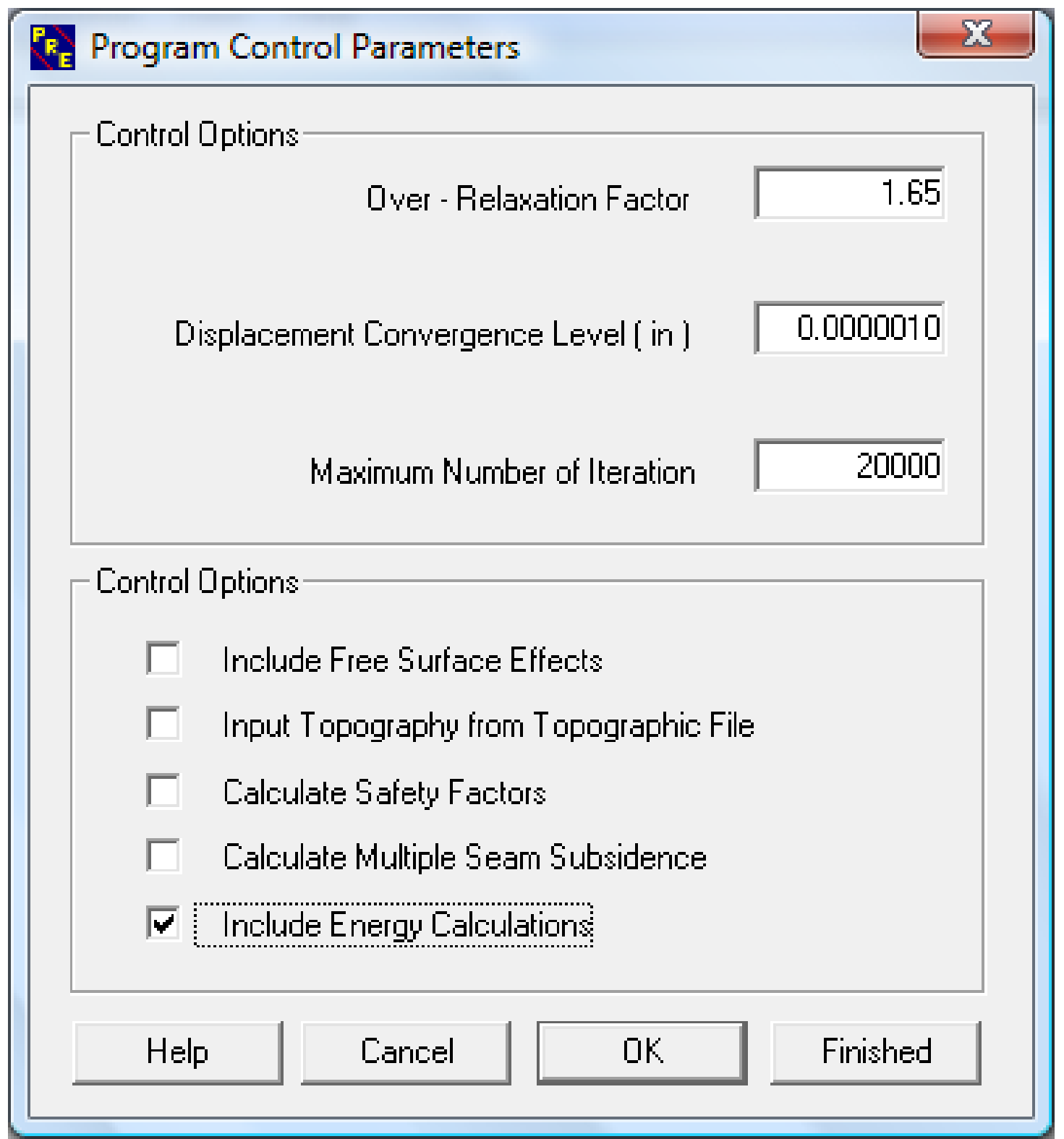

Figure 5.6: The Program Control Parameters form in LamPre 3.0.

\subsubsection{Application of LamPlt 3.0}

After the input file is run in LaModel 3.0 (its user interface unchanged from the previous LaModel 2.1) the LamPlt 3.0 program is required to process the output file that it created. The only change in the LamPlt program consists of an expanded list of available stress items (from a total of 12 to a total of 18) in all the available plots (colored square, cross section, history, and 
fishnet ). As an example, a colored square plot with the Dissipated Energy stress item selected is shown in Figure 5.7.

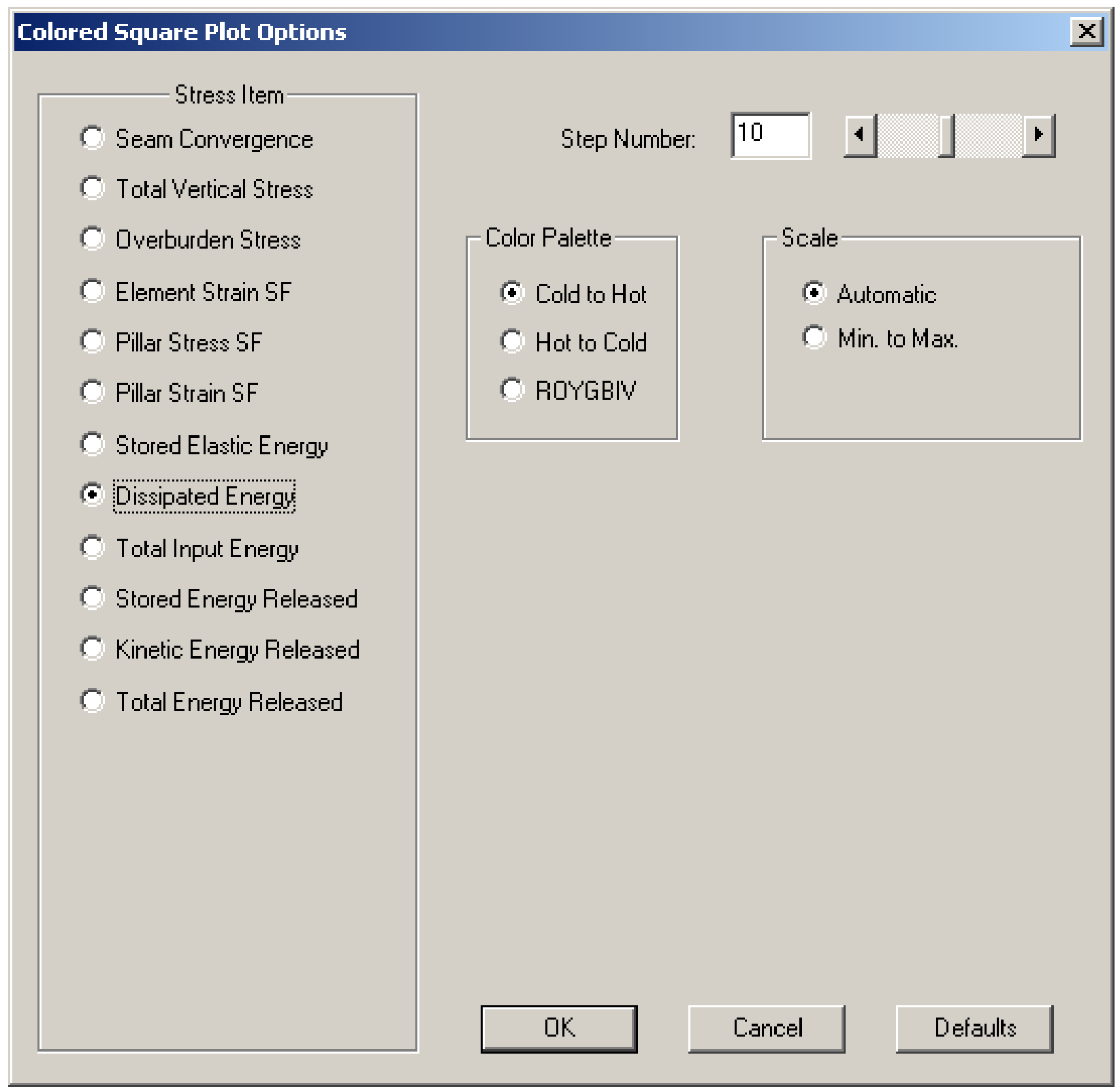

Figure 5.7: LamPlt 3.0 Colored Square Plot Options. 


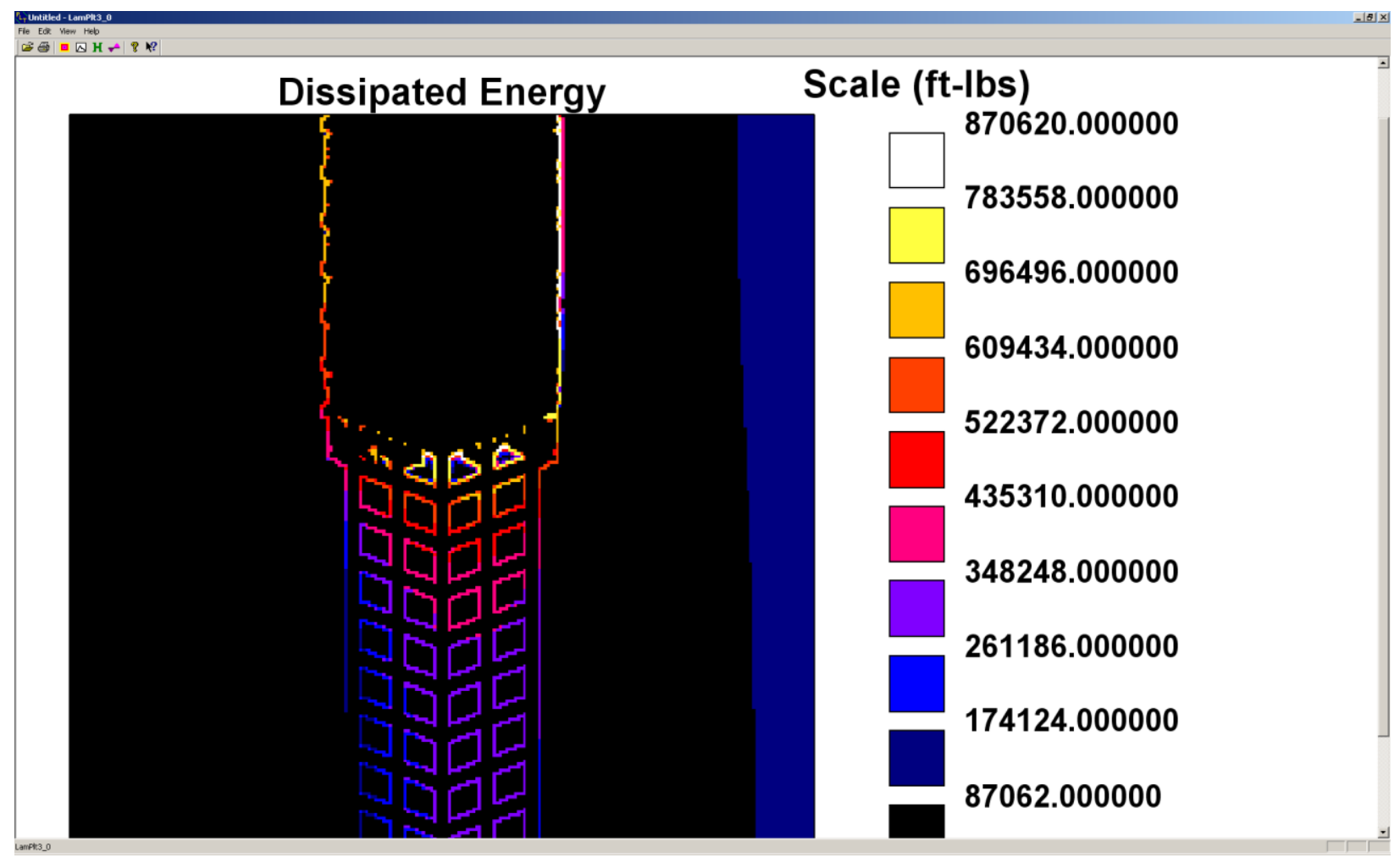

Figure 5.8: LamPlt 3.0 Dissipated Energy colored square plot.

While a colored square plot works well for globally visualizing the energy quantities calculated in LaModel, it is not the best choice for accurately analyzing or comparing models. In the application of LaModel 3.0 to the case study by Newman (2008), the history plot was used extensively. Figure 5.9 shows the History Plot dialog box with the Total Energy Released stress option selected. The same coordinate range used in the case study application is shown, with the total stress value selected. 


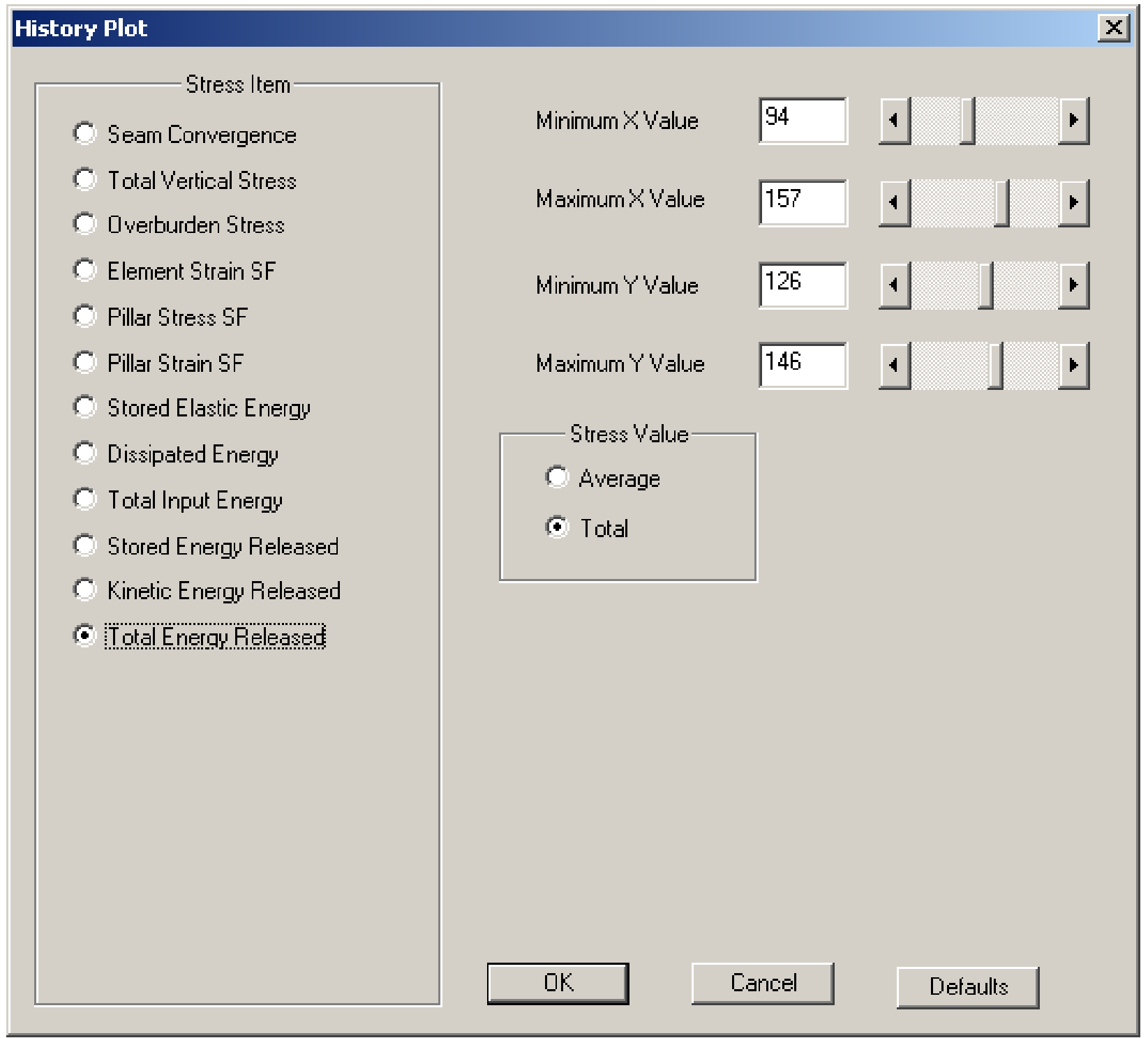

Figure 5.9: LamPlt 3.0 History Plot Options.

By selecting this stress item, a history plot of the Total Energy Release is displayed (see Figure 5.10). The history plot, which allows a comparison of the stress items between steps, provides the tool for the detailed analysis used in the case study. 


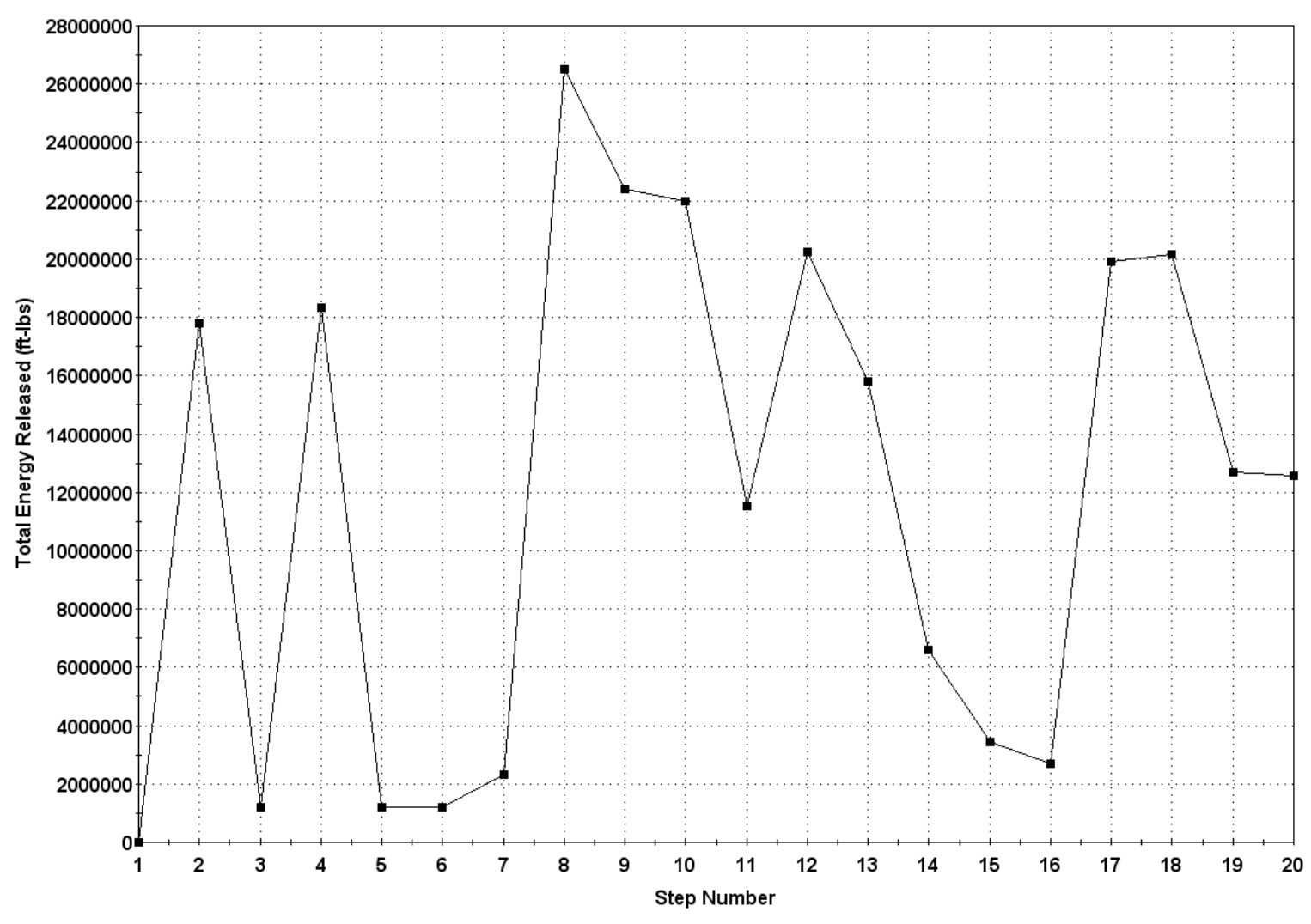

Figure 5.10: $\quad$ LamPlt 3.0 Total Energy Released History Plot.

For further analysis purposes, these plots can be saved as ASCII files. Once saved, it can be opened in Microsoft Excel to create the charts seen in the analysis in section 5.3. The practical application detailed above is appropriate for any comparison between steps such as various cut sequences.

\subsection{Application of the LaModel ERR Calculations to the Case Study}

\subsubsection{Cut Sequences Modeled}

To utilize the new ERR calculations in LaModel 3.0 in a practical situation (in a similar analysis to the case of Zipf and Heasley, 1990); they are applied to the Darby Seam mine originally analyzed by Newman, 2008. In Newman's original stress analysis, five variations of the "Christmas Tree" pillar retreat method were analyzed to determine the location of the highly 
stressed cuts, which would be more likely to cause a bump during extraction. Essentially, the vertical stresses in each cut were quantitatively compared looking for the highest pre-extraction stresses. Those cuts with the highest stresses where assumed the most bump prone.

\subsubsection{Calibration of the Model}

Before the cut sequences could be analyzed with the energy calculations, the critical input parameters to the LaModel program needed to be calibrated. The lamination thickness was calibrated so that $90 \%$ of the abutment load was distributed within the extent of the gob load (D), where the depth (h) was $2000 \mathrm{ft}$ (Heasley, 2008).

$$
\mathrm{D}=5 \sqrt{\mathrm{h}}
$$

This resulted in a lamination thickness of 1200 feet. Then, the final gob modulus was calibrated so that the average gob stress would be about 293 psi, as specified by assuming a $21^{\circ}$ abutment angle (Heasley, 2008). This resulted in a final gob modulus of 750,000 psi.

With the lamination thickness and final gob modulus determined, the third and final critical parameter to calibrate was the coal strength. For this analysis, in order to calculate the energy values most accurately, it was determined that strain-softening coal properties should be used (see Figure 3.1). These strain-softening coal properties were developed following the techniques proposed by Karabin and Evanto (2001). For determining the peak coal strength, the MarkBieniawski stress gradient was used:

$$
\sigma_{\mathrm{e}-\mathrm{s}}=\mathrm{S}_{\mathrm{I}}\left(0.64+2.16\left(\frac{\mathrm{x}}{\mathrm{h}}\right)\right)
$$

Where:

$$
\begin{aligned}
& \sigma_{\mathrm{e}-\mathrm{s}}=\text { peak stress of the element } \\
& \mathrm{S}_{\mathrm{I}}=\text { in situ coal strength } \\
& \mathrm{x} \quad=\text { distance from the element center to the free face } \\
& \mathrm{h} \quad=\text { seam height }
\end{aligned}
$$


For determining the residual coal strength $\left(S_{R}\right)$ and residual coal strain $\left(\varepsilon_{r}\right)$, the equations developed by Karabin and Evanto (2001) were used:

$$
\mathrm{S}_{\mathrm{R}}=\sigma_{e-s}[0.2254 \times \ln (x)]
$$

and

$$
\varepsilon_{\mathrm{r}}=4 \times \varepsilon_{\mathrm{p}}
$$

Where:

$\varepsilon_{\mathrm{r}}=$ the residual strain of the element

$\varepsilon_{\mathrm{p}}=$ the peak strain of the element

With the previous three equations, once the insitu coal strength and modulus are known, the complete behavior of the coal pillars can be determined. To calibrate the optimum insitu coal strength, a model of the Close In 3 cut sequence was developed. In this model, the coal strength was then adjusted to match the calculated total energy release values with the observed conditions underground, where the final cuts in the belt entry (cuts 35-42) were noted to be the most highly stressed, or bump prone (Newman, 2008). The Total Energy Release was calculated using the history plot in LaModel over the pillars in the active pillar line $(\mathrm{x}=94-157$ and $\mathrm{y}=$ 126-146). After the Total Energy Release was calculated, it was normalized per element removed in a given step. In this case, each step was one cut. Initially, a strain-softening coal strength of 1550 psi was used (see Figure 5.11). This resulted in the highest energy releases during mining occurring in the second-to-last entry/last full pillar (cuts 26-31), in particular cut 28 (see Figure 5.11). As the coal strength was increased, the energy release gradually shifted away from the second-to last entry and into the last entry as observed in the field. Ultimately, a strain-softening coal strength of 1700 psi appeared to provide the best match to the observed field conditions.

With the 1700 psi coal strength, the two largest energy releases are cuts 39 and 41, and cut 36 (which was noted as being bump-prone in the field) is the seventh largest energy release. In this calibration model, the highest energy releases were consistently associated with mining the second-to-last and last entries. This seems reasonable since retreat in the second-to-last entry 
removes the last complete highly stressed pillar and retreat in the last entry removes the final highly stressed half-pillars. However, in the field, most of the bump activity was associated with mining the last entry and only one bump out of eight was observed while mining the second-tolast entry. Within the constraints of the previously determined input parameters (the lamination thickness, and gob modulus), varying the coal strength alone was not able to shift the majority of the energy release to the retreat of the last entry or to make cut 36 (were a number of bump events were know to occur) the maximum energy release. In the future, a number of the other input parameters beside coal strength should be investigated to better optimize the calculated energy values.

In this calibration analysis, only the normalized total energy released over the active pillar row was considered. In a more general form, the following results depict the energy as a total release and its components (kinetic release and stored release). In addition to better understanding of the input parameters, looking at the static energy quantities or changes in released energy should also be investigated to facilitate a better understanding of bump potential.

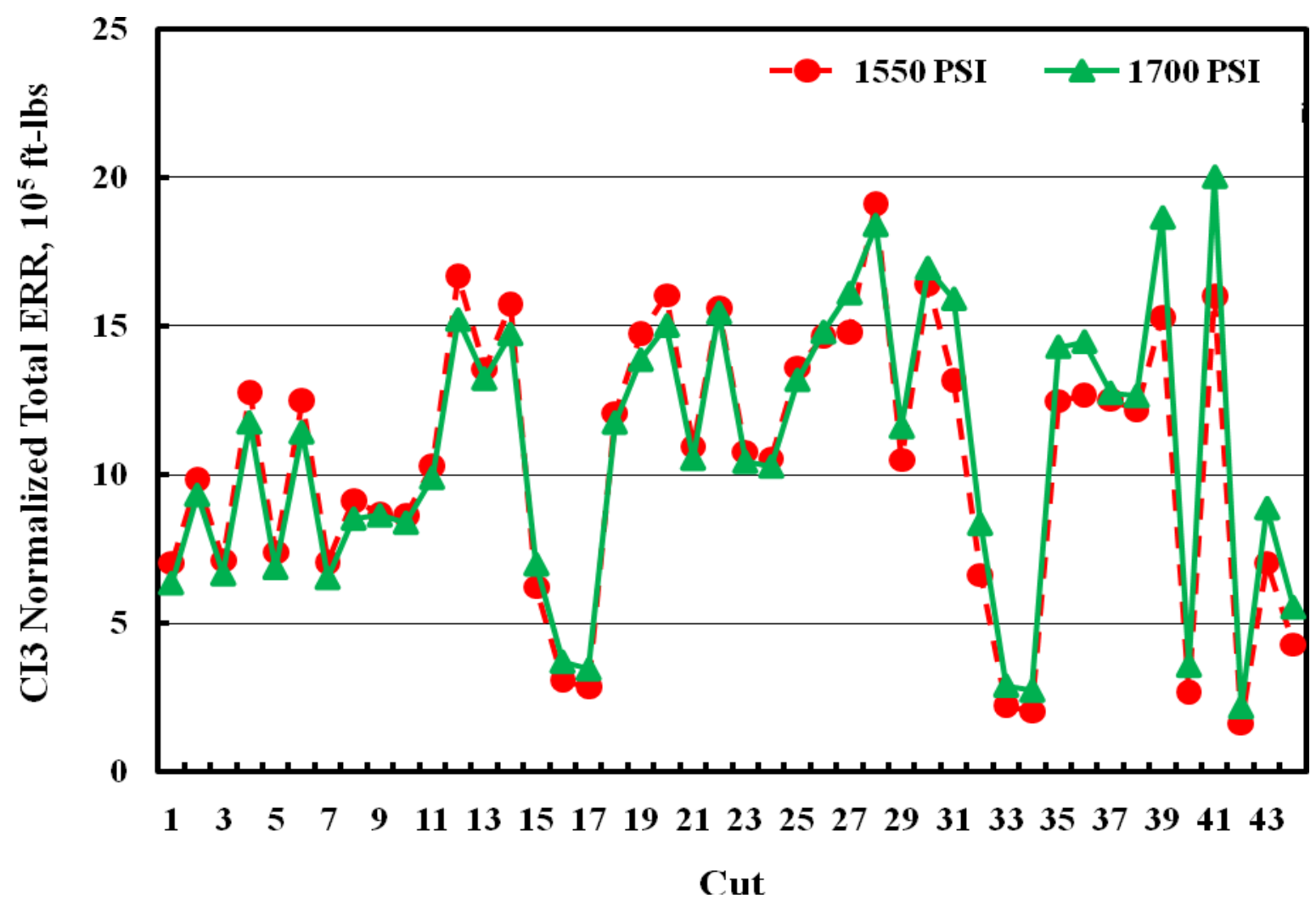

Figure 5.11: Energy release as a function of coal strength. 


\section{$\underline{\text { 5.3.3 Results }}$}

After the coal strength was calibrated using the Close In 3 (CI3) cut sequence, the calibrated properties were applied to models for: the Close in 3, Close In 4, Close In 5, Close In 4 with Bump Cuts and Close In 5 with Bump Cuts retreat sequences. The calculated energy results for the CI3 cut sequence is shown in Figure 5.12. In these models, the kinetic, stored, dissipated, and total energy released all are charted from the same area of the model as the calibration case. In general, it can be seen that the majority of the energy release comes from the stored energy and that all of the components of the total energy release follow the same general trends between steps.

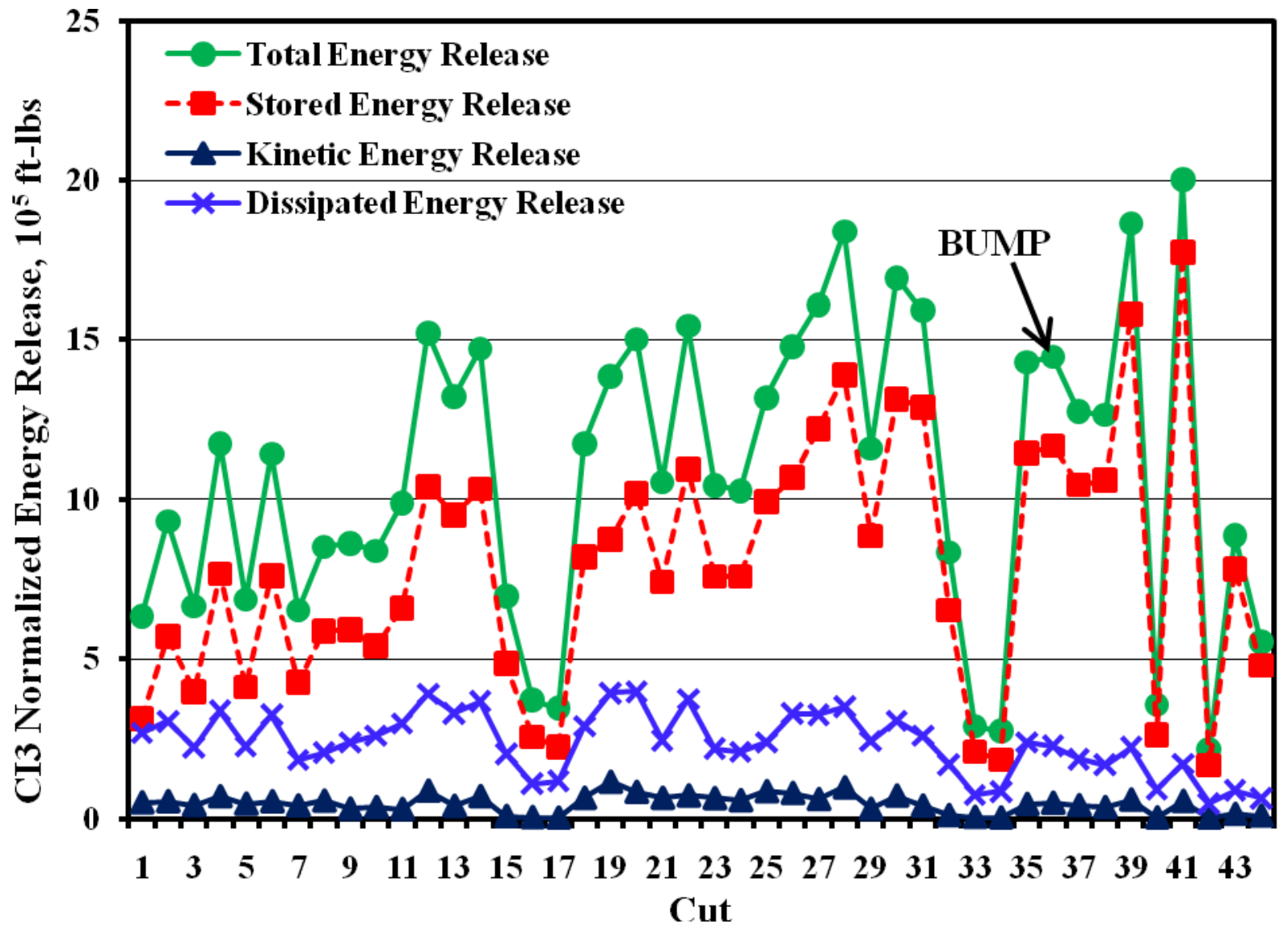

Figure 5.12: Close in $3(\mathrm{CI} 3)$ normalized energy release versus cut

For the $\mathrm{CI} 3$ cut sequence, the majority of bumps in the field occurred in the \#36 cut, being the first cut into the last half pillar (the \#3 entry). In addition, the majority of bumps occurred using this cut sequence (see Table 5.1). Not only does this cut sequence tend to concentrate 
stress due to mining toward the center of the panel, it was also used for a longer period of time than any of the other cut sequences. The calculated energy results for the CI4 cut sequence is shown in Figure 5.13.

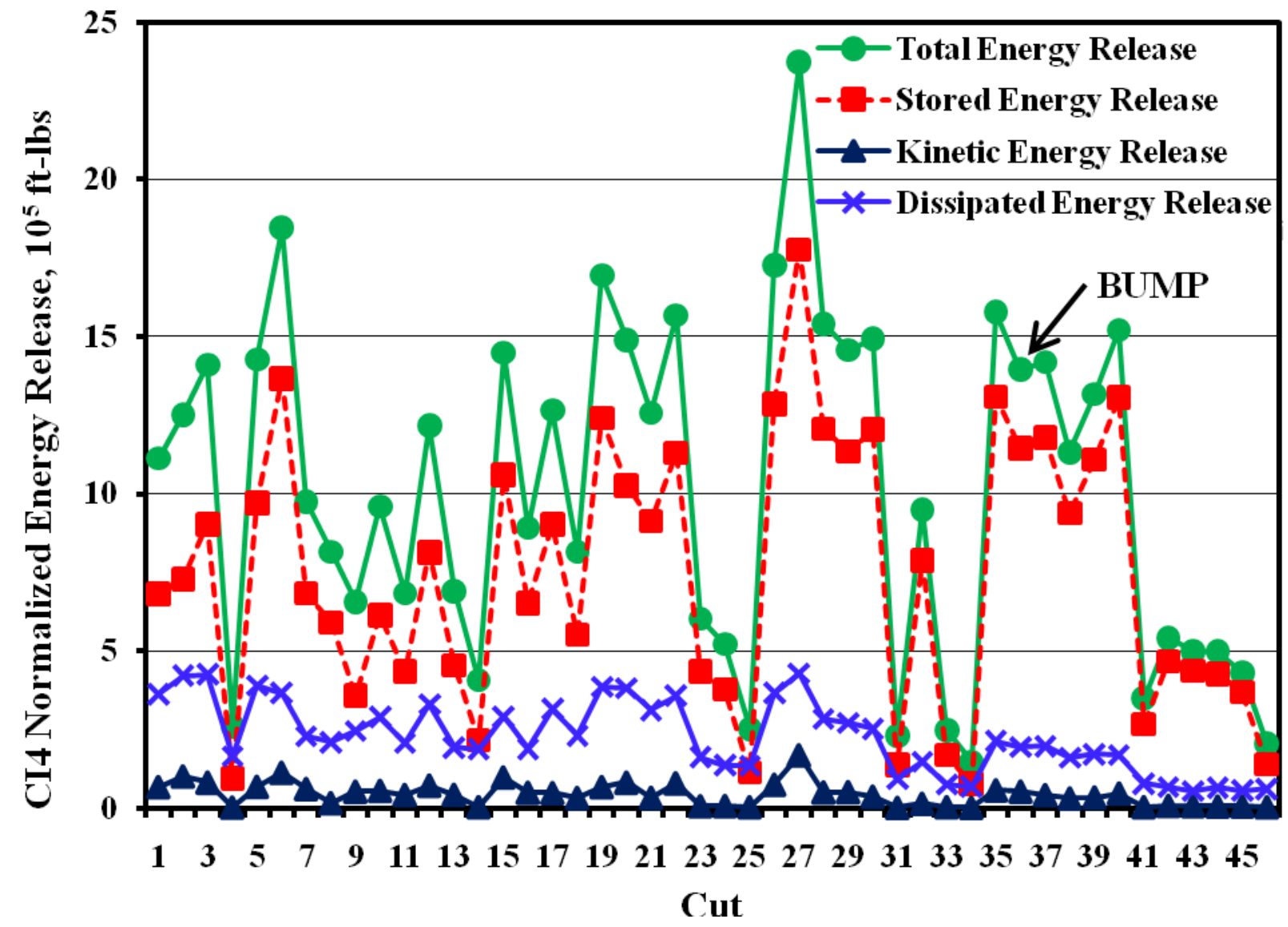

Figure 5.13: Close in 4 (CI4) normalized energy release versus cut.

For the CI4 cut sequence, two bumps occurred in the field while mining cut 36 (Newman, 2008). In the LaModel energy calculations for CI4, mining the second-to-last (middle) entry (cuts 26-31) shows the highest energy releases (consistent with the analysis of CI3); however, cut 36 does show high energy release. The peak at cut 27 (the first cut into the last full pillar) was theoretically expected (cutting into a highly stressed pillar) and consistent with the CI3 sequence even though a bump was not recorded at this location. Figure 5.14 shows the calculated energy results for the CI5 cut sequence. 


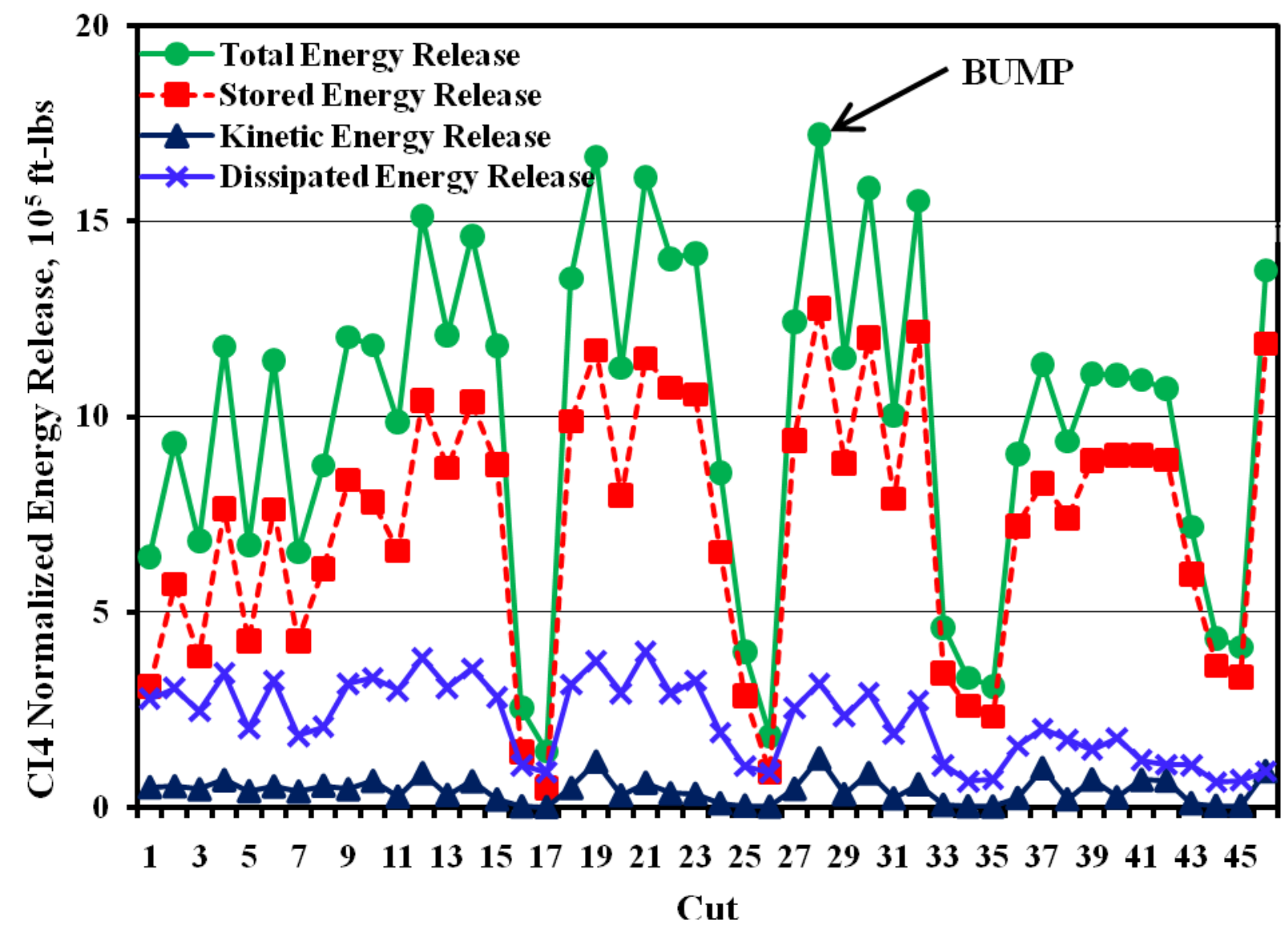

Figure 5.14: Close in 5 (CI5) normalized energy release versus cut.

For the CI5 cut sequence, the LaModel energy calculations show the highest energy releases in the middle and second-to-last entry (the \#4 entry). In the model, the highest energy release occurs at cut 28 , and this exactly agrees with the field observations were the one recorded bump for the CI5 sequence occurred during cut 28 . It should also be considered that the CI5 sequence shows less variability over space and time than the $\mathrm{CI} 3$ or CI4 sequence.

As shown in the previous figures, bumps tended to occur in the \#36 cut. In these models, it can be seen that the highest energy releases are associated with mining in the middle and last side entries, and fairly equal in three sequences (see Figures 5.12, 5.13, and 5.14). As was seen in the LaModel analysis, there is not a decisive difference (within 10\%) in energy release (or bump potential) between these first three models, and all of them were subject to coal bumps in the field. 
The last cut sequences to be analyzed are the Close In 4 with Bump Cuts (CI4 BC) and the Close In 5 with Bump Cuts (CI5 BC) retreat sequences. The calculated energy results for the CI4 BC cut sequence is shown in Figure 5.15.

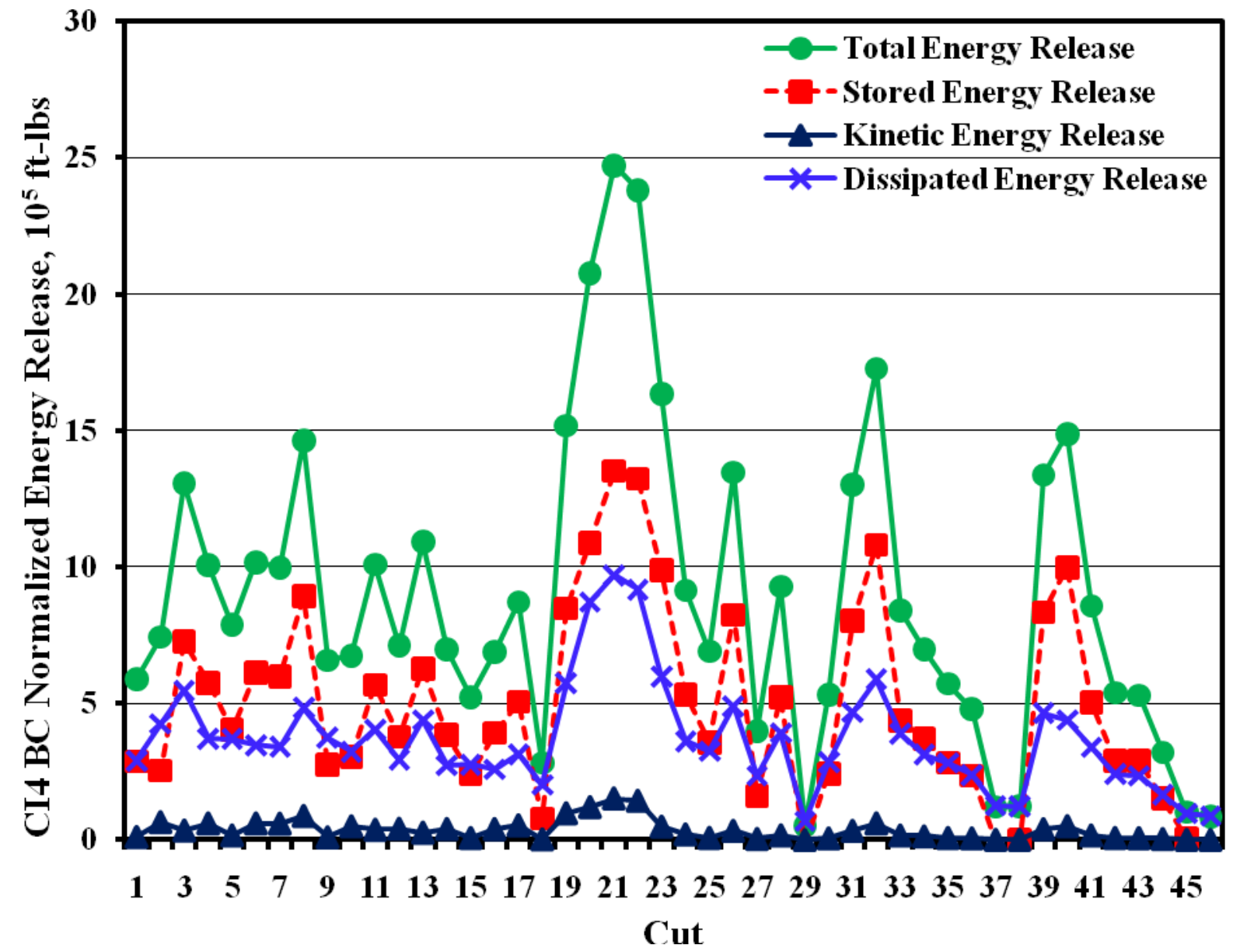

Figure 5.15: Close in 4 Bump Cut (CI4 BC) normalized energy release versus cut.

In this model, it can be clearly seen that the highest energy releases are associated with mining the bump cuts (cuts 19-21). . In addition, the CI4 cut sequence created an additional hurdle in the form of mining two rows of pillars. The energy values for the CI4 are calculated the same as above except two rows are totaled $(y=111-146)$ then discounted $11.3 \%$ to account for the extra energy involved with the second row. Figure 5.16 shows the calculated energy results for the CI5 BC cut sequence. 


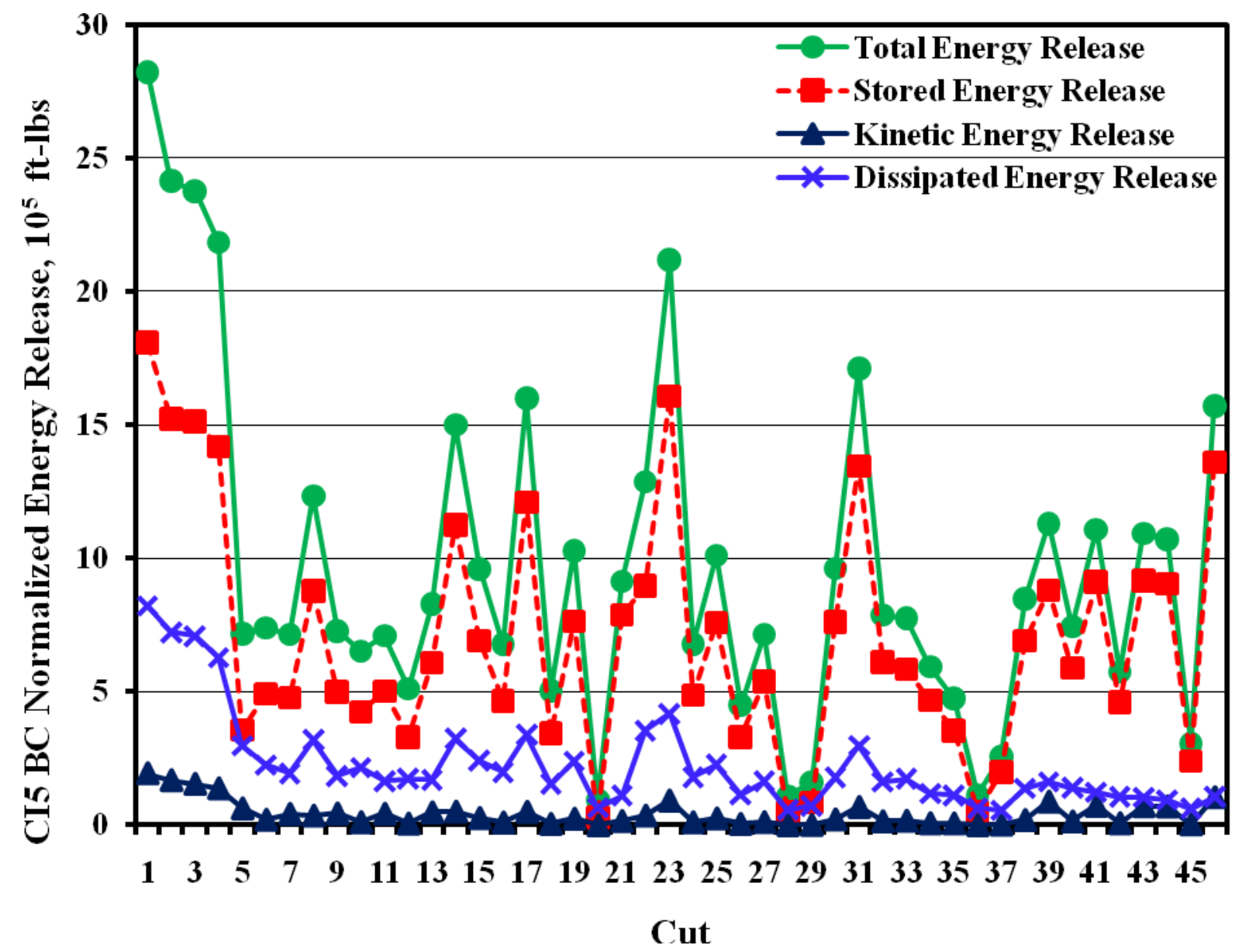

Figure 5.16: Close in 5 Bump Cut (CI5 BC) normalized energy release versus cut.

It can be seen that the CI5 BC cut sequence is quite similar to that of the CI4BC. The major difference being the high energy bump cuts are cuts 1-4 in this case. The energy releases associated with the bump cuts are 20-40\% higher than any of the energy releases from the previous models. While this high energy release indicates the bump cuts may be bump prone (and certainly, bumps have occurred during bump cuts at other locations), a couple of ancillary factors suggest that the bump cut is still a good technique for safely dissipating energy. First, each of these bump cuts is taken in a different pillar, therefore the cumulative energy release is spread over a larger area and a larger amount of time, as compared to pulling a pillar with consecutive cuts with the Christmas tree method. Second, the bump cuts are taken in the outby side of fairly stable/stiff pillars, which may further help eliminate potential bumps during that cut (a function of mine stiffness).. 
After the bump cuts, the remaining cuts in the sequences generally show a reduced energy release. In the $\mathrm{CI} 4 \mathrm{BC}$ sequence, the subsequent peak energy release while extracting the pillars has been reduced $28 \%$ as compared to the CI4 without bump cuts. In the CI5 BC sequence, the majority of the energy release values have decreased or stayed the same, except for one fairly high energy release at cut 23 . This resulted in a $16 \%$ reduction as compared to the CI5 without bump cute. Based on this energy analysis, the cut sequences with bump cuts may potentially be a good technique to reduce the face bumps. However, the inefficient (therefore unproductive and uneconomic) nature of taking the bump cuts precluded the mine from adopting these cut sequences (Newman, 2008). 


\section{Chapter 6}

\section{Summary and Conclusions}

The research presented in this thesis has detailed the development, verification, and practical application of the new energy calculations in LaModel 3.0. These new energy calculations, originally derived by Salamon (1984) and Zipf and Heasley (1990), proved to add a significant new feature to the LaModel program. For verification of the calculations, prior research using the energy calculations in MULSIM/NL to analyze four retreat mining cut sequences was duplicated with LaModel 3.0 with very similar results. Finally, the new energy calculations were applied to a practical case history for analyzing the bump potential of different cut sequences.

The practical application of the ERR calculations for analyzing the cut sequences highlighted several key points. First, an adequate calibration of the critical input parameters is required in order to begin to produce reasonably accurate results. Second, the analysis showed that, at this point in the application of the energy release calculations, it is difficult to adequately calibrate the model to match field results on a cut-by-cut basis. Certainly, other parameters may need to be more accurately, or better, calibrated such as roof stiffness, gob loading, coal residual stress or coal residual strain. Also, other factors may need to be considered in conjunction with energy calculations for analyzing bump potential such as local mine stiffness and/or post-failure pillar stiffness. However, the energy calculations did provide a reasonably good quantifiable measure of the cuts and the areas that were generally more prone to bumps versus cuts and areas that were not prone to bumps. In addition, the analysis clearly indicated the ability of the bump cuts to relocate and adjust the timing of the energy release. Misused, this ability to move the energy release around in time and space could make the situation worse, however, with proper design, the bump cuts have the potential to help reduce the hazards associated with bumps.

The analysis of coal bump potential with energy calculations is still very much in its infancy. Hopefully, by incorporating these calculations into the new LaModel 3.0 program, researchers will have another tool for improving mine design in bump prone areas. Moreover, through additional application of energy analysis to various bump situations, the experience can be gained to provide better parameter calibration and protocols that will result in more accurate energy analysis and safer retreat mining. 


\section{Chapter 7}

\section{Suggestions for Future Research}

The previously detailed ERR research is shown to be yet another tool for researchers and engineers when designing mines in bump prone conditions. As with most research, additional questions were raised during the project which suggest topics for additional research.

Throughout this research work, questions regarding the time dependencies of the ERR, the post failure pillar behavior, the gob loading and its associated final modulus, and local mine stiffness were raised.

As discussed previously, the uniformity of the ERR should be considered in conjunction with its magnitude. Although it was noted that certain cut sequences were more uniform than others were, no special consideration was given to time or space. Although it is difficult in a coal mining situation to put a given time interval on each cut (unlike spacing), it could be possible to group series of cuts in a given entry (cuts taken in rapid succession) and separate them from other entries (cuts requiring moving the miner). An analysis similar to this could allow for the effect of space and time to be considered, providing a more thorough analysis.

Certainly, to better understand pillar failure and coal bump behavior, the post-failure behavior of coal pillars needs to be better understood. There has been some lab work in this area, but almost no field data from post-failure pillars. All of the parameters describing the posfailure behavior of pillars need to be investigated. What is the post-failure softening modulus? What is the post-failure residual strength? How does the width-to-height ratio affect these values? A great deal of very useful research could be done to investigate the post-failure behavior of coal pillars.

Another critical and poorly understood factor in the ERR models described above is the amount of overburden loading that that occurs in the gob. There have been many field stress measurements that try to determine the abutment and gob loading when coal is fully extracted. The abutment angle concept seems to work fairly well for an "average" gob loading, but in a deeper cover situation, the average abutment angle concept seems to break down (Heasley, 2008). Also, the gob loading is certainly affected by geology, seam thickness, panel width, panel depth, etc., but these relationships have never been adequately determined. 
In the past, the local mine stiffness (LMS) was found to correlate with bump incidents similar to the ERR. The Local Mine Stiffness calculation has been used with some success in the 80's and 90's. With LMS, the calculation looks at the relative stiffness of the support pillars in the post failure range and compares that to the loading stiffness of the surrounding rock mass. If the loading stiffness is softer than the support stiffness, then a dynamic failure can occur. Just as with the ERR, the same rock mass modulus paradox exists. That is, the LMS varies inversely with the rock mass modulus, meaning that a weaker overburden is more likely to cause a bump. Just as with the ERR, assuming a constant rock mass modulus would make comparisons between cut sequences (or other parameters) appropriate. By modifying mining geometries and pillar sizes, these dynamic LMS conditions can be eliminated. The previous Local Mine Stiffness calculations were also implemented in the MULSIM/NL program, and could presently be a more useful analytical tool if they were implemented into the more modern LaModel program. 


\section{References}

Cook, N. G. W., E. Hoek, J. P. G. Pretorious, W. D. Ortlepp, and M. D. G. Salamon, 1966, “Rock Mechanics Applied to the Study of Rock Bursts,” J. S. Afr. Inst. Min. and Metall., v. 66, p. 436-528.

Crouch, S. L. and C. Fairhurst, 1973, “The Mechanics of Coal Mine Bumps and the Interaction Between Coal Pillars, Mine Roof, and Floor,” BuMines OFR 53-73, 88 pp.

Heasley, K. A., 2008, "Some Thoughts on Calibrating LaModel," Proc. of the $27^{\text {th }}$ Int. Conf. on Ground Control in Mining, WVU, Morgantown, WV, July 29-31, p. 7-13.

Heasley, K. A., 1998, "Numerical Modeling of Coal Mines with a Laminated DisplacementDiscontinuity Code," Ph.D. Dissertation, Colorado School of Mines, 179 pp.

Heasley, K. A., 1991, "An Examination of Energy Calculations Applied to Coal Bump Prediction," Proc. 32nd U.S. Symp. on Rock Mech. p. 481-490.

Heasley, K. A. and J. C. Zelanko, 1992, "Pillar Design in Bump-Prone Ground Using Numerical Models with Energy Calculations,” BuMines IC 9315, p. 50-60.

Hodgson, K. and N. C. Joughin, 1966, “The Relationship Between Energy Release Rate, Damage, and Seismicity in Deep Mines,” Proc. 8th U.S. Symp. on Rock Mech., p. 194-203.

Iannacchione, A. T. and J. C. Zelanko, 1995, “Occurrence and Remediation of Coal Mine Bumps: A Historical Review," Proc. Mechanics and Mitigation of Violent Failure in Coal and Hard-Rock Mines, BuMines SP 01-95, p. 27-67.

Karabin G. J. and M. A. Evanto, 2001, "Experience with the Boundary-Element Method of Numerical Modeling to Resolve Complex Ground Control Problems," Proc. of the 2nd Int. Wrkshp on Coal Pillar Mechanics and Design, NIOSH IC 9448, p. 89-113.

Maleki, H., J. Aggson, F. Miller, and J. F. T. Agapito, 1987, “Mine Lay-out Design for Coal Bump Control," Proc. 6th Int. Conf. on Ground Control in Mining, WVU, Morgantown, WV, June 9-11, p. 32-46.

Maleki, H., P. F. Wopat, R. C. Repsher, and R. J. Tuchman, 1995, "Proc. Mechanics and Mitigation of Violent Failure in Coal and Hard-Rock Mines,” BuMines SP 01-95, 355 pp.

Newman, D., 2008, “Coal Mine Bumps: Case Histories of Analysis and Avoidance,” Proc. of the $27^{\text {th }}$ Int. Conf. on Ground Control in Mining, WVU, Morgantown, WV, July 29-31, p. 1-6. 
Salamon, M. G. D., 1984, "Energy Considerations in Rock Mechanics: Fundamental Results,” J. S. Afr. Inst. Min. Metall., v. 84, no. 8. p. 236-242.

Salamon, M. D. G., 1963, "Elastic Analysis of Displacement and Stresses Induced by Mining Seam or Reef Deposits (Part I),” J. S. Afr. Inst. Min. and Metall., v. 64, no. 4, p. 128-149. Zipf, R. K., 1992, “MULSIM/NL Theoretical and Programmers Manual,” BuMines IC 9321, 51 pp.

Zipf, R. K. and K. A. Heasley, 1990, "Decreasing Coal Bump Risk through Optimal Cut Sequencing with a Non-Linear Boundary Element Program," Proc. of the 31st U.S. Symp. On Rock Mech., Golden, CO, June 18-20, p. 947-954. 


\section{Appendix A \\ Derivation of the Energy for the Strain Hardening Gob Model}

The derivation of this gob model starts with the assumption that the tangent modulus of the gob increases linearly with stress from an initial modulus of $E_{I}$ to a final modulus of $E_{F}$ over the stress range of zero to $\sigma_{\mathrm{u}}$, the ultimate stress. Thus, the value of the tangent modulus (E) at any stress value $(\sigma)$ can be written as:

$$
\mathrm{E}=\left[\frac{\mathrm{E}_{\mathrm{F}}-\mathrm{E}_{\mathrm{I}}}{\sigma_{\mathrm{u}}}\right] \sigma+\mathrm{E}_{\mathrm{I}}
$$

From the theory of elasticity, we know that the differential relation between stress $(\sigma)$ and strain $(\varepsilon)$ is:

$$
\mathrm{d} \sigma=\mathrm{E} \mathrm{d} \varepsilon \quad \text { or } \quad \mathrm{d} \varepsilon=\frac{1}{\mathrm{E}} \mathrm{d} \sigma
$$

By substituting equation A.1 into the second part of equation A.2 the following integral can be written obtained with limits of integration between zero and $\varepsilon$ or $\sigma$ respectively:

$$
\int_{0}^{\varepsilon} \mathrm{d} \varepsilon=\int_{0}^{\sigma} \frac{1}{\left[\frac{\mathrm{E}_{\mathrm{F}}-\mathrm{E}_{\mathrm{I}}}{\sigma_{\mathrm{u}}}\right] \sigma+\mathrm{E}_{\mathrm{I}}} \mathrm{d} \sigma
$$

By solving the integral in equation A.3, the solution can be expressed as:

$$
\left.\varepsilon\right|_{0} ^{\varepsilon}=\left.\frac{1}{\left[\frac{\mathrm{E}_{\mathrm{F}}-\mathrm{E}_{\mathrm{I}}}{\sigma_{\mathrm{u}}}\right]} \ln \left[\left(\frac{\mathrm{E}_{\mathrm{F}}-\mathrm{E}_{\mathrm{I}}}{\sigma_{\mathrm{u}}}\right) \frac{\sigma}{\mathrm{E}_{\mathrm{I}}}+1\right]\right|_{0} ^{\sigma}
$$


After evaluation of equation A.4 with respect to the limits of integration, the following solution for strain as a function of stress and the material properties is obtained:

$$
\varepsilon=\frac{1}{\left[\frac{\mathrm{E}_{\mathrm{F}}-\mathrm{E}_{\mathrm{I}}}{\sigma_{\mathrm{u}}}\right]} \ln \left[\left(\frac{\mathrm{E}_{\mathrm{F}}-\mathrm{E}_{\mathrm{I}}}{\sigma_{\mathrm{u}}}\right) \frac{\sigma}{\mathrm{E}_{\mathrm{I}}}+1\right]
$$

By solving equation A.5 for stress, the solution for stress in terms of strain and the material properties is determined:

$$
\sigma=E_{I}\left[\frac{\sigma_{u}}{E_{F}-E_{I}}\right]\left[e^{\frac{E_{F}-E_{I}}{\sigma_{u}} \varepsilon}-1\right]
$$

Until this point, the effective modulus $\left(\mathrm{E}_{\mathrm{E}}\right)$ has been used in formulation of the above equations rather than the true modulus $\left(\mathrm{E}_{\mathrm{T}}\right)$. In Zipf's analysis, a factor must be introduced to take into account the thickness of the gob (caved zone) with respect to the mined coal seam. The gob height factor (n) is the caved zone height divided by the seam thickness and is used to modify the true modulus for the gob (which is thicker than the coal seam) to get an effective modulus to use for an equivalent gob material that is the same thickness as the seam:

$$
\mathrm{E}_{\mathrm{E}}=\frac{\mathrm{E}_{\mathrm{T}}}{\mathrm{n}}
$$

In terms of the true modulus, the stress equation A.6 can be modified with the gob height factor (n) and used in the following form

$$
\sigma=\frac{E_{I}}{n}\left[\frac{n \sigma_{u}}{E_{F}-E_{I}}\right]\left[e^{\frac{E_{F}-E_{I}}{n \sigma_{u}} \varepsilon}-1\right]
$$


In order to determine the actual energy release, the area under the stress-strain curve is needed and requires the integration of equation A.8 with respect to the strain $(\varepsilon)$. For this, we are using the limits of integration as zero for the lower boundary, the starting point on the curve and $S_{\mathrm{P}}$, the current location on the curve shown in the following equation.

$$
\int_{0}^{S_{\mathrm{P}}} \sigma d \varepsilon=\frac{\mathrm{E}_{\mathrm{I}}}{\mathrm{n}} \frac{\mathrm{n} \sigma_{\mathrm{u}}}{\mathrm{E}_{\mathrm{F}}-\mathrm{E}_{\mathrm{I}}}\left[\int_{0}^{\mathrm{S}_{\mathrm{P}}} \mathrm{e}^{\frac{\mathrm{E}_{\mathrm{F}}-\mathrm{E}_{\mathrm{I}}}{\mathrm{n \sigma _{ \textrm {u } }}}}-\int_{0}^{\mathrm{S}_{\mathrm{P}}} 1\right] \mathrm{d} \varepsilon
$$

We know that the derivative of the strain term is equation A.10.

$$
\frac{\mathrm{d}}{\mathrm{d} \varepsilon} \mathrm{e}^{\frac{\mathrm{E}_{\mathrm{F}}-\mathrm{E}_{\mathrm{I}}}{\mathrm{n \sigma _{ \textrm {u } }}}}=\frac{\mathrm{E}_{\mathrm{F}}-\mathrm{E}_{\mathrm{I}}}{\mathrm{n} \sigma_{\mathrm{u}}} \mathrm{e}^{\frac{\mathrm{E}_{\mathrm{F}}-\mathrm{E}_{\mathrm{I}}}{\mathrm{n} \sigma_{\mathrm{u}}}}
$$

Then by inspection and integration of equation A.10, the solution can be expressed as follows:

$$
\int_{0}^{S_{\mathrm{P}}} \sigma d \varepsilon=\left.\frac{E_{I}}{n} \frac{n \sigma_{u}}{E_{F}-E_{I}}\left[\frac{n \sigma_{u}}{E_{F}-E_{I}} e^{\frac{E_{F}-E_{I}}{n \sigma_{u}}}-\varepsilon\right]\right|_{0} ^{S_{P}}
$$

Finally, after consolidation of the integral between the limits of integration, the following solution is obtained and represents the area under the stress-strain curve for the strain hardening gob material in LaModel between 0 and a strain of $\mathrm{S}_{\mathrm{p}}$.

$$
\int_{0}^{S_{P}} \sigma d \varepsilon=\frac{E_{I}}{n}\left[\frac{n \sigma_{u}}{E_{F}-E_{I}}\right]^{2} e^{\frac{E_{F}-E_{I}}{n \sigma_{u}} S_{P}}-\frac{E_{I}}{n}\left[\frac{n \sigma_{u}}{E_{F}-E_{I}}\right] S_{P}-\frac{E_{I}}{n}\left[\frac{n \sigma_{u}}{E_{F}-E_{I}}\right]^{2}
$$




\section{Appendix B \\ Verification of the ERR Programming Using Manual Calculations}

Initial verification of the energy calculations implemented in the LaModel 3.0 program was accomplished by using manual calculations and then comparing those results to the program's calculations to check for potential programming errors in the code. The following section details the methods used in this initial validation process. First, a generic model was created with the following input file in LamPre 2.1 (see Figure B.1)

E. General Model Information

Project Title Check of Safety Factors and Energy Release Rate

General Parameters

Number of Seams

1

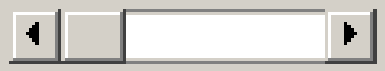

Number of In-Seam Materials

20

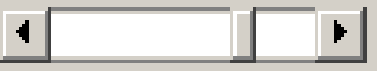

Number of Steps

3

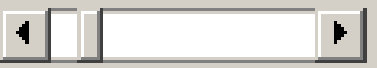

Define Off-Seam Plane

Г

\section{- Current Units}

$C$ inches and pounds per sq.inch [in, psi]

(c) feet and pounds per sq.inch [ft, psi]

C meters and pascals [m, Pa]

C meters and megapascals [m, HPa]

\section{Help}

Cancel
- Model Type

LAMODEL

C HULSIM/NL

OK

Next Form

Figure B.1: General Model Information. 
The General Model Information form allows the user to specify general parameters for the model. In this case, there is one seam, twenty in-seam materials, and three steps. In addition, the program units are specified as feet and psi. On the next form (Figure B.2), the overburden and rock mass parameters are specified.

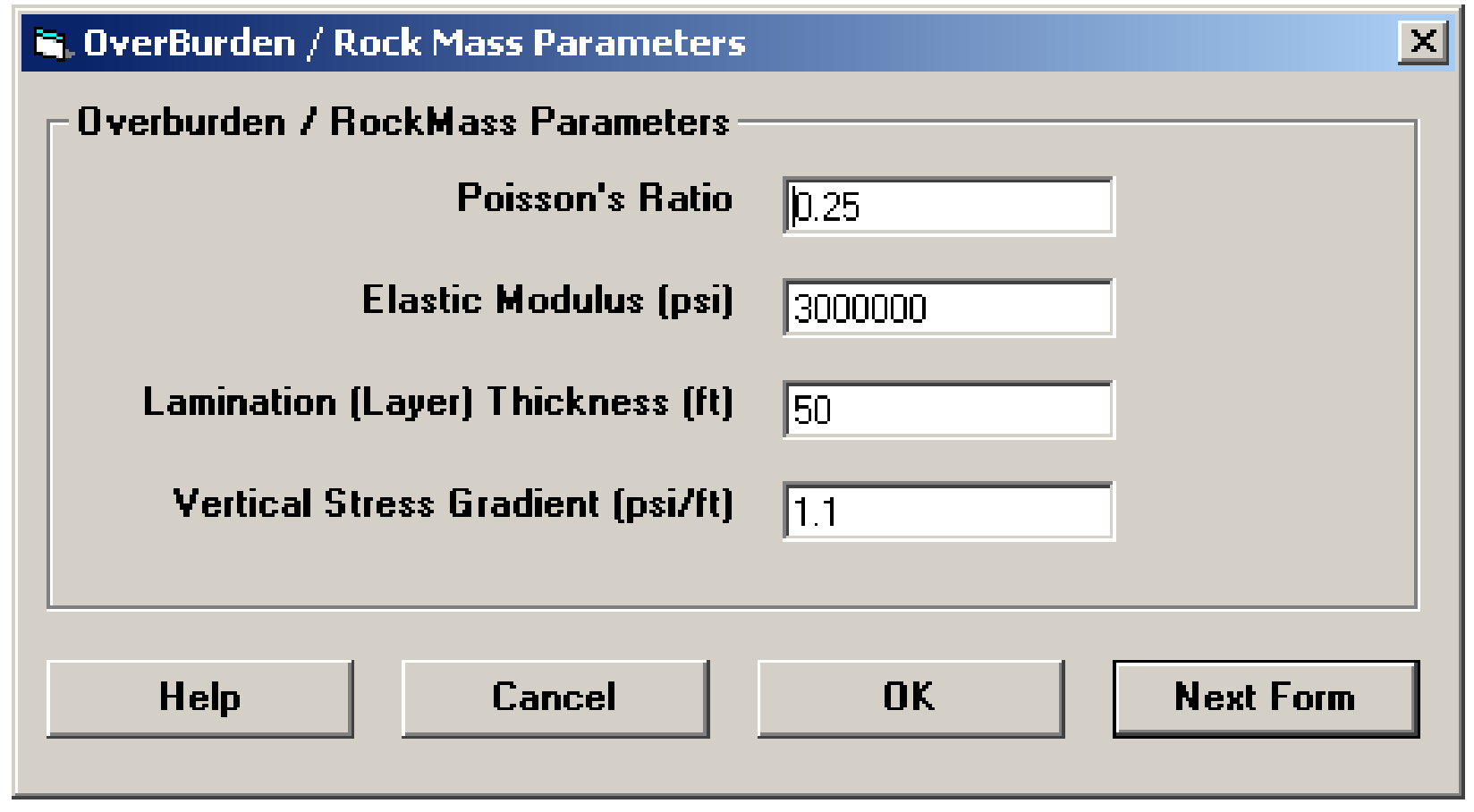

Figure B.2: Overburden / Rock Mass Parameters.

The Overburden / Rock Mass Parameters form allows the user to specify the Poisson's ratio, elastic modulus, lamination thickness, and vertical stress gradient. In this test model, we were not necessarily concerned with an attempt to model any specific real world conditions; therefore, LaModel's default parameters were used. The seam geometry and boundary conditions are input on the following form (see Figure B.3). 


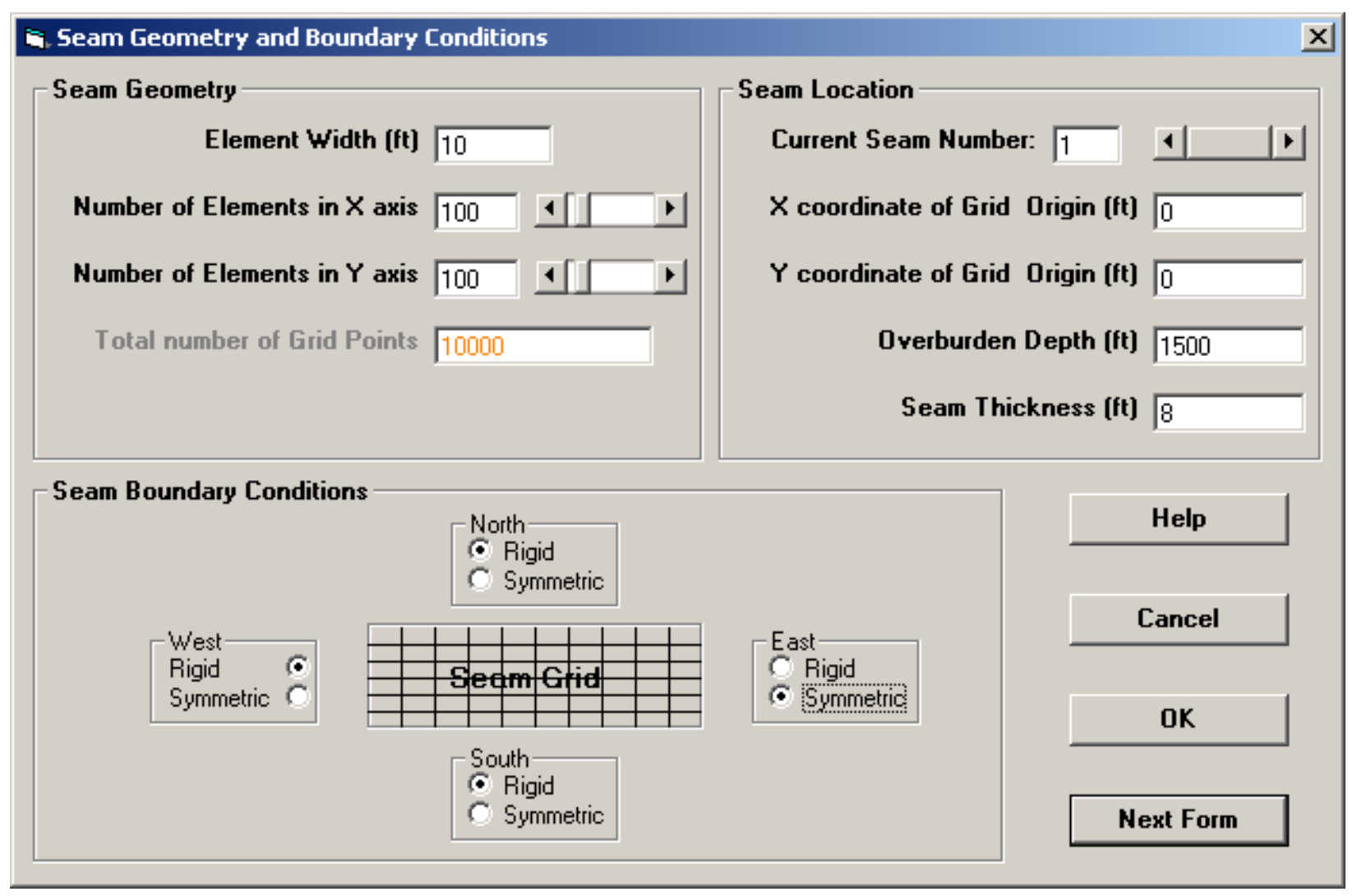

Figure B.3: Seam Geometry and Boundary Conditions.

In this form the seam geometry, seam location, and boundary condition are specified. In this test, $10 \mathrm{ft}$ elements are used in a $100 \times 100$ grid. The overburden depth and seam thickness are $1500 \mathrm{ft}$ and $8 \mathrm{ft}$ respectively. The boundary conditions default to rigid while the eastern boundary was changed to symmetric to allow both condition to be tested. After this form, a two tabbed wizard for defining in-seam materials is found. In this case, the coal wizard was used to calculate the elastic plastic coal properties A through I. Using this material wizard speeds the process of generating Mark-Bieniawski strength coal pillars but it is not necessary as the materials can also be entered in the program manually. In order to test the widest range of energy calculations in this verification process, a set of strain-softening coal properties, and both strain-hardening and bi-linear gob properties were created and entered into the program as shown in Table B.1. 


\begin{tabular}{|c|c|c|c|c|c|c|c|}
\hline & & & & & & & \\
\hline & & & & & Parameters & & \\
\hline Code & Material & $\begin{array}{l}\text { Model } \\
\text { Type }\end{array}$ & $\begin{array}{c}\text { Elastic } \\
\text { Modulus }\end{array}$ & $\begin{array}{l}\text { Poisson's } \\
\text { Ratio }\end{array}$ & $\mathbf{N A}$ & NA & NA \\
\hline $\mathrm{A}$ & Coal & $\mathrm{LE}$ & 300000 & 0.33 & 0 & 0 & 0 \\
\hline Code & Material & $\begin{array}{l}\text { Model } \\
\text { Type }\end{array}$ & $\begin{array}{c}\text { Peak } \\
\text { Stress }\end{array}$ & $\begin{array}{c}\text { Peak } \\
\text { Strain }\end{array}$ & $\begin{array}{c}\text { Plastic } \\
\text { Modulus }\end{array}$ & $\begin{array}{l}\text { Poisson's } \\
\text { Ratio }\end{array}$ & $\mathbf{N A}$ \\
\hline $\mathrm{B}$ & Coal & $\mathrm{EP}$ & 9081 & 0.03027 & 0 & 0.33 & 0 \\
\hline $\mathrm{C}$ & Coal & $\mathrm{EP}$ & 8676 & 0.03027 & 0 & 0.33 & 0 \\
\hline $\mathrm{D}$ & Coal & $\mathrm{EP}$ & 6651 & 0.02217 & 0 & 0.33 & 0 \\
\hline $\mathrm{E}$ & Coal & $\mathrm{EP}$ & 6246 & 0.02217 & 0 & 0.33 & 0 \\
\hline $\mathrm{F}$ & Coal & $\mathrm{EP}$ & 4221 & 0.01407 & 0 & 0.33 & 0 \\
\hline $\mathrm{G}$ & Coal & $\mathrm{EP}$ & 3816 & 0.01407 & 0 & 0.33 & 0 \\
\hline $\mathrm{H}$ & Coal & $\mathrm{EP}$ & 1791 & 0.00597 & 0 & 0.33 & 0 \\
\hline I & Coal & $\mathrm{EP}$ & 1386 & 0.00597 & 0 & 0.33 & 0 \\
\hline Code & Material & $\begin{array}{l}\text { Model } \\
\text { Type }\end{array}$ & $\begin{array}{c}\text { Peak } \\
\text { Stress }\end{array}$ & $\begin{array}{c}\text { Peak } \\
\text { Strain }\end{array}$ & $\begin{array}{c}\text { Residual } \\
\text { Stress }\end{array}$ & $\begin{array}{c}\text { Residual } \\
\text { Strain }\end{array}$ & $\begin{array}{l}\text { Poisson's } \\
\text { Ratio }\end{array}$ \\
\hline $\mathrm{K}$ & Coal & SS & 9081 & 0.03027 & 6070 & 0.12108 & 0.33 \\
\hline $\mathrm{L}$ & Coal & SS & 8676 & 0.02892 & 5799 & 0.11568 & 0.33 \\
\hline $\mathrm{M}$ & Coal & $\mathrm{SS}$ & 6651 & 0.02217 & 4025 & 0.08868 & 0.33 \\
\hline $\mathrm{N}$ & Coal & SS & 6246 & 0.02082 & 3780 & 0.08328 & 0.33 \\
\hline $\mathrm{O}$ & Coal & $\mathrm{SS}$ & 4221 & 0.01407 & 2149 & 0.05628 & 0.33 \\
\hline $\mathrm{P}$ & Coal & $\mathrm{SS}$ & 3816 & 0.01272 & 1943 & 0.05088 & 0.33 \\
\hline $\mathrm{Q}$ & Coal & SS & 1791 & 0.00597 & 542 & 0.02388 & 0.33 \\
\hline $\mathrm{R}$ & Coal & SS & 1386 & 0.00462 & 419 & 0.01848 & 0.33 \\
\hline Code & Material & $\begin{array}{l}\text { Model } \\
\text { Type }\end{array}$ & $\begin{array}{c}\text { Initial } \\
\text { Modulus }\end{array}$ & $\begin{array}{c}\text { Final } \\
\text { Modulus }\end{array}$ & $\begin{array}{c}\text { Virgin } \\
\text { Vertical } \\
\text { Stress }\end{array}$ & $\begin{array}{c}\text { Gob } \\
\text { Height } \\
\text { Factor }\end{array}$ & $\begin{array}{l}\text { Poisson's } \\
\text { Ratio }\end{array}$ \\
\hline $\mathrm{S}$ & Gob & $\mathrm{SH}$ & 100 & 300000 & 4000 & 1 & 0.33 \\
\hline Code & Material & $\begin{array}{l}\text { Model } \\
\text { Type }\end{array}$ & $\begin{array}{l}\text { Offset } \\
\text { Stress }\end{array}$ & $\begin{array}{l}\text { Offset } \\
\text { Strain }\end{array}$ & $\begin{array}{l}\text { Hardening } \\
\text { Modulus }\end{array}$ & $\begin{array}{c}\text { Gob } \\
\text { Height } \\
\text { Factor }\end{array}$ & $\begin{array}{l}\text { Poisson's } \\
\text { Ratio }\end{array}$ \\
\hline $\mathrm{T}$ & Gob & $\mathrm{BH}$ & 11925 & 0.1 & 150000 & 1 & 0.33 \\
\hline
\end{tabular}

Table B.1: LaModel material properties of the test case 
The final input form in LamPre allows the user to specify the program control parameters (see Figure B.4). In this form Control and Solution Options are specified. In the control options, the over-relaxation factor and the maximum number of iterations were changed from the default values to 1.75 and 20000 respectively. Since this model was created using the LamPre 2.1 preprocessor program and runs in the LaModel 3.0 program, there is no solution option for running the energy calculations (as there now is in LamPre 3.0). This requires the input file to be manually corrected (meaning a 1 must be added to the input file at the end of the program control parameters line).

\section{E. Program Control Parameters}

- Control Dptions

Drer-Relaxation Factor $\longdiv { 1 . 7 5 }$

Displacement Convergence Level [ft] 0.00001

Maximum Number of Iterations 20000

Initial Step Number 1

Solution Options

Г Include Free Surface Effects

Г Input Topography from Topographic File

『 Calculate Safety Factors

Г Calculate Multiple Seam Subsidence

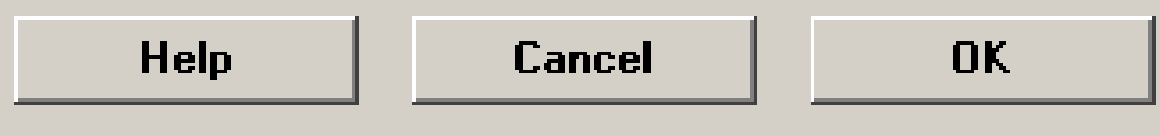

Finish

Figure B.4: Program Control Parameters. 
Once all of the input forms and creation of the material properties was complete, the seam grid was created in the grid editor. In this test, Figure B.5 depicts the seam conditions in step 2.

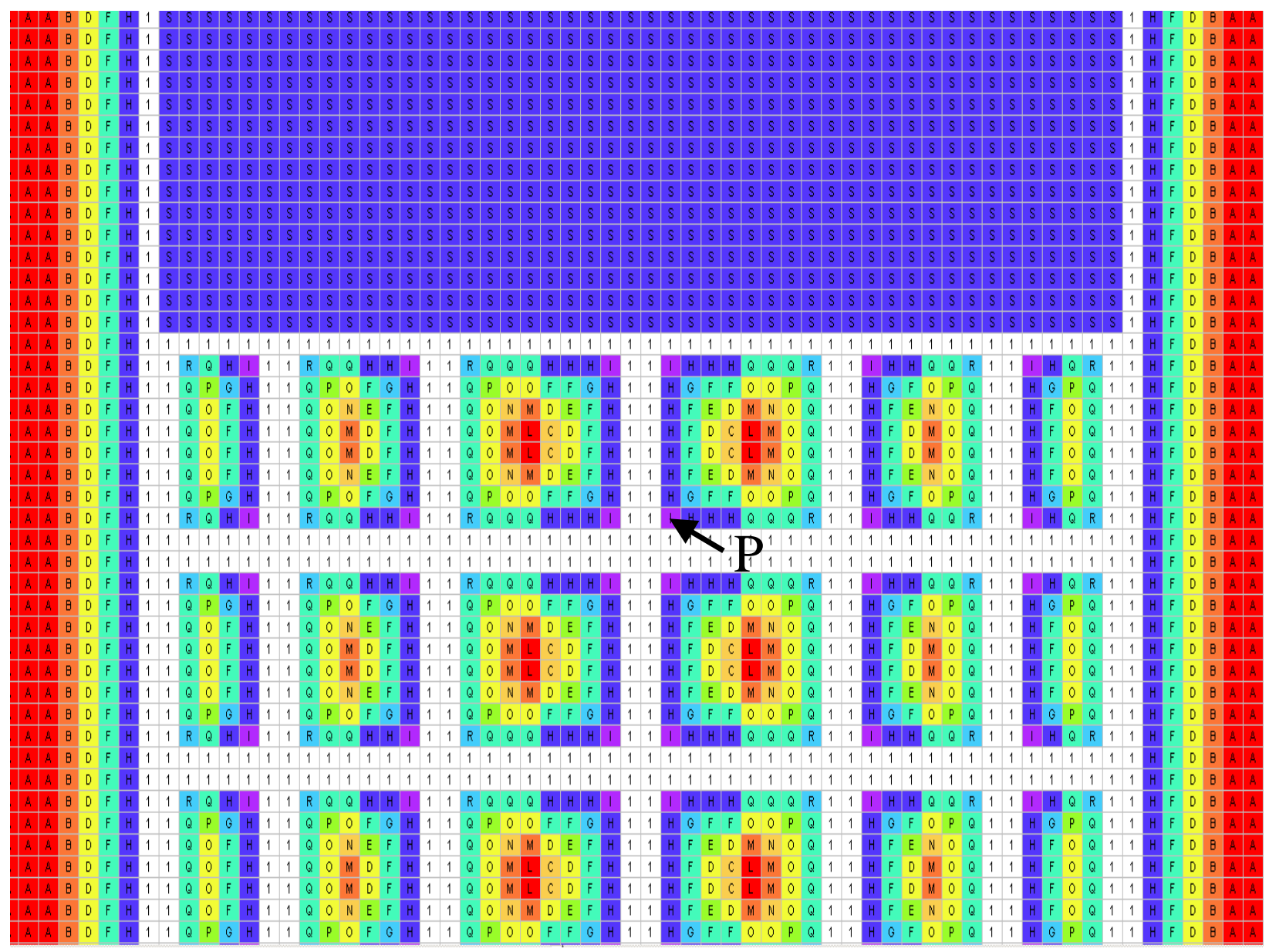

Figure B.5: LaModel grid depicting the seam condition in step 2.

It can be seen here that the seam was developed using 7 entries with varying pillar sizes. The pillars themselves are half elastic-plastic (materials B-I) and half strain softening (materials KR). In transition from step 2 to step 3, with the addition and removal of some miscellaneous elements, nearly every possible material change was tested. Figure B.6 shows the seam condition on step 3 . 


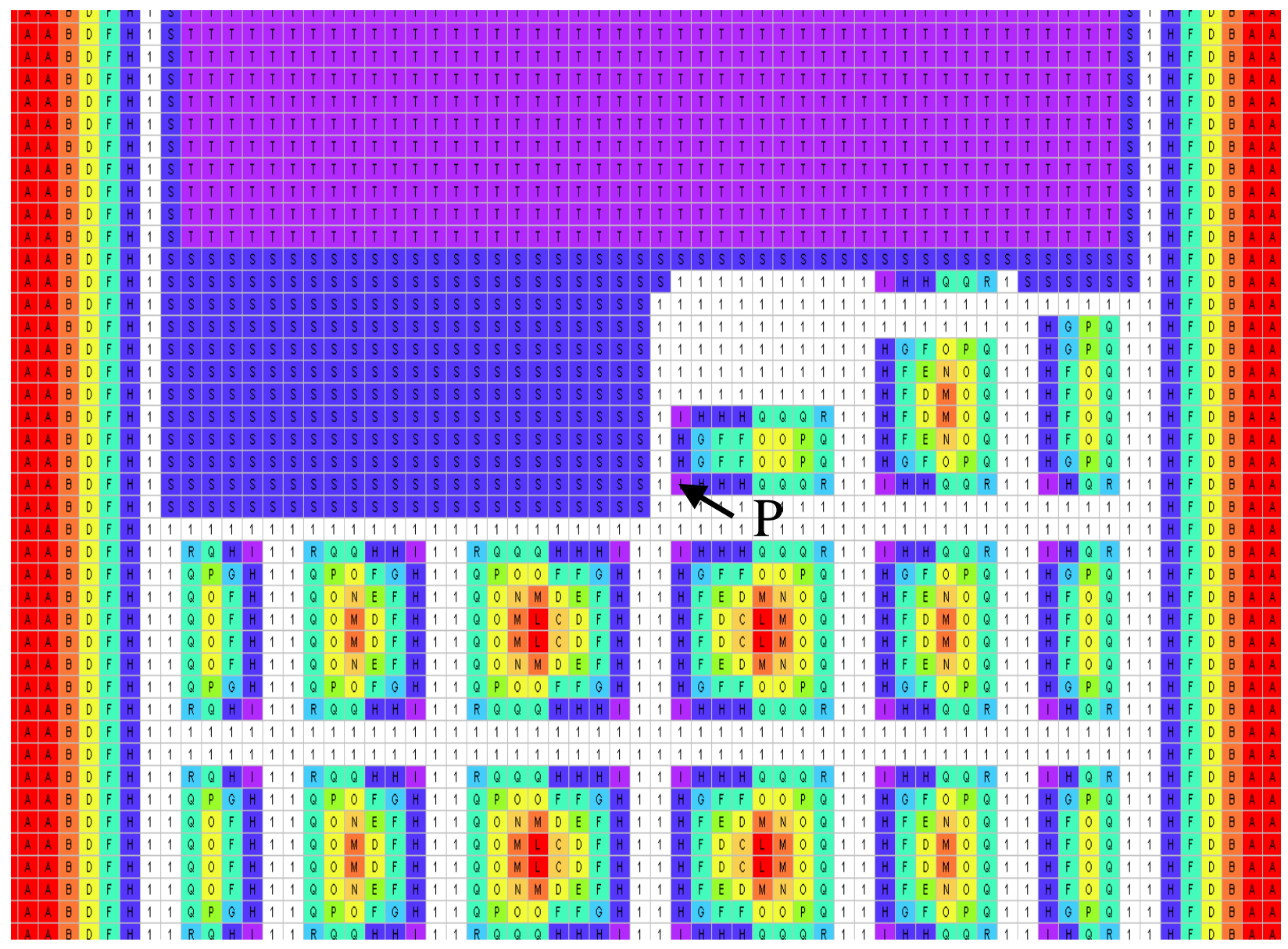

Figure B.6: LaModel grid depicting the seam condition in step 3.

It can be seen in step 3 that half of the inby pillar row has been removed and replaced with gob and half of the fourth pillar has been removed and left as an opening. In addition, the majority of strain hardening gob elements (material S) were changed to bi-linear hardening gob (material T) and miscellaneous elements were added or removed inby the remaining half of the pillar row. (In Figure B.6, the lower left corner of the half pillar remaining in step 3 is labeled as point $\mathrm{P}$ and is material $\mathrm{I}$. This point is at grid coordinates $(\mathrm{x}=52, \mathrm{y}=59)$ and can be used as a location index for locating the other materials listed in subsequent tables in this appendix.)

In LaModel, as previously discussed, both static and dynamic energy quantities are calculated. The stored energy, dissipated energy, and total input energy (static energy) values are the result of the stress, strain, and convergence levels of one particular step. The dynamic energy values (dissipated release, elastic release, and kinetic release) result from changes in 
convergence, stress and material type between steps. The stress and displacement values taken from the LaModel output of the verification model and used to calculate the static energy quantities for specific cells are shown in table B.2.

\begin{tabular}{|c|c|c|c|c|c|c|c|}
\hline Test & $\begin{array}{c}\text { Grid } \\
\text { Location } \\
(\mathbf{X}, \mathbf{Y})\end{array}$ & $\begin{array}{c}\text { Step } 2 \\
\text { Model } \\
\text { Type }\end{array}$ & $\begin{array}{c}\text { Step } 3 \\
\text { Model } \\
\text { Type }\end{array}$ & $\begin{array}{l}\text { Step } 2 \\
\text { Stress }\end{array}$ & $\begin{array}{c}\text { Step } 2 \\
\text { Disp }\end{array}$ & $\begin{array}{l}\text { Step } 3 \\
\text { Stress }\end{array}$ & $\begin{array}{c}\text { Step } 3 \\
\text { Disp }\end{array}$ \\
\hline 1 & $(53,59)$ & $\begin{array}{c}\text { EP Coal } \\
\text { (H) }\end{array}$ & $\begin{array}{l}\text { Stays the } \\
\text { Same (H) }\end{array}$ & $1.79 \mathrm{E}+03$ & 2.90E-01 & $1.79 \mathrm{E}+03$ & $3.11 \mathrm{E}-01$ \\
\hline 2 & $(54,59)$ & $\begin{array}{c}\text { EP Coal } \\
(\mathrm{H})\end{array}$ & $\begin{array}{l}\text { Stays the } \\
\text { Same }(\mathrm{H})\end{array}$ & $1.79 \mathrm{E}+03$ & 2.85E-01 & $1.79 \mathrm{E}+03$ & $2.98 \mathrm{E}-01$ \\
\hline 3 & $(52,56)$ & $\begin{array}{c}\text { EP Coal } \\
(\mathrm{H})\end{array}$ & $\begin{array}{l}\text { EP Coal } \\
\text { (I) }\end{array}$ & $1.79 \mathrm{E}+03$ & 3.46E-01 & $1.39 \mathrm{E}+03$ & 3.64E-01 \\
\hline 4 & $(59,56)$ & $\begin{array}{l}\text { SS Coal } \\
\text { (Q) }\end{array}$ & $\begin{array}{l}\text { SS Coal } \\
\text { (R) }\end{array}$ & $5.42 \mathrm{E}+02$ & 3.78E-01 & $4.19 \mathrm{E}+02$ & $2.92 \mathrm{E}-01$ \\
\hline 5 & $(52,48)$ & $\begin{array}{l}\text { SH Gob } \\
\text { (S) }\end{array}$ & $\begin{array}{l}\text { BH Gob } \\
\text { (T) }\end{array}$ & $5.48 \mathrm{E}+02$ & $6.42 \mathrm{E}-01$ & $3.63 \mathrm{E}+03$ & 2.43E-01 \\
\hline 6 & $(59,48)$ & $\begin{array}{l}\text { SH Gob } \\
\text { (S) }\end{array}$ & $\begin{array}{l}\text { BH Gob } \\
\text { (T) }\end{array}$ & $5.28 \mathrm{E}+02$ & $6.38 \mathrm{E}-01$ & $3.15 \mathrm{E}+03$ & $2.11 \mathrm{E}-01$ \\
\hline 7 & $(49,56)$ & $\begin{array}{c}\text { EP Coal } \\
(\mathrm{H})\end{array}$ & $\begin{array}{l}\text { SH Gob } \\
\text { (S) }\end{array}$ & $1.79 \mathrm{E}+03$ & 3.46E-01 & $5.94 \mathrm{E}+01$ & 4.07E-01 \\
\hline 8 & $(45,56)$ & $\begin{array}{l}\text { SS Coal } \\
\text { (L) }\end{array}$ & $\begin{array}{l}\text { SH Gob } \\
\text { (S) }\end{array}$ & $8.36 \mathrm{E}+03$ & 3.08E-01 & $7.90 \mathrm{E}+01$ & 4.37E-01 \\
\hline 9 & $(62,50)$ & $\begin{array}{l}\text { SH Gob } \\
\text { (S) }\end{array}$ & $\begin{array}{l}\text { EP Coal } \\
\text { (I) }\end{array}$ & $2.91 \mathrm{E}+02$ & 5.75E-01 & $1.39 \mathrm{E}+03$ & $2.30 \mathrm{E}-01$ \\
\hline 10 & $(67,50)$ & $\begin{array}{l}\text { SH Gob } \\
\text { (S) }\end{array}$ & $\begin{array}{l}\text { SS Coal } \\
\text { (R) }\end{array}$ & $1.85 \mathrm{E}+02$ & $5.27 \mathrm{E}-01$ & $4.19 \mathrm{E}+02$ & $1.99 \mathrm{E}-01$ \\
\hline 11 & $(52,50)$ & $\begin{array}{l}\text { SH Gob } \\
\text { (S) }\end{array}$ & $\begin{array}{l}\text { Opening } \\
\text { (1) }\end{array}$ & $3.09 \mathrm{E}+02$ & $5.82 \mathrm{E}-01$ & $0.00 \mathrm{E}+00$ & $3.15 \mathrm{E}-01$ \\
\hline 12 & $(50,56)$ & $\begin{array}{l}\text { Opening } \\
\text { (1) }\end{array}$ & $\begin{array}{l}\text { SH Gob } \\
\text { (S) }\end{array}$ & $0.00 \mathrm{E}+00$ & 3.59E-01 & $5.31 \mathrm{E}+01$ & 3.96E-01 \\
\hline
\end{tabular}

Table B.2: LaModel stress and displacement values 
Here, the grid location references in Table B. 2 correspond to the coordinates displayed (not the actual mine coordinates) in LamPre 2.1. In addition, the material model changes between steps are shown. The static energy quantities for each of these elements were calculated manually and compared to the model results (see Table B.3). As you can see in the table, the LaModel calculations and the manual check calculations were identical to at least 3 significant digits.

\begin{tabular}{|c|c|c|c|c|c|c|c|}
\hline Test & $\begin{array}{c}\text { Grid } \\
\text { Location } \\
(\mathbf{X}, \mathbf{Y})\end{array}$ & $\begin{array}{c}\text { Calculated } \\
\text { Stored } \\
\text { Energy }\end{array}$ & $\begin{array}{c}\text { LaModel } \\
\text { Stored } \\
\text { Energy }\end{array}$ & $\begin{array}{c}\text { Calculated } \\
\text { Dissipated } \\
\text { Energy }\end{array}$ & $\begin{array}{c}\text { LaModel } \\
\text { Dissipated } \\
\text { Energy }\end{array}$ & $\begin{array}{c}\text { Calculated } \\
\text { Total } \\
\text { Input } \\
\text { Energy }\end{array}$ & $\begin{array}{c}\text { LaModel } \\
\text { Total } \\
\text { Input } \\
\text { Energy }\end{array}$ \\
\hline 1 & $(53,59)$ & $6.16 \mathrm{E}+05$ & $6.16 \mathrm{E}+05$ & $6.79 \mathrm{E}+06$ & $6.79 \mathrm{E}+06$ & $7.40 \mathrm{E}+06$ & $7.40 \mathrm{E}+06$ \\
\hline 2 & $(54,59)$ & $6.16 \mathrm{E}+05$ & $6.16 \mathrm{E}+05$ & $6.44 \mathrm{E}+06$ & $6.44 \mathrm{E}+06$ & $7.06 \mathrm{E}+06$ & $7.06 \mathrm{E}+06$ \\
\hline 3 & $(52,56)$ & $4.77 \mathrm{E}+05$ & $4.77 \mathrm{E}+05$ & $6.30 \mathrm{E}+06$ & $6.30 \mathrm{E}+06$ & $6.78 \mathrm{E}+06$ & $6.78 \mathrm{E}+06$ \\
\hline 4 & $(59,56)$ & $3.37 \mathrm{E}+04$ & $3.37 \mathrm{E}+04$ & $2.64 \mathrm{E}+06$ & $2.64 \mathrm{E}+06$ & $2.68 \mathrm{E}+06$ & $2.68 \mathrm{E}+06$ \\
\hline 5 & $(52,48)$ & $5.05 \mathrm{E}+06$ & $5.05 \mathrm{E}+06$ & $1.30 \mathrm{E}+06$ & $1.30 \mathrm{E}+06$ & $6.35 \mathrm{E}+06$ & $6.35 \mathrm{E}+06$ \\
\hline 6 & $(59,48)$ & $3.81 \mathrm{E}+06$ & $3.81 \mathrm{E}+06$ & $9.82 \mathrm{E}+05$ & $9.82 \mathrm{E}+05$ & $4.79 \mathrm{E}+06$ & $4.79 \mathrm{E}+06$ \\
\hline 7 & $(49,56)$ & $6.77 \mathrm{E}+02$ & $6.77 \mathrm{E}+02$ & $8.27 \mathrm{E}+04$ & $8.27 \mathrm{E}+04$ & $8.34 \mathrm{E}+04$ & $8.34 \mathrm{E}+04$ \\
\hline 8 & $(45,56)$ & $1.20 \mathrm{E}+03$ & $1.20 \mathrm{E}+03$ & $1.12 \mathrm{E}+05$ & $1.12 \mathrm{E}+05$ & $1.13 \mathrm{E}+05$ & $1.13 \mathrm{E}+05$ \\
\hline 9 & $(62,50)$ & $4.77 \mathrm{E}+05$ & $4.77 \mathrm{E}+05$ & $3.65 \mathrm{E}+06$ & $3.65 \mathrm{E}+06$ & $4.12 \mathrm{E}+06$ & $4.12 \mathrm{E}+06$ \\
\hline 10 & $(67,50)$ & $3.37 \mathrm{E}+04$ & $3.37 \mathrm{E}+04$ & $2.08 \mathrm{E}+06$ & $2.08 \mathrm{E}+06$ & $2.12 \mathrm{E}+06$ & $2.12 \mathrm{E}+06$ \\
\hline 11 & $(52,50)$ & $0.00 \mathrm{E}+00$ & $0.00 \mathrm{E}+00$ & $0.00 \mathrm{E}+00$ & $0.00 \mathrm{E}+00$ & $0.00 \mathrm{E}+00$ & $0.00 \mathrm{E}+00$ \\
\hline 12 & $(50,56)$ & $5.41 \mathrm{E}+02$ & $5.41 \mathrm{E}+02$ & $7.34 \mathrm{E}+04$ & $7.34 \mathrm{E}+04$ & $7.40 \mathrm{E}+04$ & $7.40 \mathrm{E}+04$ \\
\hline
\end{tabular}

Table B.3: Comparison between manual and program calculation of static energy values. 
Following the verification of the static energy quantities, the same process of manual calculation and comparison was used to verify many of the dynamic energy calculations (see Table B.4). For this verification purposes, only the Kinetic Energy Release and the Total Energy Release was calculated and compared. Again, as you can see in the table, the LaModel calculations and the manual check calculations were identical to at least 3 significant digits.

\begin{tabular}{|c|c|c|c|c|c|c|c|}
\hline Test & $\begin{array}{c}\text { Grid } \\
\text { Location } \\
(\mathbf{X}, \mathbf{Y})\end{array}$ & $\begin{array}{c}\text { Step } 2 \\
\text { Model } \\
\text { Type }\end{array}$ & $\begin{array}{l}\text { Step } 3 \\
\text { Model } \\
\text { Type }\end{array}$ & $\begin{array}{c}\text { Calculated } \\
\text { Kinetic } \\
\text { Energy } \\
\text { Release }\end{array}$ & $\begin{array}{l}\text { LaModel } \\
\text { Kinetic } \\
\text { Energy } \\
\text { Release }\end{array}$ & $\begin{array}{c}\text { Calculated } \\
\text { Total } \\
\text { Energy } \\
\text { Release }\end{array}$ & $\begin{array}{c}\text { LaModel } \\
\text { Total } \\
\text { Energy } \\
\text { Release }\end{array}$ \\
\hline 1 & $(53,59)$ & $\begin{array}{l}\text { EP Coal } \\
(\mathrm{H})\end{array}$ & $\begin{array}{l}\text { Stays the } \\
\text { Same }(H)\end{array}$ & $0.00 \mathrm{E}+00$ & $0.00 \mathrm{E}+00$ & $5.48 \mathrm{E}+05$ & $5.48 \mathrm{E}+05$ \\
\hline 2 & $(54,59)$ & $\begin{array}{l}\text { EP Coal } \\
(\mathrm{H})\end{array}$ & $\begin{array}{l}\text { Stays the } \\
\text { Same }(\mathrm{H})\end{array}$ & $0.00 \mathrm{E}+00$ & $0.00 \mathrm{E}+00$ & $3.25 \mathrm{E}+05$ & $3.25 \mathrm{E}+05$ \\
\hline 3 & $(52,56)$ & $\begin{array}{c}\text { EP Coal } \\
(\mathrm{H})\end{array}$ & $\begin{array}{l}\text { EP Coal } \\
\text { (I) }\end{array}$ & $4.01 \mathrm{E}+05$ & $4.01 \mathrm{E}+05$ & $5.40 \mathrm{E}+05$ & $5.40 \mathrm{E}+05$ \\
\hline 4 & $(59,56)$ & $\begin{array}{l}\text { SS Coal } \\
\text { (Q) }\end{array}$ & $\begin{array}{l}\text { SS Coal } \\
\text { (R) }\end{array}$ & $-5.96 \mathrm{E}+05$ & $-5.96 \mathrm{E}+05$ & $-5.73 E+05$ & $-5.73 E+05$ \\
\hline 5 & $(52,48)$ & $\begin{array}{l}\text { SH Gob } \\
\text { (S) }\end{array}$ & $\begin{array}{l}\text { BH Gob } \\
\text { (T) }\end{array}$ & $-1.20 \mathrm{E}+07$ & $-1.20 \mathrm{E}+07$ & $-1.70 \mathrm{E}+07$ & $-1.70 \mathrm{E}+07$ \\
\hline 6 & $(59,48)$ & $\begin{array}{l}\text { SH Gob } \\
\text { (S) }\end{array}$ & $\begin{array}{l}\text { BH Gob } \\
\text { (T) }\end{array}$ & $-1.13 \mathrm{E}+07$ & $-1.13 E+07$ & $-1.51 \mathrm{E}+07$ & $-1.51 \mathrm{E}+07$ \\
\hline 7 & $(49,56)$ & $\begin{array}{c}\text { EP Coal } \\
(\mathrm{H})\end{array}$ & $\begin{array}{l}\text { SH Gob } \\
\text { (S) }\end{array}$ & $8.17 \mathrm{E}+05$ & $8.17 \mathrm{E}+05$ & $1.43 \mathrm{E}+06$ & $1.43 \mathrm{E}+06$ \\
\hline 8 & $(45,56)$ & $\begin{array}{l}\text { SS Coal } \\
\text { (L) }\end{array}$ & $\begin{array}{l}\text { SH Gob } \\
\text { (S) }\end{array}$ & $7.88 \mathrm{E}+06$ & $7.88 \mathrm{E}+06$ & $2.13 \mathrm{E}+07$ & $2.13 \mathrm{E}+07$ \\
\hline 9 & $(62,50)$ & $\begin{array}{l}\text { SH Gob } \\
\text { (S) }\end{array}$ & $\begin{array}{l}\text { EP Coal } \\
\text { (I) }\end{array}$ & $-4.16 \mathrm{E}+06$ & $-4.16 \mathrm{E}+06$ & $-4.62 E+06$ & $-4.62 E+06$ \\
\hline 10 & $(67,50)$ & $\begin{array}{c}\text { SH Gob } \\
\text { (S) }\end{array}$ & $\begin{array}{l}\text { SS Coal } \\
(\mathrm{R})\end{array}$ & $-1.43 \mathrm{E}+06$ & $-1.43 \mathrm{E}+06$ & $-1.46 \mathrm{E}+06$ & $-1.46 \mathrm{E}+06$ \\
\hline 11 & $(52,50)$ & $\begin{array}{l}\text { SH Gob } \\
\text { (S) }\end{array}$ & $\begin{array}{l}\text { Opening } \\
\text { (1) }\end{array}$ & $-5.93 E+05$ & $-5.93 E+05$ & $-5.74 \mathrm{E}+05$ & $-5.74 \mathrm{E}+05$ \\
\hline 12 & $(50,56)$ & $\begin{array}{l}\text { Opening } \\
\text { (1) }\end{array}$ & $\begin{array}{l}\text { SH Gob } \\
\text { (S) }\end{array}$ & $1.39 \mathrm{E}+04$ & $1.39 \mathrm{E}+04$ & $1.33 \mathrm{E}+04$ & $1.33 \mathrm{E}+04$ \\
\hline
\end{tabular}

Table B.4: Comparison between manual and program calculation of dynamic energy values. 
Observing the corresponding values in the previous two tables essentially validates the energy calculations in LaModel 3.0. Table B.5, below, shows the equations from Chapter 3 that were used to calculate the respective energy quantities.

\begin{tabular}{|c|c|c|c|c|c|c|c|c|}
\hline Test & $\begin{array}{c}\text { Grid } \\
\text { Location } \\
(\mathbf{X}, \mathbf{Y})\end{array}$ & $\begin{array}{c}\text { Step } 2 \\
\text { Model } \\
\text { Type }\end{array}$ & $\begin{array}{l}\text { Step } 3 \\
\text { Model } \\
\text { Type }\end{array}$ & $\begin{array}{c}\text { Step 3 } \\
\text { Stored } \\
\text { Energy } \\
\text { Equation }\end{array}$ & $\begin{array}{c}\text { Step 3 } \\
\text { Dissipated } \\
\text { Energy } \\
\text { Equation }\end{array}$ & $\begin{array}{c}\text { Step } 3 \\
\text { Total } \\
\text { Input } \\
\text { Energy } \\
\text { Equation }\end{array}$ & $\begin{array}{c}\text { Kinetic } \\
\text { Energy } \\
\text { Release } \\
\text { Equation }\end{array}$ & $\begin{array}{c}\text { Total } \\
\text { Energy } \\
\text { Release } \\
\text { Equation }\end{array}$ \\
\hline 1 & $(53,59)$ & $\begin{array}{c}\text { EP Coal } \\
(\mathrm{H})\end{array}$ & $\begin{array}{l}\text { Stays the } \\
\text { Same }(H)\end{array}$ & (3.6b) & (3.6b) & $(3.6 b)$ & NA & $(3.18)$ \\
\hline 2 & $(54,59)$ & $\begin{array}{c}\text { EP Coal } \\
(\mathrm{H})\end{array}$ & $\begin{array}{l}\text { Stays the } \\
\text { Same }(H)\end{array}$ & (3.6b) & (3.6b) & $(3.6 b)$ & NA & $(3.18)$ \\
\hline 3 & $(52,56)$ & $\begin{array}{c}\text { EP Coal } \\
(\mathrm{H})\end{array}$ & $\begin{array}{l}\text { EP Coal } \\
\text { (I) }\end{array}$ & (3.6b) & (3.6b) & $(3.6 b)$ & $(3.17)$ & $(3.19)$ \\
\hline 4 & $(59,56)$ & $\begin{array}{l}\text { SS Coal } \\
\text { (Q) }\end{array}$ & $\begin{array}{l}\text { SS Coal } \\
\text { (R) }\end{array}$ & $(3.5 c)$ & $(3.5 c)$ & $(3.5 c)$ & $(3.17)$ & (3.19) \\
\hline 5 & $(52,48)$ & $\begin{array}{l}\text { SH Gob } \\
\text { (S) }\end{array}$ & $\begin{array}{l}\text { BH Gob } \\
\quad(\mathrm{T})\end{array}$ & (3.14a) & (3.14a) & (3.14a) & $(3.17)$ & (3.19) \\
\hline 6 & $(59,48)$ & $\begin{array}{l}\text { SH Gob } \\
\text { (S) }\end{array}$ & $\begin{array}{l}\text { BH Gob } \\
\text { (T) }\end{array}$ & $(3.14 a)$ & (3.14a) & (3.14a) & $(3.17)$ & $(3.19)$ \\
\hline 7 & $(49,56)$ & $\begin{array}{c}\text { EP Coal } \\
(\mathrm{H})\end{array}$ & $\begin{array}{l}\text { SH Gob } \\
\text { (S) }\end{array}$ & (3.11) & $(3.12)$ & (3.13) & $(3.17)$ & (3.19) \\
\hline 8 & $(45,56)$ & $\begin{array}{l}\text { SS Coal } \\
\text { (L) }\end{array}$ & $\begin{array}{l}\text { SH Gob } \\
\text { (S) }\end{array}$ & (3.11) & $(3.12)$ & (3.13) & $(3.17)$ & (3.19) \\
\hline 9 & $(62,50)$ & $\begin{array}{l}\text { SH Gob } \\
\text { (S) }\end{array}$ & $\begin{array}{l}\text { EP Coal } \\
\text { (I) }\end{array}$ & (3.6b) & $(3.6 b)$ & $(3.6 b)$ & $(3.17)$ & (3.19) \\
\hline 10 & $(67,50)$ & $\begin{array}{l}\text { SH Gob } \\
\text { (S) }\end{array}$ & $\begin{array}{l}\text { SS Coal } \\
\text { (R) }\end{array}$ & $(3.5 c)$ & $(3.5 c)$ & $(3.5 c)$ & $(3.17)$ & (3.19) \\
\hline 11 & $(52,50)$ & $\begin{array}{l}\text { SH Gob } \\
\text { (S) }\end{array}$ & $\begin{array}{l}\text { Opening } \\
\text { (1) }\end{array}$ & NA & NA & NA & $(3.17)$ & (3.19) \\
\hline 12 & $(50,56)$ & $\begin{array}{c}\text { Opening } \\
\text { (1) }\end{array}$ & $\begin{array}{l}\text { SH Gob } \\
\text { (S) }\end{array}$ & (3.11) & $(3.12)$ & (3.13) & $(3.17)$ & (3.19) \\
\hline
\end{tabular}

Table B.5: Equations used to calculate respective energy quantity. 
In this chart, the equations used to calculate the static and dynamic energy values are show by reference to equations detailed previously. Also shown are the material model types between steps, which are important to calculating the dynamic energy values. In conclusion, this validation using manual calculation and comparing them to the LaModel output has confirmed the accuracy of the LaModel 3.0 energy calculations. 


\section{V i t a}

\section{Morgan M. Sears}

msears@mix.wvu.edu

\section{Education}

\section{Masters of Science in Mining Engineering}

West Virginia University, Morgantown, WV 26506.

Anticipated Graduation: Dec 2009; Current GPA 3.75

Advisor: Dr. Keith A. Heasley

\section{Bachelor of Science in Mining Engineering}

West Virginia University, Morgantown, WV 26506.

May 2007; GPA 3.82

\section{Master's Thesis}

\section{"Implementing Energy Release Rate Calculations Into the LaModel Program"}

Project Goals:

1. Implement the energy release rate calculations into the program.

2. Verify the accuracy of the new program code through manual calculation comparison and application to a previously published case study.

3. Exhibit the practical application of the new calculations to a case study of a bump prone mine in central Appalachia.

\section{Job Experience}

1. Graduate Research Assistant

West Virginia University: Dept. of Mining Engineering, Morgantown, WV

August 2007 to present: Perform research in the field of ground control.

2. Mine Engineer

DPS Consulting, LLC: Summersville, WV

May 2007 to August 2008: Preformed engineering work under a registered PE including permitting, mine mapping, and surveying.

3. Engineering Internship

Brooks Run Mining, LLC: Mine 5, 9B, 10A and Mercer, Erbacon, WV

May 2006 to August 2006: Preformed underground construction and equipment recovery.

4. Engineering Internship

Massey Energy: Nicholas Energy Complex, Drennen, WV

May 2005 to August 2005: Preformed surveying and mapping work. 